Aus der Klinik für Gastroenterologie und Gastrointestinale Onkologie

(Prof. Dr. med V. Ellenrieder)

der Medizinischen Fakultät der Universität Göttingen

\title{
Urokinase-type plasminogen activator receptor contributes to chemosensitivity and epithelial-to-mesenchymal transition in PDAC
}

\author{
INAUGURAL-DISSERTATION \\ zur Erlangung des Doktorgrades \\ der Medizinischen Fakultät der \\ Georg-August-Universität zu Göttingen
}

vorgelegt von

Luo-Gen Peng

aus

Hunan, China

Göttingen 2020 
Dekan:

\section{Betreuungsausschuss}

Betreuer/in:

Ko-Betreuer/in:

\section{Prüfungskommission}

Referent/in:

Ko-Referent/in:

Drittreferent/in:
Prof. Dr. med. W. Brück

Prof. Dr. med. V. Ellenrieder

Prof. Dr. med. P. Ströbel

Prof. Dr. med. V. Ellenrieder

Datum der mündlichen Prüfung: 


\section{Table of Contents}

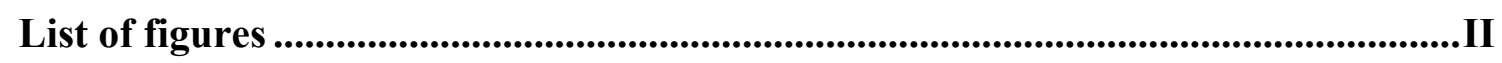

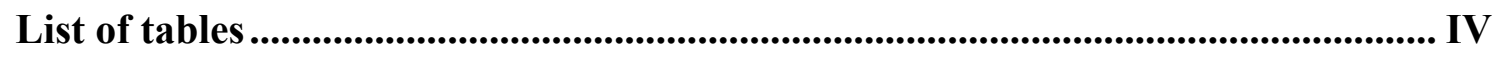

Abbreviations ...............................................................................................

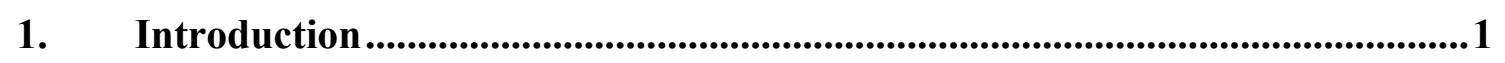

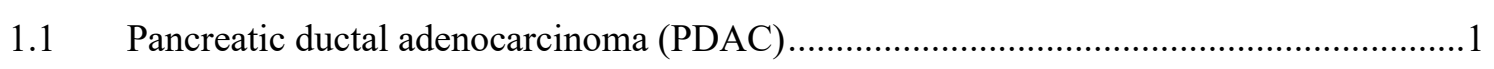

1.2 Carcinogenesis and molecular biology of PDAC .......................................................

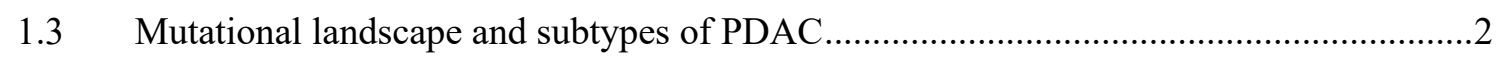

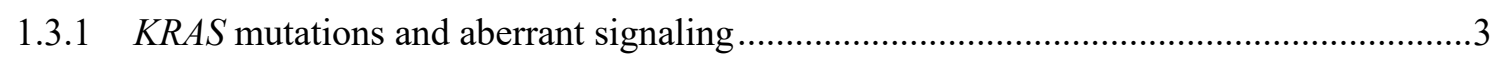

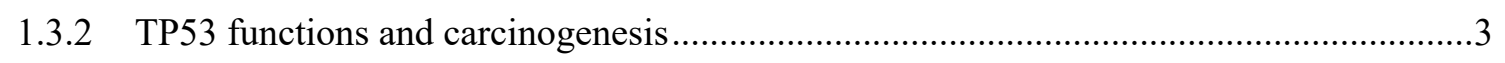

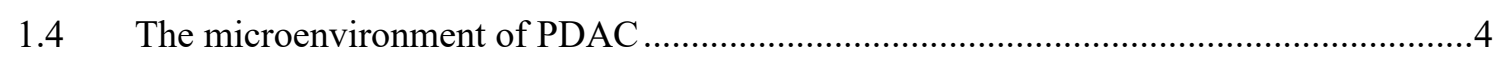

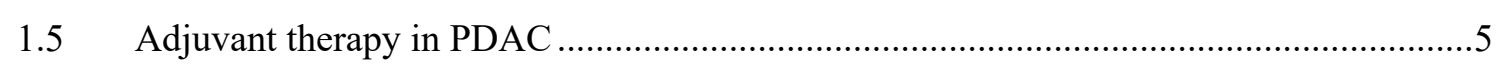

1.6 Structure and function of the urokinase plasminogen activator receptor (UPAR) in the

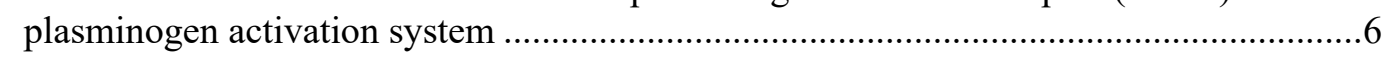

1.6.1 uPAR expression and diagnostic significance in cancer..............................................

1.6.2 The processes of UPAR in cancer........................................................................ 7

1.6.3 uPAR and epithelial-mesenchymal transition (EMT) in PDAC ......................................

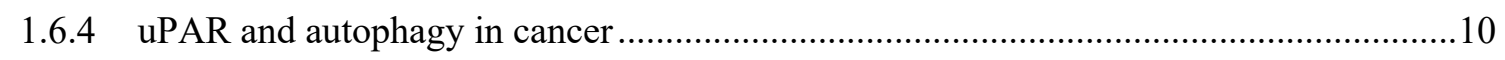

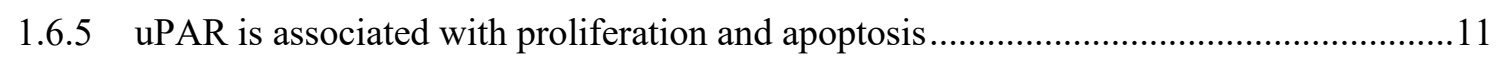

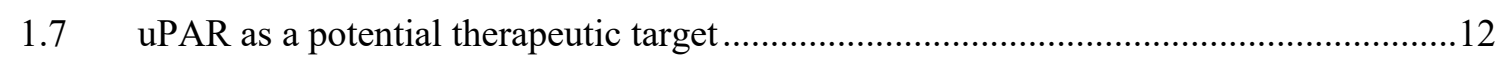

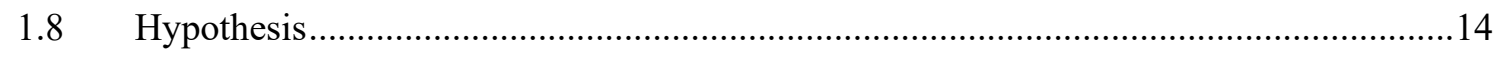

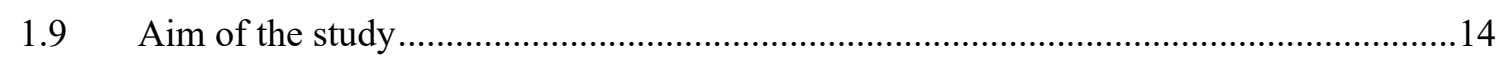

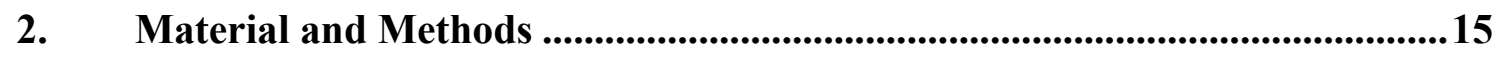

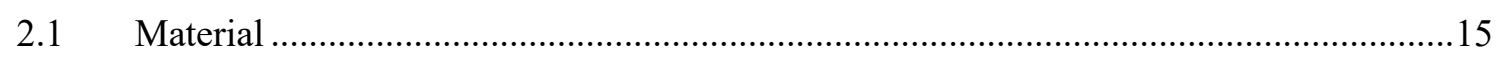

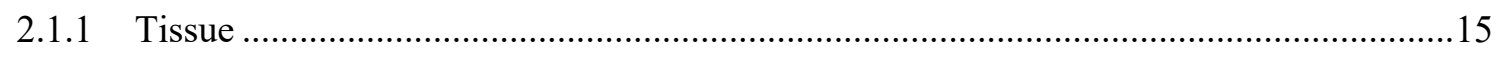

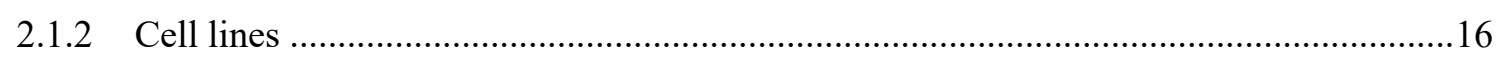

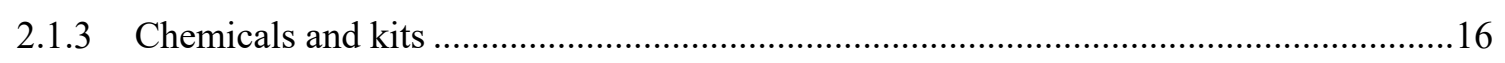

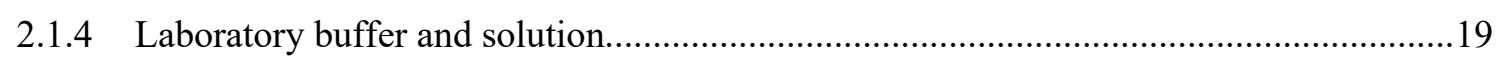

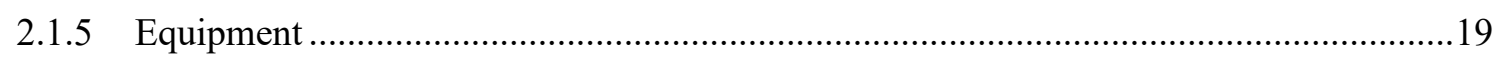

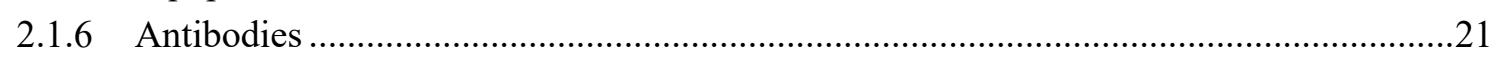

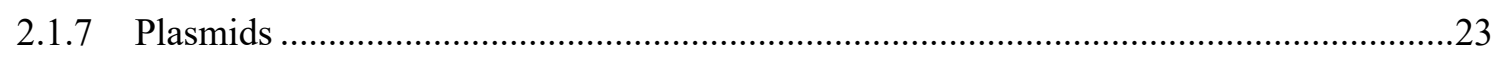

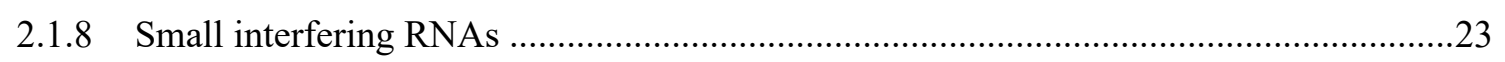

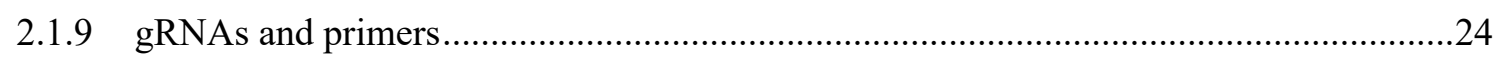

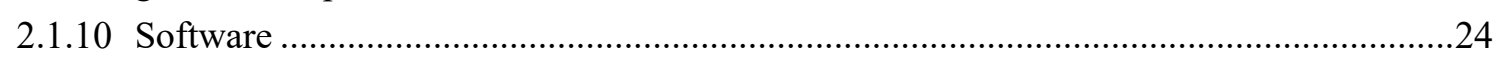

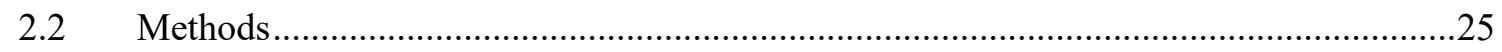

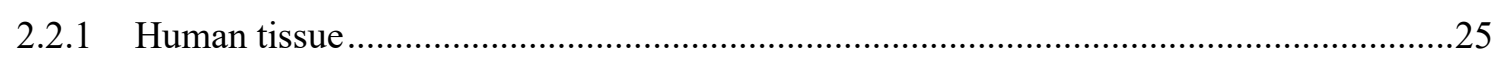

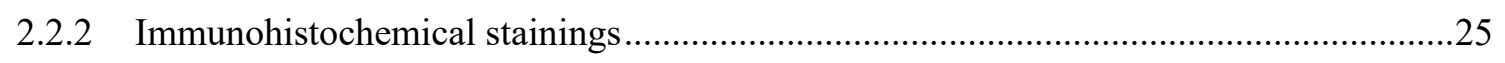

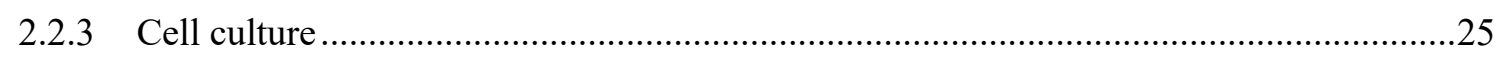




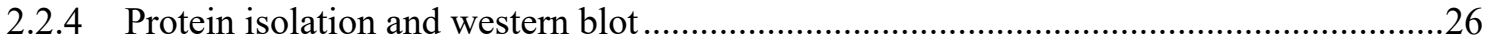

2.2.5 Enzyme linked immunosorbent assay (ELISA) _.........................................................26

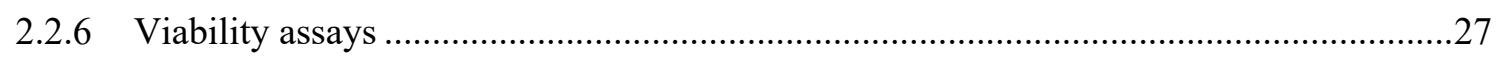

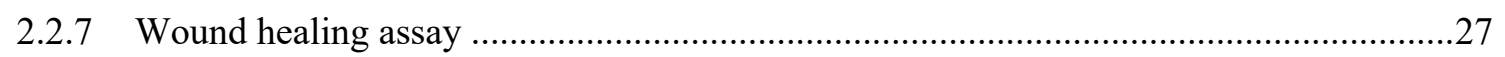

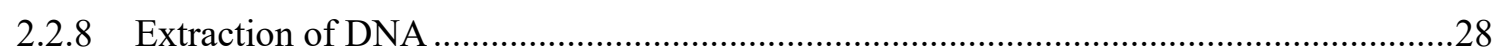

2.2.9 Mixture for polymerase chain reaction (PCR) reaction ................................................28

2.2.10 Plasmid DNA isolation and purification from Escherichia coli (E. coli) ..........................30

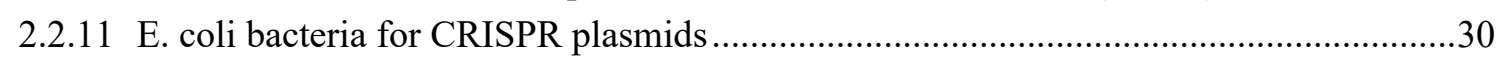

2.2.12 Generation of uPAR knock out cells using transient CRISPR/Cas9 vector constructs ...31

2.2.13 Fluorescence activated cell sorting (FACS) of transfected cells ........................................

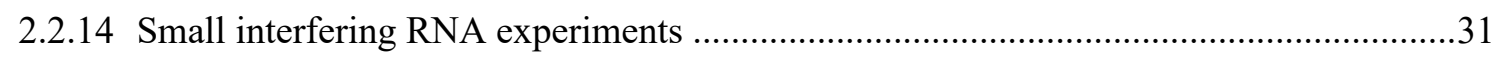

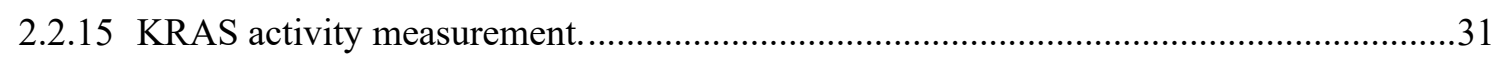

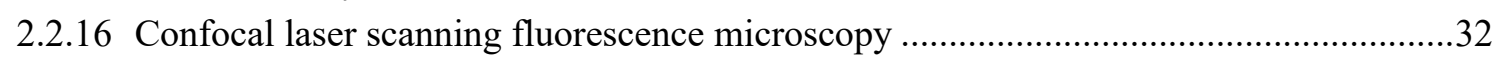

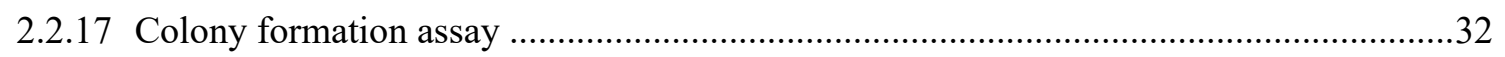

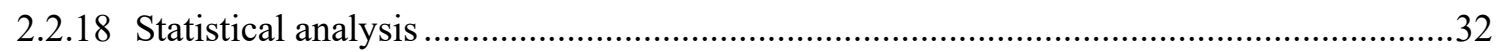

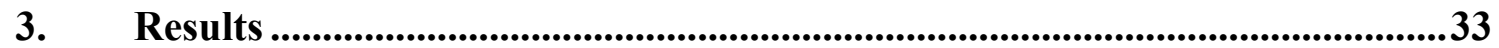

3.1 Immunohistochemistry of UPAR in clinical PDAC tissue samples shows prognostic

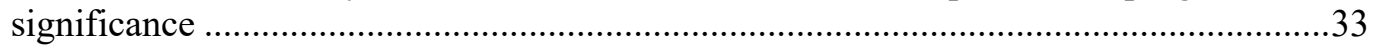

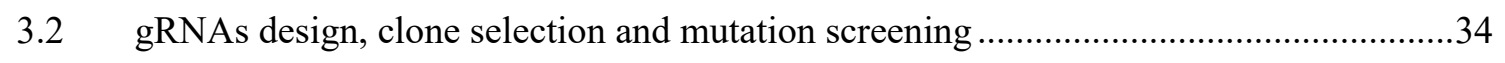

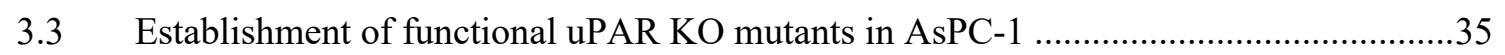

3.4 Phenotypic analysis of AsPC-1 $u P A R^{-/}$cells shows decreased cell growth, reduced migration and increased mesenchymal to epithelial transition (MET) ..............................37

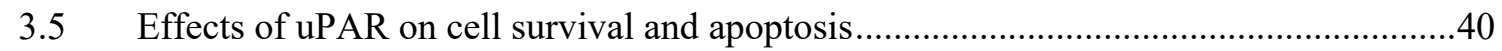

3.6 uPAR ablation and FAK activation in AsPC-1 induces gemcitabine resistance independent of ERK.

3.7 $u P A R^{-/}$initiates pFAK and activates CDC42-p38MAPK mediated autophagy and

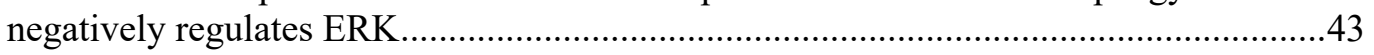

3.8 uPAR induces a functional switch from FAK/p38MAPK to ERK signaling ...................46

3.9 KRAS regulates uPAR expression and gemcitabine responsibility.................................47

3.10 Gemcitabine resistance can be reverted by inhibiting autophagy in $u P A R^{-/}$cells...........47

3.11 p38MAPK signaling and autophagy induce cellular dormancy .....................................50

3.12 Re-expression of uPAR partially restores gemcitabine sensitivity ..................................50

$3.13 \mathrm{uPAR}^{\text {low }} / \mathrm{p} 38 \mathrm{MAPK}^{\text {high }}$ status in PDAC is associated with a better prognosis ..................52

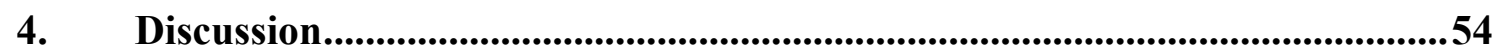

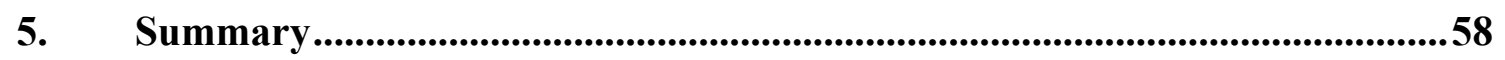

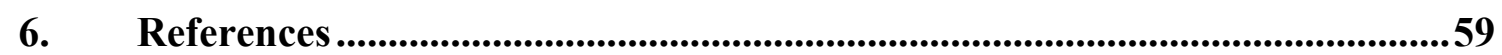




\section{List of figures}

Figure 1: Frequencies of mutations in pancreatic ductal adenocarcinomas ...............................2

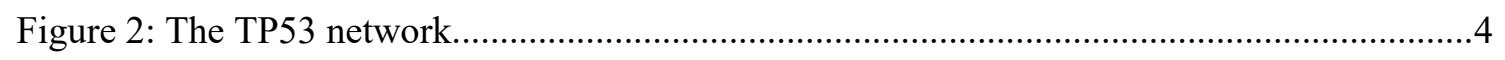

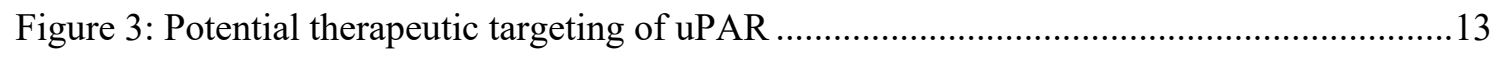

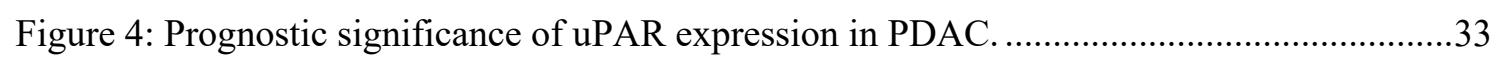

Figure 5: uPAR expression in seven PDAC cell lines and gRNAs map.......................................35

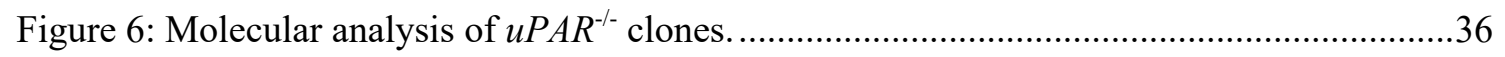

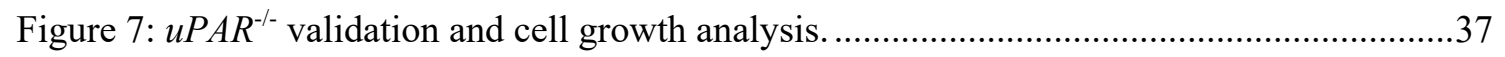

Figure 8: $u P A R^{-/-}$reduces cell migration and induces MET in PDAC cells................................40

Figure 9: $u P A R^{-/}$influences cellular plasticity but not apoptosis. ...............................................

Figure 10: Knockout of uPAR influences tumorigenicity in AsPC-1 cells.................................42

Figure 11: $u P A R^{-/}$clones activate FAK and MAPK signaling and induce resistance against gemcitabine.

Figure 12: $u P A R^{-/}$clones activate FAK and SRC signaling and induce autophagy dependent

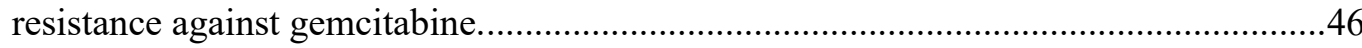

Figure 13: Pharmacologic inhibition of ERK show different effect in AsPC-1 than in $u P A R^{-/-}$

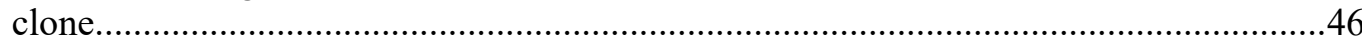

Figure 14: KRAS shows different effects in AsPC-1 than in $u P A R^{-/}$clones...............................47

Figure 15: Autophagy inhibition recovers the susceptibility to gemcitabine..............................49

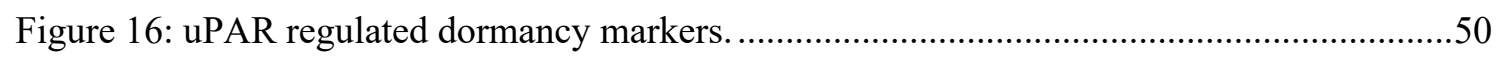

Figure 17: uPAR rescue reduces p38MAPK and recovers the migratory ability........................51

Figure 18: Statistical correlation between uPAR levels, p38MAPK activation and OS in PDAC

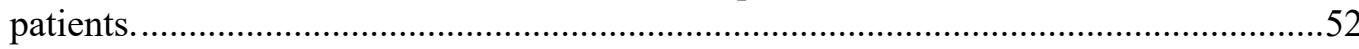

Figure 19: Signaling diagram displaying the interaction nodes used in this study......................57 


\section{List of tables}

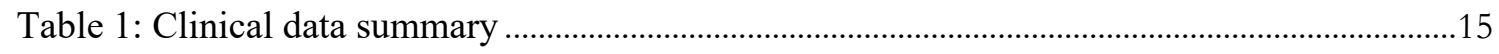

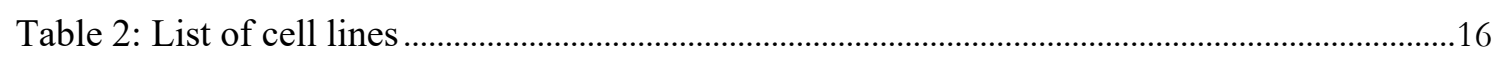

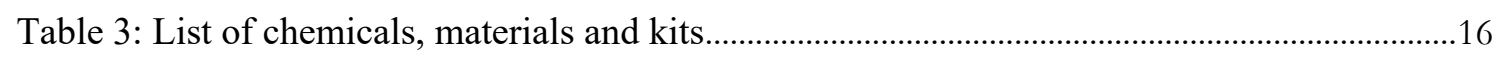

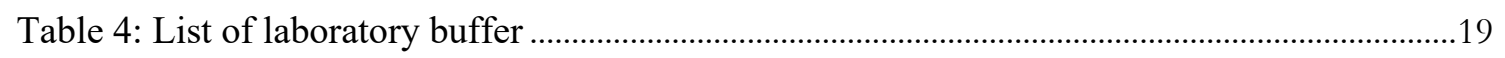

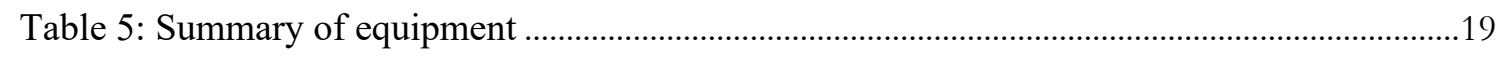

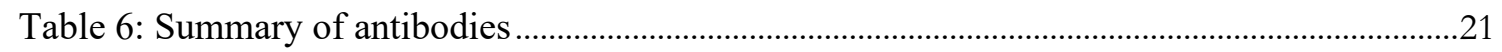

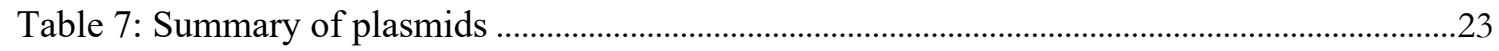

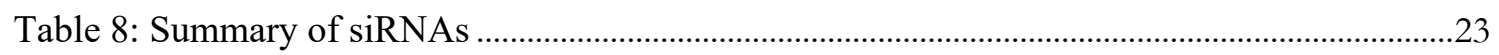

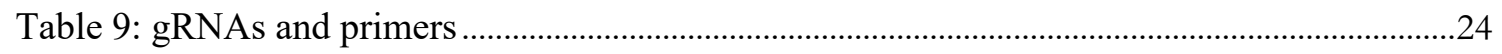

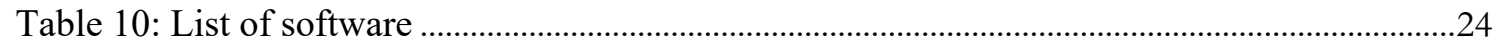

Table 11: Summary of parameters and program of PCRs...............................................................28 


\section{Abbreviations}

ATCC

ATG

Cas9

CDC42

CFU

Chk1

CNNB1

CQ

CRISPR

DAPI

DMSO

DNA

dNTP

E. coli

ECM

EDTA

EGFR

ELISA

EMT

ERK

FACS

FAK

FDA

TCF

FOXM1

GAPDH

Gem
American Type Culture Collection

Autophagy-related genes

CRISPR-associated 9

Cell division control protein 42 homolog

Colony forming units

Checkpoint kinase 1

Cyclin B1

Chloroquine

Clustered regularly interspaced short palindromic repeats

4',6-Diamidino-2-phenylindole dihydrochloride

Dimethylsulfoxide

Deoxyribonucleic acid

Deoxyribonucleotide

Escherichia coli

Extracellular matrix

Ethylenediaminetetraacetic acid

Epithelial growth factor receptor

Enzyme linked immunosorbent assay

Epithelial-mesenchymal transition

Extracellular-signal regulated kinases

Fluorescence-activated cell sorting

Focal adhesion kinase

Food and Drug Administration

Transcription factor

Forkhead box protein M1

Glyceraldehyde 3-phosphate dehydrogenase

Gemcitabine 
GFP

GLUL

GPI-Anker

gRNA

HRP

HSP27

IHC

$\mathrm{KO}$

KRAS

LC3

LRP1

NSCLC

MAPK

MET

MTHFD2

MTS

OS

p38MAPK

p62

PAI-1

PanIN

PARP

PBS

PCR

PDAC

PMSF

PSCs

RFP
Green fluorescent protein

Glutamate-ammonia ligase

Glycosylphosphatidylinositol-anker

Guide RNA

Horse radish peroxidase

Heat shock protein 27

Immunohistochemistry

Knockout

Kirsten rat sarcoma viral oncogene homologue

Microtubule-associated protein 1 light chain 3

Lipoprotein receptor-related protein 1

Non-small cell lung cancer

Mitogen-activated protein kinase

Mesenchymal-epithelial transition

Methenyltetrahydrofolate cyclohydrolase 2

3-(4,5-Dimethylthiazol-2-yl)-2,5-diphenyltetrazoliumbromid

Overall survival

Mitogen-activated protein kinase p38

Nucleoporin p62/sequestosome-1

Plasminogen activator inhibitor-1

Pancreatic intraepithelial neoplasia

Poly ADP ribose polymerase

Phosphate buffered saline

Polymerase chain reaction

Pancreatic ductal adenocarcinoma

Phenylmethanesulfonyl fluoride

Pancreatic stellate cells

Red fluorescent protein 
RIPA

RNA

RPM

RPMI

RT

SDS-PAGE

siRNA

Src

TBS

TBST

TGF-beta

TP53

Tris

uPA

UPAR

WT

ZO 1/2

(c)DNA

3-MA

5-FU
Radioimmunoprecipitation assay buffer

Ribonucleic acid

Rounds per minute

Roswell Park Memorial Institute

Room temperature

Sodiumdodecylsulfat-polyacrylamidgelelektrophorese

Small interfering RNA

Proto-oncogene tyrosine-protein kinase Src

Tris-buffered saline

Tris buffered saline with Tween 20

Transforming growth factor beta

Tumor protein $\mathrm{p} 53$

Tris-(Hydroxymethyl)-Aminomethan

Urokinase-type plasminogen activator

uPA receptor

Wild type

Zona occludens $1 / 2$

Complementary DNA

3-Methyladenine

5-Fluorouracil 


\section{Introduction}

\subsection{Pancreatic ductal adenocarcinoma (PDAC)}

PDAC is one of the most lethal cancers, with a dismal prognosis and an extremely low 5year overall survival rate $(<5 \%)$. According to the latest statistics the incidence of all pancreatic cancer globally is about 5.5 per 100,000 with $90 \%$ being adenocarcinomas. Particularly in developed countries and among men PDAC is more common. The incidence of PDAC remained steady relative to the incidence of other common solid tumors such as lung cancer and colorectal cancer over the past several decades (Bray et al. 2018; Vincent et al. 2011). However, according to estimates from the United States in 2019 , about 46,000 people will be expected to get pancreatic cancer, and more than 40,000 people are predicted to die from it (Siegel et al. 2018). In early stages pancreatic cancer is usually asymptomatic and therefore most PDAC are diagnosed at an advanced and metastasized stage and are often not resectable.

\subsection{Carcinogenesis and molecular biology of PDAC}

PDAC derives from the epithelia of the pancreatic duct and develops from a premalignant lesion termed pancreatic intraepithelial neoplasia (PanIN). The International Cancer Genome Consortium characterized four major subtypes of PDAC based on their gene expression profiles: "the pancreatic progenitor subtype", "the squamous subtype", "the aberrantly differentiated endocrine exocrine subtype" and "an immunogenic subtype" (Waddell et al. 2015). However, recent studies propose five distinct subtypes: "a pure classical", "a pure basal-like subtype" and "the immune classical", "the desmoplastic", "the stroma activated subtype" (Puleo et al. 2018). Characteristic features of PDAC include a very high activity of Kirsten rat sarcoma viral oncogene homologue (KRAS) signaling, a progression from PanIN to pancreatic cancer, a tendency to both local invasion and remote metastasis, an abundance of specific stromal matrix leading to the conundrum of hypovascular and hypoxic exposure of microenvironment, alternating the cellular metabolism and blinding of immunity (Feig et al. 2012). The accumulation of 
genetic mutations is associated with the development from dysplastic epithelium to invasive carcinoma.

\subsection{Mutational landscape and subtypes of PDAC}

The genetic landscape of PDAC is dominated by four major driving mutations: an activating KRAS mutation occurs in more than $95 \%$ of all PDACs, mutations in TP53 $(60-70 \%)$, in SMAD4 (50\%) and mutations and epigenetic silencing of the tumor suppressor gene $C D K N 2 A(>50 \%)$. Since these four genes carry mutations that appear in the primary tumors and its remote metastases, they are regarded as founder mutations (Fig. 1) (Bailey et al. 2016; Biankin et al. 2012; Ryan et al. 2014).

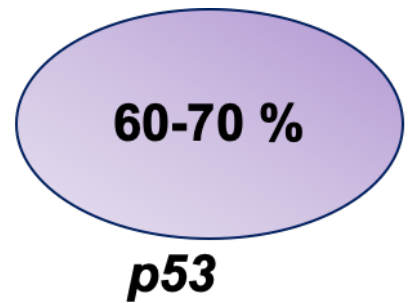

(p53 pathway)

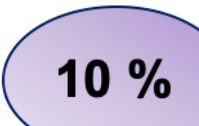

ATM BRCA2

(DNA damage response)

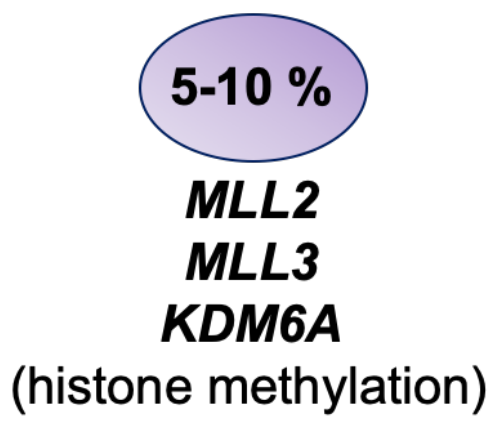

$10-15 \%$

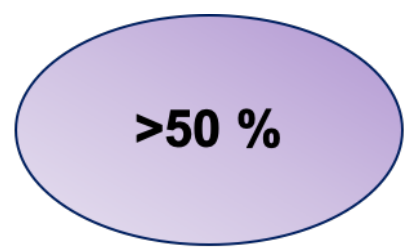

CDKN2A (growth arrest pathway)

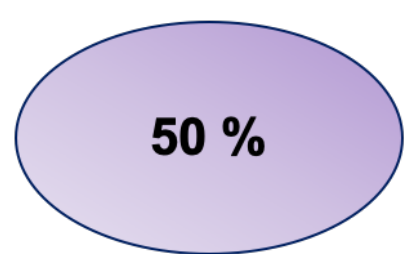

SMAD4 TGF- $\beta$ (TGF- $\beta$ pathway)

Figure 1: Frequencies of mutations in pancreatic ductal adenocarcinomas. (Bailey et al. 2016; Biankin et al. 2012; Ryan et al. 2014). 


\subsubsection{KRAS mutations and aberrant signaling}

KRAS activation is the most common oncogenic mutation in PDAC and has been well studied in the tumorigenic growth in human cancers including PDAC. Many reports showed that KRAS mutations correlate with poor prognosis (Ogura et al. 2013) therefore, targeting KRAS is one of crucial priorities straight in pancreatic cancer research. Even though several promising methods to discover a valid treatment for PDAC patients with KRAS-mutant, including direct or indirect KRAS targeting, such as inhibiting interactions, blocking cascades downstream of KRAS or disturbing the metabolic processes have been presented, after over 30 years of research an effective clinical antiRAS therapy still remains missing (Zeitouni et al. 2016). In PDAC cells, KRAS protein levels may act as a biomarker for sensitivity to KRAS inhibition, in turn endogenous KRAS may underscore the potential for resistance to even the KRAS inhibitors. (Muzumdar et al. 2017). In addition, the development of Ras-directed molecular therapeutics has encountered big challenges, due to the difficulty of targeting a molecule as small as the Ras-GTPase (Singh et al. 2009).

\subsubsection{TP53 functions and carcinogenesis}

The $p 53$ tumor-suppressor gene (TP53) is one of the most common oncogenic mutation genes in cancers including PDAC. The well-established role of wild-type TP53 has been more extensively studied in recent decades in tumor processes (Freed-Pastor and Prives 2012; Vogelstein et al. 2000; Vousden and Lane 2007). TP53 is a general stress sensor and is activated by Deoxyribonucleic acid (DNA) damage and oncogene activation. TP53 protein levels are often inhibited by a feedback loop of ubiquitin-protein ligase E3 (Mdm2) which causes a targetable TP53 proteasome-mediated degradation. Cellular stress interrupts the binding of Mdm2 to TP53 and induces TP53 activation and accumulation. These alterations are able to initiate cell-cycle arrest, cell death by the production of apoptosis or senescence initiation through a variety of inducers including many genes. For example, cyclin-dependent kinase inhibitor 1A by encoding a protein regulates cell growth arrest and senescence, and Bcl-2-Like Protein 4 and Phorbol-12myristate-13-acetate-induced protein 1, which trigger a variety of apoptosic signals (Fig.

2) (Candeias et al. 2008; Freed-Pastor and Prives 2012; Whibley et al. 2009). 


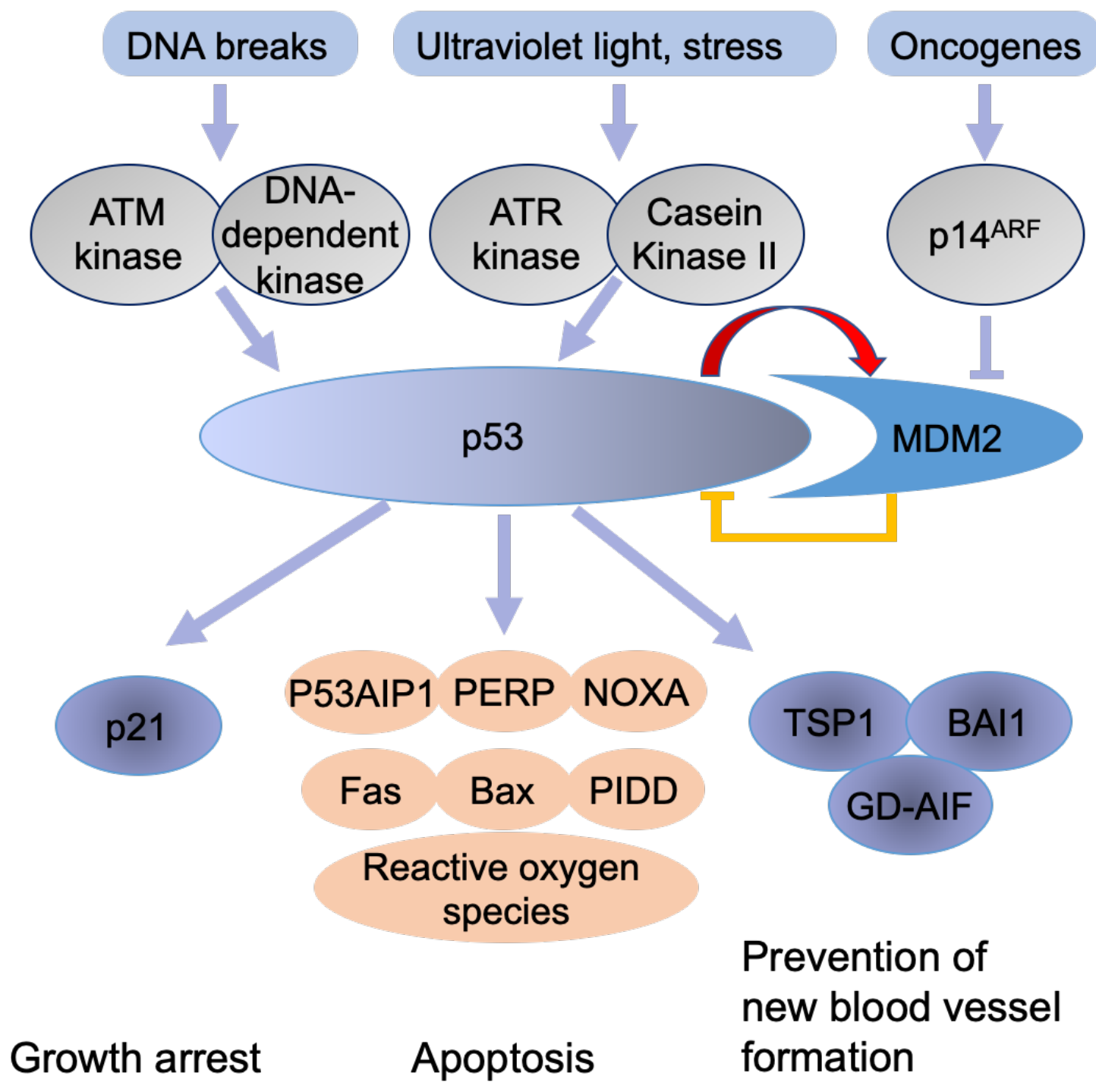

Figure 2: The TP53 network. (modified: Vogelstein et al. 2000). Activation of the network stimulates enzymatic activities that modify TP53 and its negative regulator, Mdm2.

\subsection{The microenvironment of PDAC}

Pancreatic cancer is characterized by a rich bulk of the stromal-desmoplasia reaction (Seymour et al. 1994), leading to a hypoxic environment for cancer cells. Stroma is a complex dense structure consisting of the extracellular matrix (ECM), which is composed of several cell types like pancreatic stellate cells (PSCs), collagen I, vitronectin, fibronectin, cell growth factors and non-collagenous proteins (Biondani et al. 2018). PSCs may dynamically maintain a relative balance of ECM production and degradation to regulate ECM composition (Apte et al. 2012). The role of ECM in driving tumor 
resistance in response to several therapeutic strategies is well studied. For example, stellate cells can escape cancer cells from apoptosis, leading to increased cell survival, and but also promote a formation of the niche for the cancer stem cells. In a study it was reported that PSCs may help to develop metastatic cancer cells by shifting from the local tumor site to metastatic sites (Xu et al. 2010). The pancreatic cancer in the stroma with an abundant portion of PSCs enhances and influences drug resistance and recurrence after surgery (Hamada et al. 2012). Moreover, it has been shown in vitro and in vivo that bidirectional interactions with stromal stellate cells and tumor cells (Apte et al. 2013) stimulates proliferation, migration and invasion. For example, transforming growth factor beta (TGF-beta) overexpression in pancreatic cancer induces cell growth by triggering non-canonical signaling including the mitogen-activated protein kinase (MAPK) and proto-oncogene tyrosine kinase src (c-Src) (Gore et al. 2014) have a relevance in early recurrence after resection and a poor survival (Attisano and Labbe 2004). Although it has been demonstrated that an important role for stromal PSCs in tumor and remote metastasis, such as recent many studies testing the application of genetic techniques (Ozdemir et al. 2014) or signaling pathway inhibition (Lee et al. 2014) to abolish myofibroblast numbers and functions have been controversial and indicate that the stroma plays a distinct protective role in pancreatic cancer. For example, aberrant autocrine and paracrine signaling cascades of pancreatic cancer are associated with an increased cell growth, migratory, invasion and remote metastasis (Hezel et al. 2006).

\subsection{Adjuvant therapy in PDAC}

Palliative treatment including gemcitabine-based chemotherapy is still the leading therapy in the treatment of advanced patients to improve health-related quality of life and overall survival (Wichert et al. 2008). Gemcitabine is a nucleoside analogue of deoxycytidine that has been approved by the Food and Drug Administration (FDA) in 1996 and has been extensively used for the treatment of multiple types of cancers including pancreatic cancer. In 2004, the randomized trial has been completed and confirmed a role of adjuvant chemotherapy in pancreatic cancer (Neoptolemos et al. 2004). Basic on the similar survival rates and less toxicity, the adjuvant gemcitabine treatment as the basic treatment for resected PDAC patients was established in the ESPAC-3 trial and another large clinical study reported the significance of adjuvant 
chemotherapy to overall survival time in patients with pancreatic cancer with early clinical stage I or II (Neoptolemos et al. 2017). An increasing number of studies reported that multiple aberrant signaling pathways are investigated in pancreatic carcinoma cells such as the enhancement of mitogenic signaling, underscoring the critical need for more effective therapies including combinatorial strategies (Attisano and Labbe 2004; Matsushita et al. 2007). Although patients with pancreatic cancer are best treated by a multi-disciplinary team, there is an increasing number of patients exhibiting resistance to therapeutic strategies including gemcitabine. Therefore, markers for the separation of patients with a different genetic and molecular background and specific new therapeutic strategies are urgently needed.

\subsection{Structure and function of the urokinase plasminogen activator receptor (uPAR) in the plasminogen activation system}

The main biofunction of the Glycosylphosphatidylinositol (GPI)-anchored cell membrane receptor $\mathrm{UPAR}$ is $\mathrm{UPA}$ mediated degradation of extracellular matrix components. It belongs to the superfamily of lymphocyte antigen-6 (Ly6), which is characterized by the LU domain (Ploug and Ellis 1994). The presence of 4-5 diulphide bonds formed by a tertiary structure constituting the LU domain (Jacobs et al. 1999; Kjaergaard et al. 2008). Recent studies on the crystal structure of uPAR-ligand complexes (Huai et al. 2008) show that this core domains of UPAR constitute of a concave shape with a three-finger protein domain where uPA can bind. The LU-domain of UPAR contains residues essential for binding to vitronectin (Gardsvoll and Ploug 2007; Huai et al. 2008; Madsen et al. 2007). uPAR can coordinated stimulation of proteolysis, cell adhesion and cascades of relative signaling by simultaneously binding both ligands of the vitronectin- and uPA-binding sites (Huai et al. 2008; Wei et al. 1994). It has been shown that uPA-binding to UPAR initiates a dimerization that enhances the capacity of UPAR to bind vitronectin (Cunningham et al. 2003; Sidenius et al. 2002).

\subsection{1 uPAR expression and diagnostic significance in cancer}

uPAR expression increased upon several stress signals such as tissue injury, tissue remodeling and inflammation stress. UPAR protein is found in gestational proliferating 
tissues (Floridon et al. 1999; Uszynski et al. 2004) and in keratinocytes at the edge of the wound healing (Romer et al. 1994; Solberg et al. 2001). uPAR expression has been reported in other pathologic progress such as chronic kidney disease (Wei et al. 2008) and ischemia or trauma of the central nervous system (Beschorner et al. 2000). During leukocyte activation and differentiation the high levels of UPAR is also detected (Plesner et al. 1994). uPAR is detected on a subpopulation of haematopoietic stem and progenitor cells (Tjwa et al. 2009).

Unlike in healthy and developing tissues, UPAR expression commonly correlates with a poor prognosis and is predictive of invasion and distant metastasis in human cancers including pancreatic cancer (Bene et al. 2004; Jacobs et al. 1999; Rasch et al. 2008). For instance, aberrant uPAR expression in breast cancer was described as an independent prognostic marker (Giannopoulou et al. 2007) and particularly in PDAC it has been shown that the amplification of UPAR correlates with poor prognosis and unfavorable clinical outcome (Hildenbrand et al. 2009).

\subsubsection{The processes of uPAR in cancer}

A key role of UPAR in cancer development is involved in its proteolysis system of the extracellular matrix. Glycosyl-phosphatidylinositol GPI-anchored uPAR bound to uPAPlasminogen activator inhibitor-1 (PAI-1) by a lipoprotein receptor-protein 1(LRP1). UPAR as a transmembrane adaptor connects LRP1 to the clathrin-dependent endocytosis (Conese et al. 1995; Cunningham et al. 2003), leading to activation of lysosomal degradation of UPA and PAI-1 and finally regeneration of UPAR and LRP1 (Czekay et al. 2001). Additionally, endocytic receptor 180 is also associated with uPAR regeneration (Behrendt et al. 2000). Activations of the Rho GTPase Rac and cell division control protein 42 homolog (CDC42), which not only promotes filamentous actin assembly and routes cell migration but also leads to the chemotactic response towards a catalytically inactive uPA (Sturge et al. 2003). The maintenance of a balance of cell surface uPAR prevents uPAR-mediated activations of Rac and extracellular signal-regulated kinase 1/2 (ERK 1/2) and inhibits cell capacities of migratory and chemotaxis (Ma et al. 2002; Webb et al. 2000). This balance is dysregulated in cancer progression and high uPA/uPAR constitutively converts plasminogen to active plasmin that triggers degradation of 
ECM/basement membranes and releases functional matrix metallopeptidases. ECM degradation by uPA/uPAR-MMP finally promotes cell invasion and remote metastasis.

Due to lacks a transmembrane or cytoplasmic domain, uPAR is anchored to the cell membrane through a GPI part (Brown and Waneck 1992). Active uPAR in human cancers including PDAC has been linked with poor prognosis (Kong and Park 2012). The GPIanchored $\mathrm{UPAR}$ requires co-receptors to relay its downstream signals within the cell. For example, uPAR stimulating integrins such as $\alpha_{5} \beta_{1}, \alpha_{v} \beta_{5}$ signaling can induce focal adhesion kinase (FAK) and Src phosphorylation and activate Ras-ERK signaling pathway leading to tumor cell proliferation and tumorigenicity in vivo (Aguirre-Ghiso et al. 2001; Monaghan-Benson and McKeown-Longo 2006; Plesner et al. 1994). In turn, uPAR deficient cells convert into a dormancy (Aguirre Ghiso et al. 1999; Aguirre-Ghiso et al. 2001) suggesting an important role for UPAR in regulating tumor cell proliferation and dormancy on the uPAR-integrins interaction stimulate the tyrosine phosphorylated FAK, inducing the activation of the Ras-ERK pathway (Aguirre Ghiso 2002; Liu et al. 2002). Many studies have reported that uPAR signaling through $\beta_{1}$ integrin can enhance cell invasion by promoting pericellular proteolysis (Ghosh et al. 2006; Tang et al. 2008; Wei et al. 2007). The uPAR-mediated proteolysis system also correlates with cell motility and survival via the Ras signaling (Aguirre Ghiso 2002; Kjoller and Hall 2001; Vial and Marshall 2003). Phosphorylated ERKs via uPAR primarily influences cell growth or protease levels through transcriptional regulation. Vial E. et al. (2003) also identified the key role of uPAR for cell motility and activated Rac kinases modulated in human tumor cells via oncogenic Ras-ERK signaling. Moreover, phosphorylated myosin light chain kinase via uPAR signaling also promotes to cell motility in human tumor cells (Nguyen et al. 1999) including PDAC, breast cancer. The interesting involvement of relative ERKs targets in UPAR signaling has been further investigated. For example, NUDEL as a regulator of cytoplasmic dynein within the cell, competes with CDC42 for binding CDC42GAP. Activated NUDEL by ERKs stimulates the Phosphorylation of CDC42 (Shen et al. 2008), and phosphorylated FAK by ERKs induces focal adhesion disassembly and turnover (Zheng et al. 2009). It is well known that ERKs activation can be regulated through a junction of two routes: positively through uPAR-mediated integrins such as $\alpha_{5} \beta_{1}$, which phosphorylates ERKs, and another produced by fibronectin fibrils suppress p38MAPK activation. Both, overexpressing UPAR and its interaction with the integrin directly increase ERK activity and suppresses p38MAPK activity by two feedback loops 
(regulation of a p38MAPK/ERK activity ratio that determines carcinoma cell proliferation vs. dormancy in vivo (Aguirre-Ghiso et al. 2001)).

\subsection{3 uPAR and epithelial-mesenchymal transition (EMT) in PDAC}

EMT program is a well-known process initiated by a variety of signaling pathways during cancer progression, which plays a key role in tumor development and metastasis in tumors including PDACs (Nistico et al. 2012). The loss of E-cadherin expression initiates an EMT program that induces morphological changes (Peinado et al. 2007) showing mesenchymal aspects including lack of cell polarity and three-dimensional structures and the secretion proteins forming the backbone of ECM (Thiery et al. 2009). E-cadherin is one of the most commonly used epithelial markers and $\mathrm{N}$-cadherin, vimentin or fibronectin stand for the mesenchymal phenotype (Thiery et al. 2009). It is investigated how genes are regulated in the EMT program in tumor cells. Dependent on their effect on the E-Cadherin promoter, E-Cadherin repressors were classified into two groups. Zink finger E-Box Binding Homeobox 1 and 2 (ZEB1, 2), Snail 1, Snail 2, and transcription factor (TCF) 3, and Krueppel-like factor 8 factors which bind to the E-cadherin promotor region to repress transcription (Thiery et al. 2009; Wang et al. 2007) belong to the first group. The second group includes Twist, forkhead box protein C2 and TCF4 that indirectly repress E-cadherin transcription (Solberg et al. 2001). Beta-catenin is one of crucial downstream effectors in the Wnt signaling (Hernandez et al. 2007) and is involved in early embryonic process (Umeda et al. 2006) and tumorigenesis (Reichert et al. 2000). Beta-catenin also activates Slug, which is a widely expressed transcriptional repressor. Zonula occludens 1 and 2 (ZO-1 and 2) are scaffold proteins that form the assembly of cellular tight junction formation (Helfand et al. 2004; Shin et al. 2006). Vimentin is a dynamic intermediate filament that originated from the mesenchyme. It is present in early developmental stages and is involved in re-organization of structural cytoskeleton in response to extracellular stimuli (Matter and Balda 2007). SLUG by binding to integrin promotor sequences transcriptionally inhibits integrins expression and impairs cell adhesion (Turner et al. 2006). Mounting evidence suggested that the function of the $\mathrm{uPA} / \mathrm{uPAR}$ system plays a critical role on tumor migration and invasion and metastasis due to its ability of degradation for ECM contents (Wang 2001). For example, elevated uPAR protein promotes pancreatic tumor EMT program (Huang et al. 2014) and promotes breast cancer metastasis (Lester et al. 2007). Knockdown of uPA with specific gene 
induced a reduction of Snail and vimentin and morphological features of epithelial cells suggesting that $\mathrm{UPAR}$-mediated cell signaling could play a key role in targeting to reverse EMT into MET process in cancer cells (Jo et al. 2009b). Accumulating evidence clearly suggests that the increased chemoresistance to drugs and the acquisition of an EMT-like cancer stem cell phenotype have a critical role in tumor cells (Quint et al. 2012; Yin et al. 2011). For instance, downregulation of ZEB1 not only restores E-cadherin expression but also induces an overall increased drug sensitivity (Arumugam et al. 2009). Given the importance of uPA/uPAR and EMT in pancreatic cancer during tumor development, tumor-progression, and tumor metastasis and its relevance in the response to therapy suggests that $\mathrm{uPA} / \mathrm{uPAR}$ could be a valuable target in the therapeutic strategy against pancreatic cancer.

\subsubsection{UPAR and autophagy in cancer}

Autophagy process is a critical to maintain homeostasis by removing unnecessary or excess proteins or damaged organelles by forming vesicles that then fuse with lysosomes for degradation. It is thought that autophagy regulates different cellular functions including growth, differentiation and response to nutrient deficits. It is regulated the molecular mechanism of autophagy via the family of autophagy-related genes (ATG). Two additional important factors in autophagy are the beclin-1 gene and the microtubule protein 1 light chain 3 (LC3) gene that also is related with cell growth, survival, migratory and invasion positively (Hamurcu et al. 2018). Recently a study demonstrated that the inhibition of LC3 and Beclin-1 in triple negative breast cancer cells inhibit autophagy by inhibiting uPAR/integrin- $\beta_{1} / \mathrm{Src}$ signaling (Hamurcu et al. 2018). A report described that p38MAPKs is required for cell growth and cell survival time in patients with diagnosed at colorectal cancer. Comes and colleagues (2007) showed the production of growth arrest and autophagy-related cell death by p38MAPK alpha specific inhibitor or genetic silence for colorectal cancer cells. In pancreatic cancer cells with a high basic level of autophagy, inhibition of autophagy delays tumor development in vivo and in vitro (Ying et al. 2012). In addition, a study reported the autophagy inhibition in response to $K R A S$-driven pancreatic cancers is probably independent of TP53 status (Yang and Kimmelman 2014). Macropinocytosis represented an important route of tumor nutrient uptake of KRASmutated pancreatic cancer cells, including glutamine that can enter central carbon metabolism (Commisso et al. 2013). A variety of metabolites of pancreatic cancer cells 
such as glutamine is dependent of macropinocytic protein uptake and lysosomal degradation (Kamphorst et al. 2015). Targeting specific metabolic units such as its pharmacological inhibition is an emerging strategy for pancreatic cancer. For example, blockage of regulators of tumor metabolism such as autophagy progress. Emerging evidence shows that autophagy has multi-faceted roles in cancer. Main functions of autophagy involve the promotion of the survival of dormant tumor cells (Lu et al. 2008; Sosa et al. 2014), the arrest of cancer stem cells, apoptosis and treatment resistance (Cufi et al. 2011; Wolf et al. 2013), the spreading of tumor cells into the peripheral cycle (Peng et al. 2013; Qiang et al. 2014) and the regulation of EMT (Kenific et al. 2016; Lock et al. 2014; Sharifi et al. 2016). Emerging evidence indicates that cancer therapies mediate autophagy, to allow tumor cell survival, and to be a leading cause of therapy resistance (Amaravadi et al. 2011; Kondo et al. 2005; Levy et al. 2017). It has also been suggested that autophagy may also accelerate the production of chemoresistance to drugs via promoting the selection for a cancer stem cell phenotype (Apel et al. 2008; Mowers et al. 2017).

\subsubsection{UPAR is associated with proliferation and apoptosis}

UPAR is a key node of the maintaining balance between two classical MAPK pathways, the mitogen ERK and the growth/apoptotic suppressive p38MAPK (Ellinger-Ziegelbauer et al. 1999). The MAPK/ERK pathway is well characterized in the pancreatic cancer and is often strongly activated in many pathological disease processes (He et al. 2008). The p38MAPK signaling is one of the major MAPK pathways activated by environmental stress stimuli such as ultraviolet irradiation and oxidative stress. Furthermore, the cytokines such as interleukin-1, and cytoplasmic transforming growth factor-beta and tumor necrosis factor are induced the activation of p38MAPK (Cuenda et al. 1997; Guay et al. 1997). MKK3 and MKK6 have been identified as upstream kinases responsible for p38MAPK activation (Jacobs et al. 1999; Remenyi et al. 2005; Wang et al. 1996). In addition, other regulators of the p38MAPK pathway have been defined, including the Rho family Rac, CDC42 and the small G protein-activated protein kinases (Bagrodia et al. 1995; Chiariello et al. 2010; Zhang et al. 1995). Activated p38MAPK in turn stimulates and phosphorylates a variety of related targets such as kinases and transcription factors activating a wide range of signaling pathways important in tumor formation and progression. 
The p38MAPK pathway is part of a DNA damage signaling pathway, which serves in parallel with checkpoint kinase $1(\mathrm{Chk} 1)$ as a key cell cycle check point (Reinhardt and Yaffe 2013). The p38MAPK activation leads to increased gamma H2A histone family member X phosphorylation, a marker of DNA damage, which subsequently induces apoptosis pathways (Gurgis et al. 2014). In KRAS-mutant tumor cell lines, combined inhibition of Chk1 and p38MAPK lead to an accumulation of genotoxic lesions, which results in mitotic catastrophe (Dietlein et al. 2015). Moreover, inhibition of the p38MAPK with specific inhibitors in colon cancer leads to increase reactive oxygen species production, which sensitizes cells to drug-mediated apoptosis (Pereira et al. 2013). In pancreatic cancer cells, Chk1 inhibition sensitizes cells to gemcitabine treatment, while MAPK-activated protein kinase 2 inhibition has the opposite effect and abrogates the sensitization by Chk1-inhibition (Kopper et al. 2014). Another important effector of p38MAPK activation is heat shock protein 27 (HSP27). The p38MAPK activation leads to phosphorylation of HSP27, which induces a conformational change and inhibits multimer formation and thus decreases chaperone functions of HSP27. Aberrant HSP27 expression and phosphorylation is associated with a more aggressive tumor phenotype (Katsogiannou et al. 2014; Okuno et al. 2016).

\subsection{UPAR as a potential therapeutic target}

Some therapeutic reagents or strategies targeting uPAR signaling have reached clinical trials. Current studies have for the most part worked on interfering with the proteolytic activity of uPA or inhibiting the binding of UPAR to UPA (Smith and Marshall 2010) (Fig. 3). For example, a research reported the monoclonal antibody of uPAR, binding to uPA-occupied uPAR, highly inhibited of cell proliferation, invasion, and metastasis in prostate cancer (Mahmood et al. 2018). Therefore, targeting against human uPAR agents could be also considered as a therapeutic option in PDAC with increased UPAR levels. 


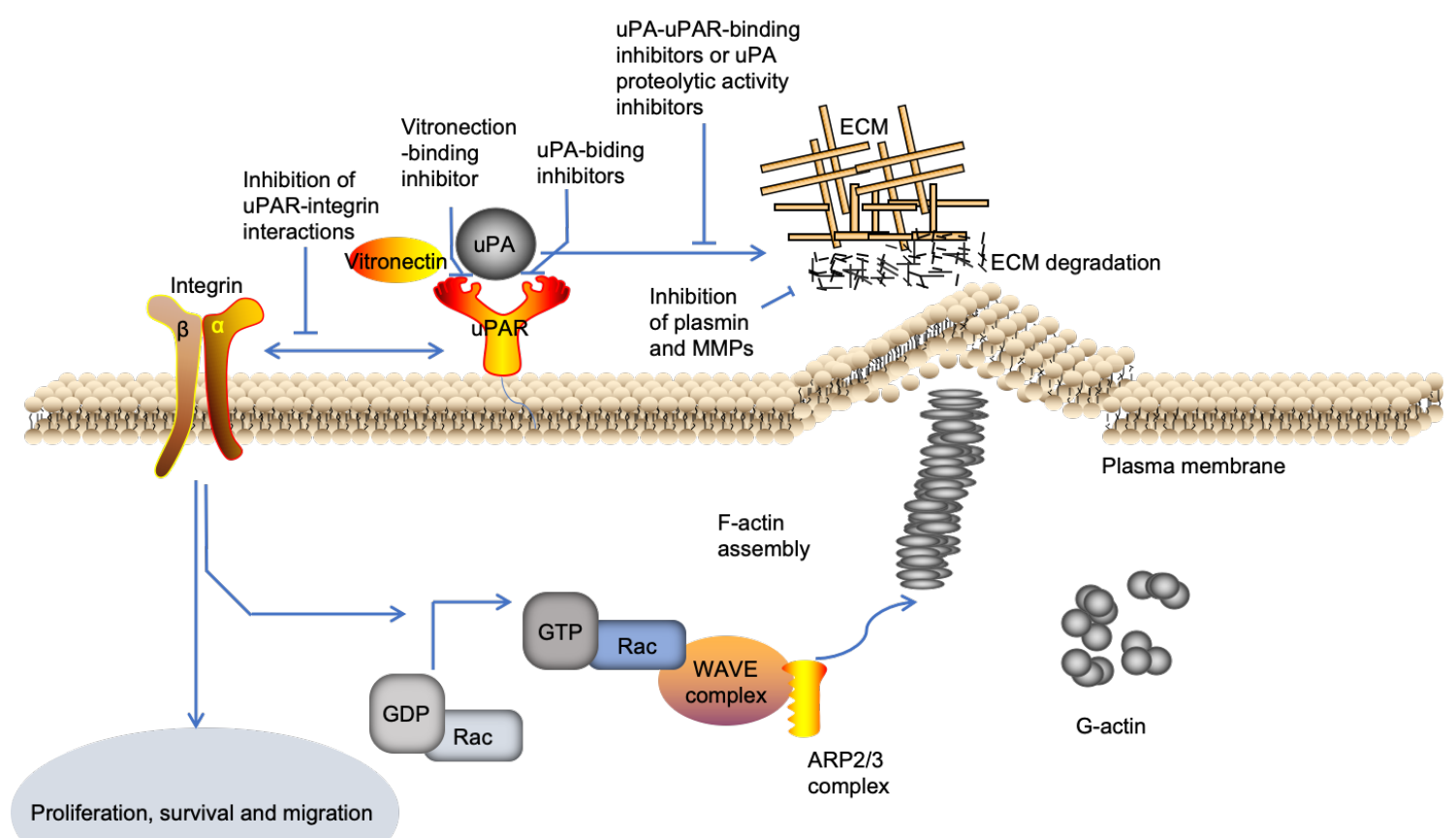

Figure 3: Potential therapeutic targeting of uPAR. (Modified: Smith and Marshall 2010). 


\subsection{Hypothesis}

Emerging evidences shows that autophagy process promotes cancer cell the acquisition of resistance to chemotherapy and radiation treatment (Amaravadi et al. 2011; Apel et al. 2008; Kondo et al. 2005; Levy et al. 2017; Mowers et al. 2017) and that activated p38MAPK triggers survival by escaping tumor cells from the cytotoxic treatment on active autophagy in TP53 defective colorectal cancer cells (Paillas et al. 2012). That autophagy-mediated chemoresistance may be TP53-dependent p38MAPK activation of the tumor (Paillas et al. 2012). It is the current hypothesis that pancreatic cancer cells rely on the MAPK/ERK pathway for proliferation, migration and metastasis, survival by UPAR and that aberrant activation of relative pathway signaling could confer drug resistance.

\subsection{Aim of the study}

PDACs with gene amplifications of the urokinase plasminogen activator receptor ( $U P A R$ ) gene have a poor prognosis. UPAR signaling has been associated with migration, metastasis and cell proliferation mediated through Ras-ERK signaling. Understanding the roles of UPAR in human pancreatic adenocarcinoma cells will help to identify targets of treatment and bring a benefit for PDAC patients. The aim of the project was to establish uPAR defective cell culture systems in vitro and to investigate the roles of UPAR in migration, metastasis and cell proliferation and survival in PDAC. 


\section{Material and Methods}

\subsection{Material}

\subsubsection{Tissue}

Table 1: Clinical data summary

\begin{tabular}{lc}
\hline Characteristic & $\begin{array}{c}\text { Pancreatic ductal } \\
\text { adenocarcinoma } \\
(\mathbf{n}=\mathbf{5 9 )}\end{array}$ \\
\hline Gender: & \\
\hline Male (\%) & $30(51)$ \\
\hline Female (\%) & $29(49)$ \\
\hline Age median (range, years) & $68(44-82)$ \\
\hline Tumor grade: & $1(1.7)$ \\
\hline G 1 (\%) & $4(6.8)$ \\
\hline G 1-2 (\%) & $28(47.5)$ \\
\hline G 2 (\%) & $6(10.2)$ \\
\hline G 2-3 (\%) & $19(32.2)$ \\
\hline G 3 (\%) & $1(1.7)$ \\
\hline G 4 (\%) & $2(3.4)$ \\
\hline Tumor stage: & $3(5.1)$ \\
\hline T stage: & $52(88.1)$ \\
\hline T 1 (\%) & $2(3.4)$ \\
\hline T 2 (\%) & $15(25.4)$ \\
\hline T 3 (\%) & $44(74.6)$ \\
\hline T 4 (\%) & $430(4-3871)$ \\
\hline N stage: & $54(92.5)$ \\
\hline N 0 (\%) & \\
\hline N 1-3 (\%) & \\
\hline Median follow-up time (range, day) & \\
\hline Reported deaths (\%) & \\
\hline
\end{tabular}




\subsubsection{Cell lines}

Table 2: List of cell lines

\begin{tabular}{|c|c|c|c|c|c|c|}
\hline Cell line & $\begin{array}{l}\text { TP53 } \\
\text { status }\end{array}$ & cDNA & Protein & $\begin{array}{l}\text { KRAS } \\
\text { status }\end{array}$ & cDNA & Protein \\
\hline AsPC-1 & mut/mut & c. $403 \mathrm{delT}$ & p.C135fs & mut/mut & c. $35 \mathrm{G}>\mathrm{A}$ & p.G12D \\
\hline $\mathrm{BxPC}-3$ & mut/mut & c. $659 \mathrm{~A}>\mathrm{G}$ & p.Y220C & $\mathrm{wt} / \mathrm{wt}$ & & \\
\hline CAPAN-1 & mut/mut & c. $476 \mathrm{C}>\mathrm{T}$ & p.A159V & mut/mut & c. $35 \mathrm{G}>\mathrm{T}$ & p.G12V \\
\hline CAPAN-2 & mut/mut & c. $375 \mathrm{G}>\mathrm{T}$ & p.I255N & wt/mut & c. $35 \mathrm{G}>\mathrm{T}$ & p.G12V \\
\hline MIA PaCa-2 & $\mathrm{mut} / \mathrm{mut}$ & c. $742 \mathrm{C}>\mathrm{T}$ & p.R248W & mut/mut & c. $35 \mathrm{G}>\mathrm{T}$ & p.G12C \\
\hline PANC-1 & mut/mut & c. $818 \mathrm{G}>\mathrm{A}$ & p.R273H & mut/mut & c. $35 \mathrm{G}>\mathrm{A}$ & p.G12D \\
\hline PATU8988T & mut/mut & c. $844 \mathrm{C}>\mathrm{T}$ & p.R828W & mut/mut & c. $35 \mathrm{G}>\mathrm{T}$ & p.G12V \\
\hline
\end{tabular}

\subsubsection{Chemicals and kits}

Table 3: List of chemicals, materials and kits

\begin{tabular}{ll}
\hline Materials & Company \\
\hline Fetal bovine serum (FBS) & Gibco, Life Technologies, Carlsbad, \\
Kalifornien, USA \\
Gemcitabine & Sigma-Aldrich, St. Louis, Missouri, USA \\
Dimethylsulfoxid (DMSO) & Sigma-Aldrich, St. Louis, Missouri, USA \\
StemMACS ${ }^{\text {TM }}$ HSC-CFU Media & Miltenyi Biotec, Bergisch Gladbach, \\
DC & Deutschland Protein Assay \\
Solution A, B and S & Bio-Rad Laboratories, \\
Penicillin-Streptomycin & Deutschland München, \\
& Gibco, Life Technologies, Carlsbad, \\
& Kalifornien, USA \\
L-Glutamin & Gibco, Life Technologies, Carlsbad, \\
& Kalifornien, USA
\end{tabular}




\begin{tabular}{|c|c|c|}
\hline \multirow{2}{*}{$\begin{array}{l}\text { Materials } \\
\text { RPMI-Medium }\end{array}$} & \multicolumn{2}{|l|}{ Company } \\
\hline & $\begin{array}{l}\text { Gibco, Life Technologies, } \\
\text { Kalifornien, USA }\end{array}$ & Carlsbad, \\
\hline BigDye $^{\mathrm{TM}}$ Terminator v3.1 Cycle & Thermo Fisher Scientific, & Waltham, \\
\hline Sequencing Kit & Massachusetts, USA & \\
\hline BigDye XTerminator ${ }^{\mathrm{TM}}$ Purification & Thermo Fisher Scientific, & Waltham, \\
\hline Kit & Massachusetts, USA & \\
\hline ExoSAP-IT ${ }^{\mathrm{TM}}$ PCR Product Cleanup & $\begin{array}{l}\text { Thermo Fisher Scientific, } \\
\text { Massachusetts, USA }\end{array}$ & Waltham, \\
\hline 4x Laemmli Sample Puffer & $\begin{array}{l}\text { Bio-Rad Laboratories, } \\
\text { Deutschland }\end{array}$ & München, \\
\hline TGS & $\begin{array}{l}\text { Bio-Rad Laboratories, } \\
\text { Deutschland }\end{array}$ & München, \\
\hline Magermilchpulver, Blotting grad & $\begin{array}{l}\text { Carl Roth } \mathrm{GmbH}+\text { Co. KG, } \\
\text { Deutschland }\end{array}$ & Karlsruhe, \\
\hline Muse $^{\mathrm{TM}}$ Count \& Viability Kit & Merck KGaA, Darmstadt, Deutsc & hland \\
\hline MyTaq TM HS Mix & Bioline, London, UK & \\
\hline Orthovanadat & Sigma-Aldrich, St. Louis, Missou & Iri, USA \\
\hline Page Ruler Plus Prestained Ladder & Thermo Scientific, Massachusetts & , USA \\
\hline $\begin{array}{l}\text { PBS Dulbecco (Phosphat Buffered } \\
\text { Saline) }\end{array}$ & Merck KGaA, Darmstadt, Deutsc & hland \\
\hline Complete EDTA & $\begin{array}{l}\text { Roche Diagnostics GmbH, } \\
\text { Deutschland }\end{array}$ & Mannheim, \\
\hline PMSF (Phenylmethylsulfonylfluorid) & $\begin{array}{l}\text { Carl Roth } \mathrm{GmbH}+\text { Co. KG, } \\
\text { Deutschland }\end{array}$ & Karlsruhe, \\
\hline Ponceau & $\begin{array}{l}\text { Carl Roth } \mathrm{GmbH}+\text { Co. KG, } \\
\text { Deutschland }\end{array}$ & Karlsruhe, \\
\hline Puregene ${ }^{\circledR}$ Core Kit A & Qiagen, Hilden, Deutschland & \\
\hline Re-Blot Strong Solution (10x) & Merck KGaA, Darmstadt, Deutsc & hland \\
\hline
\end{tabular}




\section{Materials}

Human uPAR Quantikine ELISA Kit

JX 401 (NO.349087-34-9)

10x Tris/Glycine/SDS

Western Lightning Plus-ECL

CellTiter 96 Aqueous One Solution Promega, Madison, Wisconsin, USA

Reagent

HiPerFect Transfection Reagent

Qiagen, Hilden, Germany

X-tremeGENETM $\quad$ HP DNA Sigma-Aldrich, St. Louis, Missouri, USA

Transfection Reagent

LB-Medium

G418 solution

QIAGEN Plasmid Maxi Kit 25

Allstars Neg. siRNA

Staurosporine

Isopropanol

Agarose

Kanamycin

Ampicillin

Proteinase K

RNase A

SCH772984

Chloroquine

3-Methyladenine

\section{Company}

Tocris Bioscience, Bristol, UK

Bio-Rad Laboratories, Munich, Germany

PerkinElmer, Waltham,USA

USA

Sigma-Aldrich, St. Louis, Missouri, USA

Sigma-Aldrich, St. Louis, Missouri, USA

Qiagen, Hilden, Germany

Qiagen, Hilden, Germany

Tocris Bioscience, Bristol, UK

Merck Millipore

Roth, Schoemperlenstr, Karlsruhe

Thermo Scientific, Massachusetts, USA

Thermo Scientific, Massachusetts, USA

Qiagen, Hilden, Germany

Qiagen, Hilden, Germany

MedChem Tronica, Sollentuna, SWEDEN

Sigma-Aldrich, St. Louis, Missouri, USA

Sigma-Aldrich, St. Louis, Missouri, USA 


\subsubsection{Laboratory buffer and solution}

Table 4: List of laboratory buffer

\section{Buffer and solution}

Lysis buffer

$10 \mu 1$ PMSF (100 mM), $10 \mu 1$ Sodium orthovanadate (100 mM), $40 \mu l$ Complete-EDTA, $940 \mu l$ RIPA solution

RIPA solution 1x PBS pH 7.4, 0.5\% sodium deoxycholate, 1\% NP40

10x Tris-buffered saline (TBS) $4.2 \mathrm{~g}$ Tris, $26 \mathrm{~g}$ Tris-HCL, $292.4 \mathrm{~g} \mathrm{NaCl}, \mathrm{pH} 7.4$ with $\mathrm{HCl}, \mathrm{ddH}_{2} \mathrm{O}$ to $1 \mathrm{~L}$

1x Tris-buffered saline with $10 \mathrm{ml}$ Tween 20, $1 \mathrm{~L} \mathrm{10x}$ Tris-buffered saline, $9 \mathrm{~L}$ Tween 20 (TBST) $\mathrm{dd}_{2} \mathrm{O}$

Ponceau-Rot solution 0.2 g Ponceau Rot, $3 \mathrm{ml}$ Acetic acid, $\mathrm{ddH}_{2} \mathrm{O}$ to 100 $\mathrm{ml}$

Lysogeny broth (LB)-Medium $5 \mathrm{~g}$ Yeast extract, $10 \mathrm{~g} \mathrm{NaCl}, 10 \mathrm{~g}$ Trypton, $1 \mathrm{~L}$ $\mathrm{ddH}_{2} \mathrm{O}$ pH 7.0, autoclaved

\subsubsection{Equipment}

Table 5: Summary of equipment

\section{Equipment}

Heraeus flow hood

Standard-Incubator

$4^{\circ}$ Refrigerator

$-20^{\circ}$ Refrigerator

\section{Manufacturer}

Thermo, Fisher Scientific GmbH, Schwerte, Germany

BINDER GmbH, Tuttlingen, Germany SIMENS Aktiengesellschaft, Munich, Germany

SIMENS Aktiengesellschaft, Munich, Germany 


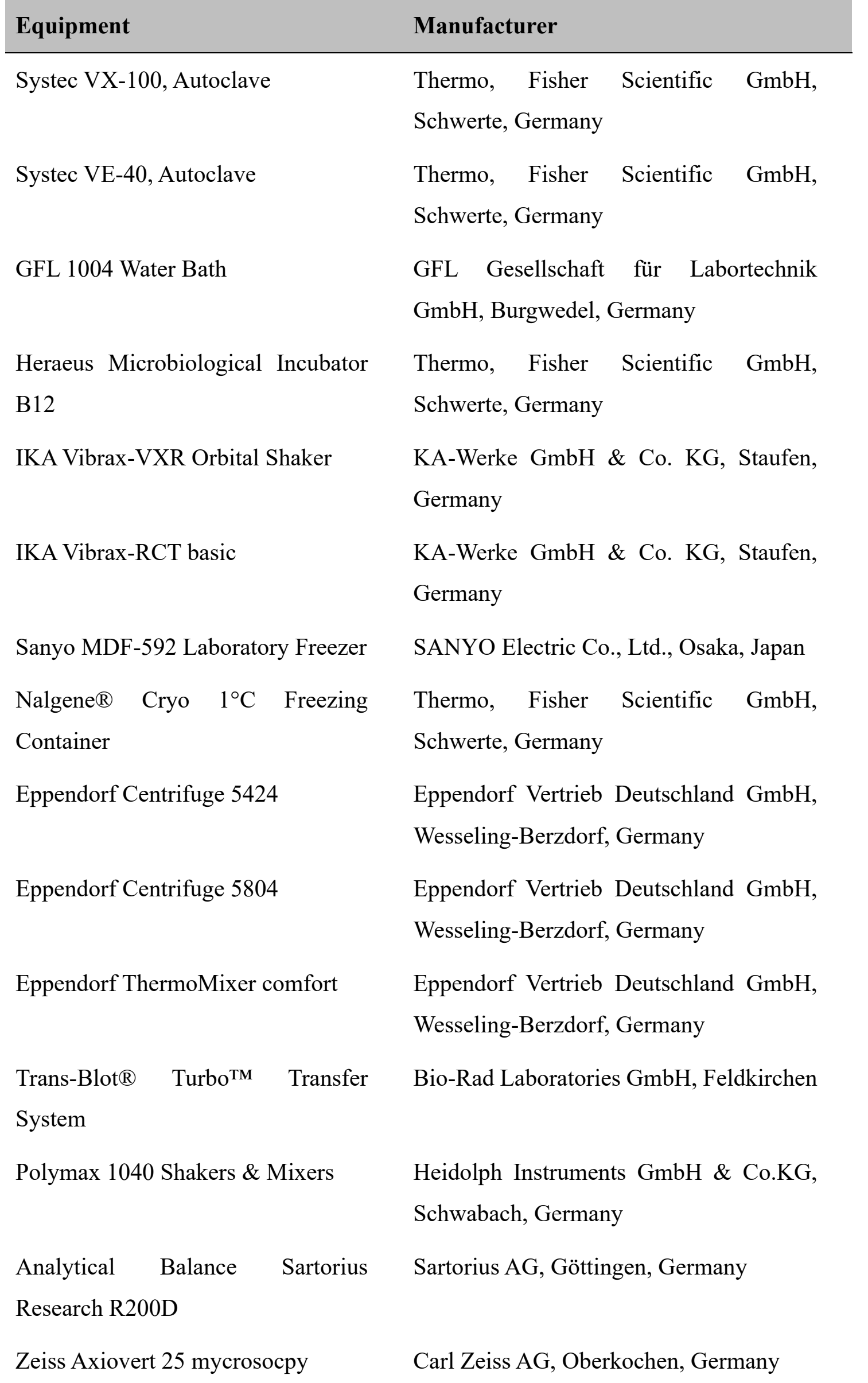




\begin{tabular}{|c|c|}
\hline Equipment & Manufacturer \\
\hline Merck's Muse Cell Analyzer & Merck KGaA, Darmstadt, Germany \\
\hline Scotsman AF 80 & SCOTSMAN, Milan, Italy \\
\hline Olympus BX41 & $\begin{array}{l}\text { Olympus Europa SE \& Co. KG, Hamburg, } \\
\text { Germany }\end{array}$ \\
\hline $\begin{array}{l}\text { Olympus IX81 Laser Confocal } \\
\text { Microscopes }\end{array}$ & $\begin{array}{l}\text { Olympus Europa SE \& Co. KG, Hamburg, } \\
\text { Germany }\end{array}$ \\
\hline Fusion Fx Vilber Lourmat & $\begin{array}{l}\text { Vilber Lourmat Deutschland } \mathrm{GmbH} \text {, } \\
\text { Eberhardzell, Germany }\end{array}$ \\
\hline The peqSTAR $2 \mathrm{X}$ & VWR International, Pennsylvania, USA \\
\hline $\begin{array}{l}\text { Applied Biosystems } 3500 \text { Genetic } \\
\text { Analyzer }\end{array}$ & $\begin{array}{l}\text { Thermo, Fisher Scientific GmbH, } \\
\text { Schwerte, Germany }\end{array}$ \\
\hline QIAxecl Advanced DNA screen & Qiagen, Hilden, Germany \\
\hline BD FACSAria ${ }^{\mathrm{TM}}$ II sorter & BD Biosciences, San Jose, USA \\
\hline Nano2000 Drop & $\begin{array}{l}\text { Thermo, Fisher Scientific } \mathrm{GmbH} \text {, } \\
\text { Schwerte, Germany }\end{array}$ \\
\hline
\end{tabular}

\subsubsection{Antibodies}

Table 6: Summary of antibodies

\begin{tabular}{llll}
\hline Antibodies (phosphorylated site) & Manufacturer & $\begin{array}{l}\text { Dilution } \\
\text { WB }\end{array}$ & 2 $^{\text {nd }}$ antibody \\
\hline p38MAPK(Thr180/Tyr182) & Cell Signaling & $1: 1.000$ & Rabbit IgG \\
\hline p44/42 MAPK (Thr202/Tyr204) & Cell Signaling & $1: 1.000$ & Rabbit IgG \\
\hline pSrc (Tyr416) & Cell Signaling & $1: 1.000$ & Rabbit IgG \\
\hline pFAK (Tyr397) & Cell Signaling & $1: 1.000$ & Rabbit IgG \\
\hline pCDC42 (Ser71) & Cell Signaling & $1: 1.000$ & Rabbit IgG \\
\hline p62 (Ser403) & Cell Signaling & $1: 1.000$ & Rabbit IgG \\
\hline
\end{tabular}




\begin{tabular}{|c|c|c|c|}
\hline Antibodies (Clone) & Manufacturer & $\begin{array}{l}\text { Dilution } \\
\text { WB }\end{array}$ & $2^{\text {nd }}$ antibody \\
\hline Cyclin B(D5C10) & Cell Signaling & $1: 1.000$ & Rabbit IgG \\
\hline FoxM1 (D12D5) & Cell Signaling & $1: 1.000$ & Rabbit IgG \\
\hline LC3B (D11) & Cell Signaling & $1: 1.000$ & Rabbit IgG \\
\hline E-Cadherin (24E10) & Cell Signaling & $1: 1.000$ & Rabbit IgG \\
\hline TCF8/ZEB1 (D80D3) & Cell Signaling & $1: 1.000$ & Rabbit IgG \\
\hline N-Cadherin (D4R1H) & Cell Signaling & $1: 1.000$ & Rabbit IgG \\
\hline Vimentin (D21H3) & Cell Signaling & $1: 1.000$ & Rabbit IgG \\
\hline ZO-1 (D7D12) & Cell Signaling & $1: 1.000$ & Rabbit IgG \\
\hline Snail (C15D3) & Cell Signaling & $1: 1.000$ & Rabbit IgG \\
\hline Slug (C19G7) & Cell Signaling & $1: 1.000$ & Rabbit IgG \\
\hline$\beta$-Catenin (D10A8) & Cell Signaling & $1: 1.000$ & Rabbit IgG \\
\hline Claudin-1 (D5H1D) & Cell Signaling & $1: 1.000$ & Rabbit IgG \\
\hline Glutamine Synthetase & Sigma & $1: 1.000$ & Rabbit IgG \\
\hline KRAS (NO.240005) & Cell biolabs & $1: 500$ & Rabbit IgG \\
\hline MTHFD2 & Abnova & $1: 1.000$ & Mouse-IgG \\
\hline PARK7 & Abcam & $1: 1.000$ & Rabbit IgG \\
\hline$\beta$-Actin & Cell Signaling & $1: 1.000$ & Rabbit IgG \\
\hline GADPH & Sigma-Aldrich & $1: 1.000$ & Rabbit IgG \\
\hline$\beta$-Actin & Sigma-Aldrich & $1: 1.000$ & Mouse-IgG \\
\hline Alexa488 & Life Technologies & 1:1.000 & Rabbit IgG \\
\hline Alexa555 & Life Technologies & $1: 1.000$ & Mouse-IgG \\
\hline
\end{tabular}




\subsubsection{Plasmids}

Table 7: Summary of plasmids

\section{Plasmids}

U6gRNA-CAS9-2A-RFP

U6gRNA-CAS9-2A-GFP

PLAUR

(NM_002659)

\section{Company}

Sigma-Aldrich, St. Louis, Missouri, USA

OriGene Technologies, Inc. Maryland, USA

(CAT: RG201222)

\subsubsection{Small interfering RNAs}

Table 8: Summary of siRNAs

\begin{tabular}{lll}
\hline Targets & Name & Cat. No. \\
KRAS 1 & Hs_KRAS2_8 & SI02662051 \\
KRAS 2 & Hs_KRAS2_3 & SI00071015 \\
P38MAPK 1 & Hs_MAPK14_5 & SI00300769 \\
P38MAPK 2 & Hs_MAPK14_7 & SI00605164 \\
FAK 1 & Hs_PTK2_5 & SI00287791 \\
FAK 2 & Hs_PTK2_9 & SI00301532 \\
CDC42 1 & Hs_CDC42_15 & SI00287791 \\
CDC42 2 & Hs_CDC42_7 & SI02757328 \\
ATG5 & Hs_APG5L_6 & SI0265531 \\
\hline
\end{tabular}




\subsection{9 gRNAs and primers}

Table 9: gRNAs and primers

\begin{tabular}{ll}
\hline Targets & Sense $\left(\mathbf{5} \boldsymbol{\prime}^{\rightarrow} \mathbf{3}\right.$ ') \\
\hline uPAR Forward & CATGCAGTGTAAGACCCAACGGGGA \\
uPAR Reverse & AATAGGTGACAGCCCGGCCAGAGT \\
GAPDH Forward & GGTGGTCCAGGGGTCTTACT \\
GAPDH Reverse & CGACCACTTTGTCAAGCTCA \\
gRNA 1 & GGACCCTGAGCTATCGGACTGG \\
gRNA 2 & AGGTAACGGCTTCGGGAATAGG \\
uPAR CRISPR GFP Forward & CTGTCCCCATGGAGTCTCAC \\
uPAR CRISPR GFP Reverse & CATCCAGGCACTGTTCTTCA \\
uPAR CRISPR RFP Forward & CTGGAGCTGGTGGAGAAAAG \\
uPAR CRISPR RFP Reverse & GGATTGGGATGATGATGAGG \\
\hline
\end{tabular}

* All primers used for PCR were designed using Primer 3 (http://simgene.com/Primer3) and tested by primer-BLAST search (National Center for Biotechnology Information).

\subsubsection{Software}

Table 10: List of software

Software

Image J Version 1.52j

Geneious 11.0.4

i-control ${ }^{\mathrm{TM}}$

Fusion

Magellan ${ }^{\mathrm{TM}}$

Microsoft Excel

GraphPad Prism 7

\section{Company}

National Institutes of Health and the Laboratory, Bethesda, USA

Biomatters Ltd., Aukland, Neuseeland

Tecan Trading AG, Männedorf, Schweiz

Vilber Lourmat, Collégien, Frankreich

Tecan Trading AG, Männedorf, Schweiz

Microsoft Corporation, Redmond, Washington, USA

GraphPad Software, La Jolla, Kalifornien, USA 


\subsection{Methods}

\subsubsection{Human tissue}

Tissue sample from 59 PDAC patients were provided by the Institute of Pathology of the Medical Center Göttingen (Table 1). The study was approved by the ethics committee of the University Medical Center Göttingen (GÖ 912/15).

\subsubsection{Immunohistochemical stainings}

Tissue samples were arranged on tissue microarrays (TMA) before immunostaining. Immunohistochemical reactions were performed on a Dako AutoStainer Link 48 (Dako). $2 \mu \mathrm{m}$ tissue sections of TMAs were incubated in EnVision Flex Target Retrieval Solution (Dako), $\mathrm{pH}$ high or low, depending on specific antibody, followed by incubation with the primary antibody Phospho-p38MAPK (Thr180/Tyr182) (D3F9) XP® Rabbit mAb \#4511 at room temperature (RT) for $20 \mathrm{~min}$. Immunodetection was performed with a polymeric secondary antibody coupled to HRPO peroxidase (EnVision Flex+, Dako) and DAB (Dako). Tissue samples were analyzed by light microscopy after counterstaining with Meyer's haematoxylin and evaluated for positive or negative staining.

\subsubsection{Cell culture}

The human pancreatic cancer cell lines AsPC-1, MIA PaCa-2, BxPC-3, PANC-1, CAPAN-2, PATU8988T cell lines were purchased from American Type Culture Collection (ATCC), maintained in RPMI-1640 supplemented with $10 \%$ fetal bovine serum, $1 \%$ penicillin $\mathrm{G}$ sodium and streptomycin sulfate, $1 \% \mathrm{D}$-glucose and L-glutamine (Complete RPMI). The CAPAN-1 cell line was cultured in Dubecco's Modified Eagle's Medium supplemented with $10 \%$ fetal bovine serum, $1 \%$ penicillin $\mathrm{G}$ sodium and streptomycin $\mathrm{B}$ and $1 \%$ glutamine and D-glucose. Cells were maintained in a humidified incubator at $37{ }^{\circ} \mathrm{C}$ and $5 \% \mathrm{CO}_{2}$ and medium was refreshed every $72 \mathrm{~h}$. Cultures were passaged in a 1:4 dilution upon $80 \%$ confluence (cells were under 30 passages). 


\subsubsection{Protein isolation and western blot}

The cell pellet was resuspended in a cell number dependent volume of RIPA lysis buffer (see Materials 2.1.4) and incubated on ice for $30 \mathrm{~min}$. The lysate was centrifuged at 14,000 rounds per minute $(\mathrm{RPM})$ at $4{ }^{\circ} \mathrm{C}$ for $30 \mathrm{~min}$ and the supernatant was transferred to a fresh tube. Protein concentration was measured with $\mathrm{DC}^{\mathrm{TM}}$ protein assay. Solution $\mathrm{S}$ was diluted 1:50 in solution A. $20 \mu 1$ of this mixture were added to a 96-well plate. $2 \mu 1$ protein lysate was added and $200 \mu 1$ solution B was added and incubated for $10 \mathrm{~min}$ at RT. The absorbance was measured by Tecan microplate reader Infinite ${ }^{\circledR}$ M2000 Pro (Software: Magellan ${ }^{\mathrm{TM}}$, Tecan) and the concentration was calculated according to an internal standard curve. $20 \mu \mathrm{g}$ protein per sample was dissolved in sample buffer, which consisted of $0.25 \mathrm{M}$ Tris- $\mathrm{HCl}$ ( $\mathrm{pH} 6.8$ ) containing $5 \%$ (mass/volume) sodium dodecyl sulphate, $5 \%$ (volume/volume) 2-mercaptoethanol, $8 \mathrm{M}$ urea and $0.01 \%$ (mass/volume) bromophenol blue. SDS-PAGE (10\%) gels were loaded with a total volume of $20 \mu 1$ per sample and run $15 \mathrm{~min}$ at 80 voltage following one hour at $125 \mathrm{~V}$. Proteins were electrotransferred as a transfer mini model (Trans-Blot Turbo transfer system) for 7 min onto Immobilon PVDF. The membrane was blocked in $5 \%$ fat-free milk for one hour at RT and subsequently incubated and shaking with primary antibody diluted in Tris buffered saline with Tween 20 (TBST) (Table 2) at $4{ }^{\circ} \mathrm{C}$ overnight. On the second day, the membrane was rinsed 3 times for $10 \mathrm{~min}$ at RT in phosphate buffered saline (PBS) with $0.1 \%$ Tween 20 . Next, the membrane was incubated with secondary antibody (Table 2) diluted in TBST for $1 \mathrm{~h}$ at RT. Scanning of the membrane was performed on a Fusion Imaging System (The Fusion) using automatically exposure. A prestained protein ladder PageRuler Plus was used.

\subsubsection{Enzyme linked immunosorbent assay (ELISA)}

Cell lysates were diluted 10-fold and $50 \mu 1$ of cell lysates or standard was added into every well containing $100 \mu \mathrm{l}$ of assay diluent RD1W. Wells were covered with the adhesive strip provided and incubated for $2 \mathrm{~h}$ at RT. Supernatant was aspirated and each well was washed three times with $400 \mu$ l wash buffer. $200 \mu$ of human uPAR conjugate was added into each well, covered with a new adhesive strip and incubated for $2 \mathrm{~h}$ at RT. Then the supernatant was removed and $200 \mu$ of substrate solution was added to each well. The samples were incubated for $30 \mathrm{~min}$ at RT and protected from light before the reaction was 
stopped with $50 \mu \mathrm{l}$ of stop solution. The absorbance was measured within $30 \mathrm{~min}$ by using a microplate reader set to $450 \mathrm{~nm}$ and reference set to $540 \mathrm{~nm}$. Subsequently the concentration per $10^{6}$ cells of UPAR was calculated with the help of the generated standard curve.

\subsubsection{Viability assays}

Viability assays were performed using MTS [3-(4,5-dimethylthiazol-2-yl)-5-(3carboxymethoxyphenyl)-2-(4-sulfophenyl)-2H-tetrazolium, inner salt] assay. $10^{5}$ Cells were plated in microtiter culture plates in a total volume of $100 \mu \mathrm{l} /$ well. After overnight incubation the medium was exchanged by $200 \mu 1$ new medium with increasing concentrations of gemcitabine and p38MAPK inhibitors or DMSO control. Before measurement, $20 \mu \mathrm{l}$ of $5 \mathrm{~m} / \mathrm{ml}$ MTS were added to each well, followed by an incubation for $2 \mathrm{~h}$ at $37{ }^{\circ} \mathrm{C}$ and $5 \% \mathrm{CO}_{2}$. Absorbance was measured at $570 \mathrm{~nm}$ and $460 \mathrm{~nm}$ as reference in a microtiter plate reader (Tecan infinite 200pro). All experiments were performed at least in triplicates. Measured values of different concentrations were averaged, background absorbency was subtracted and values were expressed as percentage compared to untreated control cells (cell viability). The half maximal inhibitory concentration (IC50) or growth curve was estimated by plotting drug concentrations against cell viability assuming a linear relation.

\subsubsection{Wound healing assay}

Scratches (wounds) were created by scraping the $100 \%$ confluent cell monolayer with a $100 \mu \mathrm{l}$ sterile tip after incubating cells for $24 \mathrm{~h}$ with medium containing $1 \% \mathrm{FBS}$. The wounded cultures were washed twice with cold sterile PBS to remove detached cells and then maintained with $1 \%$ FBS medium. The wound closure was monitored after $0 \mathrm{~h}, 24$ h, 48 h, 72 h with an inverted Leica microscope equipped with a Canon EOS 650D camera. The relative cell migration distance was calculated based on the distance the cells migrated into the wound area and expressed as percentage of control. 


\subsubsection{Extraction of DNA}

For DNA isolation the puregene core kit A from Qiagen was used. Trypsinized cells were centrifuged and the pellet was resuspended in $300 \mu 1$ lysis plus $10 \mu 1$ Proteinase $\mathrm{K}$ and incubated for $1 \mathrm{~h}$ at $55^{\circ} \mathrm{C}$. After addition of $1.5 \mu \mathrm{l}$ RNase A solution the lysate was incubated for $10 \mathrm{~min}$ at $37^{\circ} \mathrm{C}$. The lysate was placed on ice for one minute. $100 \mu 1$ protein precipitation solution was added and vortexed for $15 \mathrm{sec}$. The lysate was centrifuged at 4 ${ }^{\circ} \mathrm{C}$ and 14,000 RPM for $5 \mathrm{~min}$. The supernatant was removed into a new tube. $300 \mu 1100$ $\%$ isopropanol were added and the tube was inverted $30 \mathrm{x}$. After centrifugation $(1,400$ RPM) the DNA pellet was washed with $300 \mu 170 \%$ ethanol and centrifuged again. The supernatant was removed. The pellet was dried shortly before it was resuspended in $50 \mu 1$ Hydration Solution. Quantification and purity assessment of total DNA was completed by using the NanoDrop spectrophotometer (Nano2000 Drop Thermo scientific). DNA was considered pure if the ratio of absorbance readings at $260 \mathrm{~nm}$ and $280 \mathrm{~nm}$ was between 1.8 and 2.1. The DNA was stored at $-20{ }^{\circ} \mathrm{C}$.

\subsubsection{Mixture for polymerase chain reaction (PCR) reaction}

Table 11: Summary of parameters and program of PCRs

\section{PCR program for screen of $\mathrm{KO}$}

Reagents

MyTaq Mix, 2x

Primer forward

Primer reverse

Sample template

ddH2O

Total volume $(\mu \mathrm{l})$

0.5

0.5

1

8

20

The parameters of PCR

\section{Temperature}

Time

Initial denaturation
$95{ }^{\circ} \mathrm{C}$

$3 \min$ 
Start cycle, $45 \mathrm{x}$

Denaturation

$95^{\circ} \mathrm{C}$

$15 \mathrm{sec}$

Annealing

$60{ }^{\circ} \mathrm{C}$

$15 \mathrm{sec}$

Elongation

$72{ }^{\circ} \mathrm{C}$

$25 \mathrm{sec}$

Final elongation

$72{ }^{\circ} \mathrm{C}$

$2 \min$

Storage

$4{ }^{\circ} \mathrm{C}$

$\infty$

\section{Component of PCR mixture reaction for Cycle Sequence}

\section{Reagents}

5x Big Dye buffer

5x Big Dye

Sequencing primer

ExoSAP DNA

ddH2O

Total

\section{volume $(\mu \mathrm{l})$}

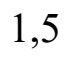

1

3.2

2

2,3

10

\section{The PCR of ExoSAP Cleanup}

Reagents

volume $(\mu \mathrm{l})$

ExoSAP

ddH2O

PCR Product

10

\section{The parameters of ExoSAP Cleanup}

\section{Temperature}

Time

Initial denaturation

$37^{\circ} \mathrm{C}$

$30 \mathrm{sec}$

Start cycle, $25 \mathrm{x}$

Incubation 1

$37^{\circ} \mathrm{C}$

$15 \mathrm{sec}$

Incubation 2

$80^{\circ} \mathrm{C}$

$15 \mathrm{sec}$ 
Close cycle

Store forever

$4{ }^{\circ} \mathrm{C}$

$\infty$

The sequence parameters of Cycle Sequencing

Temperature

Time

Initial denaturation

$96^{\circ} \mathrm{C}$

$1 \mathrm{~min}$

Start cycle, $25 \mathrm{x}$

Denaturation

$96^{\circ} \mathrm{C}$

$10 \mathrm{sec}$

Elongation

$60{ }^{\circ} \mathrm{C}$

$3 \mathrm{~min}$

Close cycle

Store forever

$4{ }^{\circ} \mathrm{C}$

$\infty$

\subsubsection{Plasmid DNA isolation and purification from Escherichia coli $(E$. coli)}

E. coli bacteria carrying the clustered regularly interspaced short palindromic repeats (CRISPR) plasmids were added in $50 \mu \mathrm{l}$ of LB medium at $37{ }^{\circ} \mathrm{C}$. Kanamycin was used for the screening of competent $E$. coli. A resistance to kanamycin was designed into the CRISPR plasmid. The isolation of plasmid DNA was completed with the QIAGEN plasmid maxi kit according to the manufacturer's instructions.

\subsubsection{E. coli bacteria for CRISPR plasmids}

$1 \mu \mathrm{l}$ of CRISPR plasmid mix was added into the E. coli medium before E. coli bacteria was inserted into ice for $20 \mathrm{~min}$. The mixture was heated at $42{ }^{\circ} \mathrm{C}$ without shaking for 45 sec after incubation for $30 \mathrm{~min}$ on ice. The bacteria were rescue on ice for $1 \mathrm{~min}$ and transformed into the tube with $400 \mu \mathrm{LB}$ medium and mixed gently. The mixture was incubated with shaking at $420 \mathrm{rpm}$ for 1 hour at $37^{\circ} \mathrm{C}$. After incubation 10-100 $\mu 1$ of the bacteria solution were removed on LB-agar plates (kanamycin $100 \mu \mathrm{g} / \mathrm{ml}$ ) by pipette and incubated at $37^{\circ} \mathrm{C}$ for one night. 


\subsubsection{Generation of uPAR knock out cells using transient CRISPR/Cas9 vector constructs}

Cells were transfected with the two CRISPR/Cas9 constructs pCMV-Cas9-RFP and pCMV-Cas9-GFP as described in 2.1.7 and 2.1.9 using the X-tremeGENE HP DNA transfection reagent (Merck), according to the manufacturer's instructions. $72 \mathrm{~h}$ posttransfection, green and red double positive cells were sorted by fluorescence activated cell sorting (FACS) and single cells were cultured in a 96-well plate.

\subsubsection{Fluorescence activated cell sorting (FACS) of transfected cells}

The cells were carefully resuspended and transferred to a common $15 \mathrm{ml}$ Falcon tube. FACS sorting was carried out at the core facility at the University Medical Center Göttingen. Single cells with both GFP and RFP signals was sorted into a 96-well plate containing $100 \mu \mathrm{l} /$ well complete RPMI medium. The cells were incubated under the same conditions before transfection. The old medium was replaced with the fresh medium every three days. After 3 weeks the cells were transferred to a 6-well plate. When cell density was up to $80 \%$, isolations of DNA from 6-well plate performed genetic analysis.

\subsubsection{Small interfering RNA experiments}

Unless stated otherwise cells were transfected with $80 \mathrm{nM}$ siRNA with HiPerFect transfection reagent by manufacturer. Transfection medium mixture: $9.6 \mu 1$ siRNA, $12 \mu 1$ HiPerFect, RPMI without FCS up to $100 \mu$. The mixture was incubated at RT for 25 min and added to 300,000 cells in $2 \mathrm{ml}$ medium per well for 6 well-plate. Cells were incubated for $24 \mathrm{~h}$ or $48 \mathrm{~h}$ before further processing. A summary of the siRNAs used is shown in Table 3.

\subsubsection{KRAS activity measurement.}

A KRAS activation assay (STA-400-K-T, Cell Biolabs) was performed according to the manufacturer's recommendations. Briefly, $1 \mathrm{mg}$ protein lysate was subjected to Raf1 RBD agarose beads and incubated at $4{ }^{\circ} \mathrm{C}$ for $1 \mathrm{~h}$ under agitation. Beads were pelleted at 14,000 RPM for $10 \mathrm{sec}$ and the supernatant was discarded. After three washing steps the 
supernatant was carefully removed and the bead pellet was resuspended in 4x Laemmli buffer. The mixture was boiled for $5 \mathrm{~min}$ and centrifuged for $10 \mathrm{sec}$ at 14,000 RPM. 20 $\mu 1$ of the supernatant was subjected to a western blot.

\subsubsection{Confocal laser scanning fluorescence microscopy}

Cells were plated on coverslips in a 12 well-plate at a density of $3 \times 10^{5}$ cells $/ \mathrm{ml}$ one day before the experiment. Cells were fixed with cold $\left(-20^{\circ} \mathrm{C}\right)$ methanol or acetone on ice for 5 min, washed with PBS and blocked with $1 \%$ FCS in PBS at RT for 30 min. Primary antibody incubation was carried out in PBS at $4{ }^{\circ} \mathrm{C}$ overnight. Alexa 488 or 555conjugated secondary anti-rat or anti-mouse antibodies were used for $2 \mathrm{~h}$ incubation at RT. After washing with PBS, sample analysis was done by using an Olympus IX81 confocal laser scanner microscope equipped with an HCX PL APO 63 x 1.4 oil CS objective in combination with Leica confocal software.

\subsubsection{Colony formation assay}

To produce a single-cell suspension, trypsinized cells were resuspended and diluted to the desired cell concentration of $5 \times 10^{3}$ cells $/ \mathrm{ml}$. $0.8 \mathrm{ml}$ of the cell suspension were transferred into a sterile tube containing $3.2 \mathrm{ml} \mathrm{HSC-CFU} \mathrm{basic} \mathrm{media} \mathrm{and} \mathrm{mixed} \mathrm{gently}$ by pipette while avoiding any air bubbles. The cells were transferred to a sterile dish in triplicates and incubated at $37{ }^{\circ} \mathrm{C}$ and $5 \% \mathrm{CO}_{2}$. Clones were screened with a microscope every two days until cells in control dishes had formed sufficiently large clones. Cell counting was performed using a stereomicroscope and an automatic counting system.

\subsubsection{Statistical analysis}

Statistical analysis was performed using GraphPad 7.0e and expressed as Mean \pm SEM. Two group comparisons were performed using student's t-test. Cell growth and resistance comparison were analyzed using One-way ANOVA. Survival analyses were performed using the Kaplan-Meier method and tested using Log-Rank (Cox-Mantel) test. A p value of $<0.05$ was considered significant $(* p<0.05, * * p<0.01, * * * p<0.001)$. 


\section{Results}

\subsection{Immunohistochemistry of uPAR in clinical PDAC tissue samples shows prognostic significance}

It was previously shown that $u P A R$ gene amplification in PDAC correlates with poor prognosis (Hildenbrand et al. 2009). Immunohistochemical staining of uPAR in a cohort of 59 patients (Table 1) revealed that also the protein expression level of uPAR has prognostic value. Patients with high uPAR signals had a significantly shorter overall survival (OS) than patients with low uPAR levels (median survival time in patients with high uPAR: 323 days, patients with low uPAR: 704 days, Cox-Mantel test, $95 \%$ confidence interval 1.35 to $3.51, p<0.05$ ) (Fig. 4).

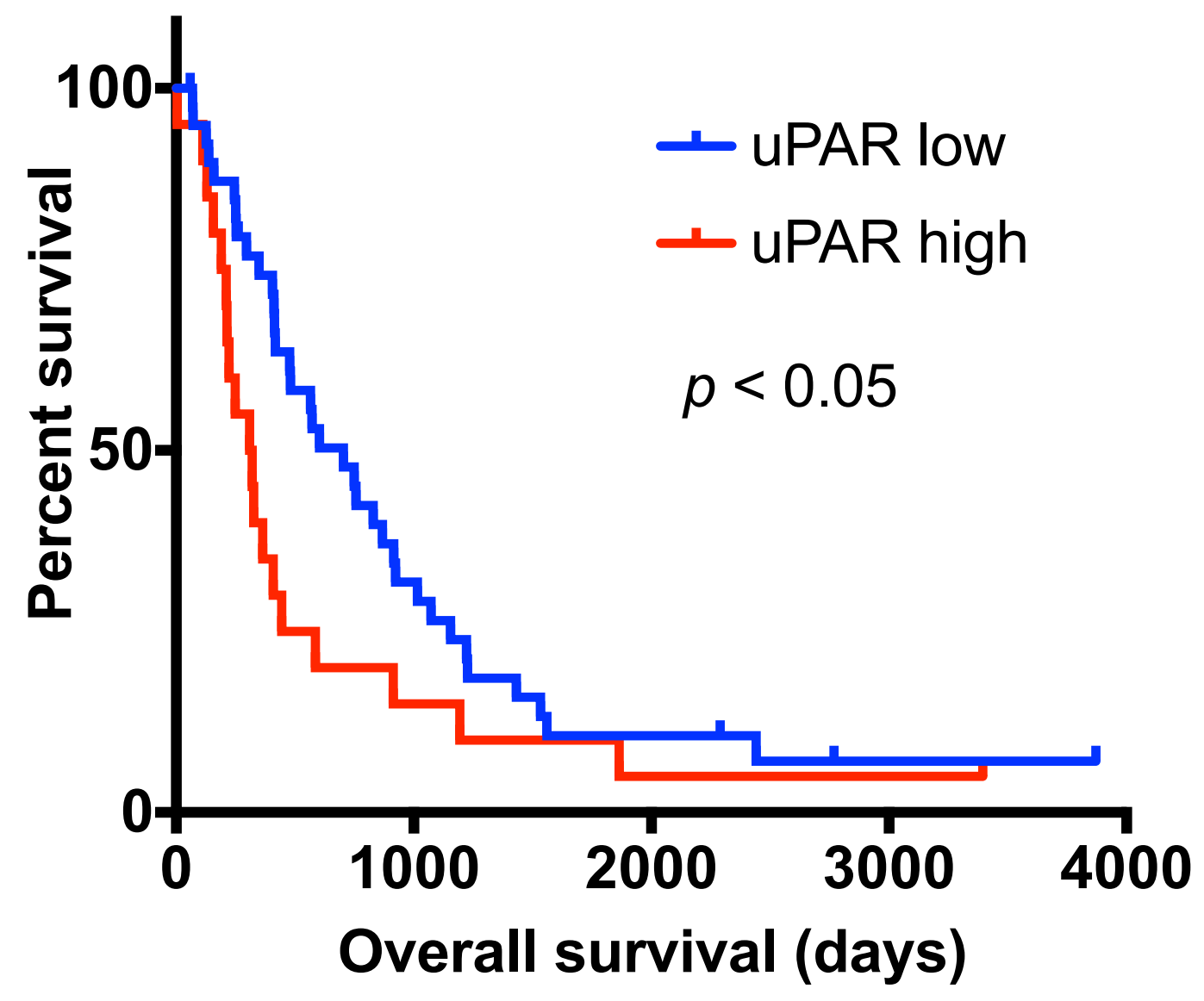

Figure 4: Prognostic significance of uPAR expression in PDAC. Kaplan-Meier analysis of the overall survival of patients with pancreatic cancer, according to the expression level of uPAR IHC H-score. Significantly shorter median survival in patients with tumors with high-H-score (red) compared to tumors low-H-score (blue). Kaplan-Meier analysis, Cox-Mantel-test, $p<0.05$. 
To address the functional aspects of uPAR in vitro, we evaluated UPAR levels in a panel of seven human PDAC cell lines (AsPC-1, BxPC-3, CAPAN-1, CAPAN-2, MIA PaCA2, PATU8988T and PANC-1) by ELISA (Fig. 5A). This revealed AsPC-1 as the cell line with the highest and PANC-1 with the lowest uPAR level (Fig. 5A). Therefore, AsPC-1 was chosen to further study the function of UPAR by the generation of a specific CRISPR/Cas9 knock out (KO).

\section{2 gRNAs design, clone selection and mutation screening}

Two gRNAs direct against exon 3 and 4 of $u P A R$ were selected from a gRNA library provided by Sigma (sigmaaldrich.com) and purchased as CRISPR-Cas9-GFP/RFP allone-in plasmids as listed in section 2.1.9. Fig. 5B shows the genomic map, the locations and sequences of the guide RNAs. Cell culture and the transfection of the combined plasmids were performed as described in the sections 2.2.3 and 2.2.12. The transfection efficiency and the activity of the CRISPR/Cas9 were monitored via fluorescence signals $24 \mathrm{~h}$ after transfection (Fig. 6A). The primers used to amplify the relevant genomic fragments are summarized in Table 4. 

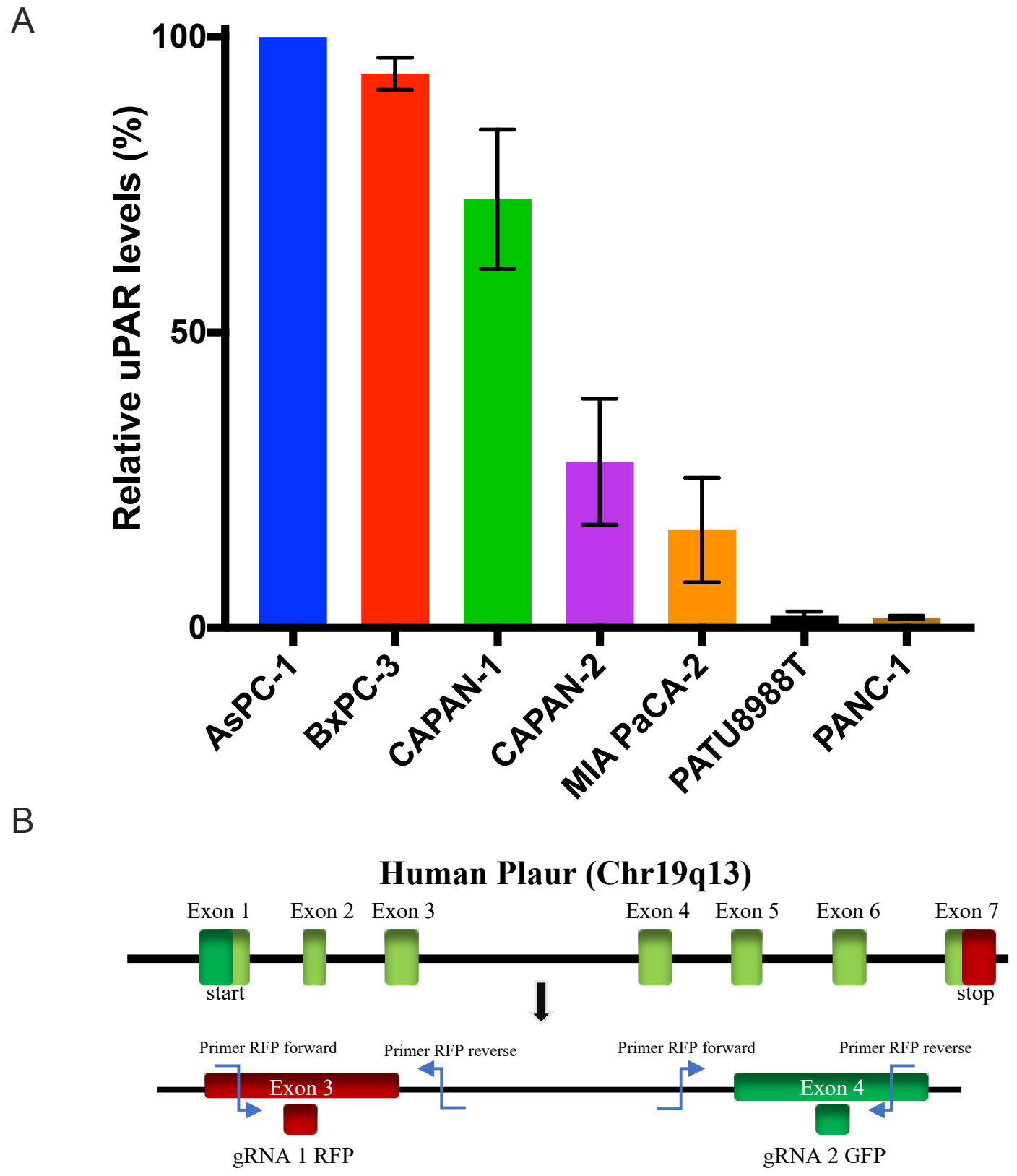

Figure 5: uPAR expression in seven PDAC cell lines and gRNAs map. A: Verification of UPAR expression by ELISA in seven pancreatic cancer cell lines. Results are presented as mean $\pm S E M$ from 3 different. B: Schematic representation of the strategy used to generate $u P A R$ mutants by CRISPR/Cas9. Double-stranded gDNA breaks were produced by Cas9 in $u P A R$ exons 3 and 4.

\subsection{Establishment of functional $u P A R$ KO mutants in AsPC-1}

Two AsPC-1 $u P A R \mathrm{KO}\left(u P A R^{-/}\right)$clones (clone 12,14$)$ were initially chosen. These clones contained a deletion on one allele in combination with a smaller gRNA target specific out of frame mutation on the second allele leading to a functional homozygous $u P A R$ KO (Fig. 6B-E). $u P A R^{-/}$was confirmed ELISA as described in section 2.2.5. In 
clones 12 and 14 the level of uPAR protein was reduced to background levels (Fig. 7A) $(p<0.05)$. Therefore, the AsPC-1 $u P A R^{-/-}$clones 12 and 14 were chosen for further functional analyses.

A

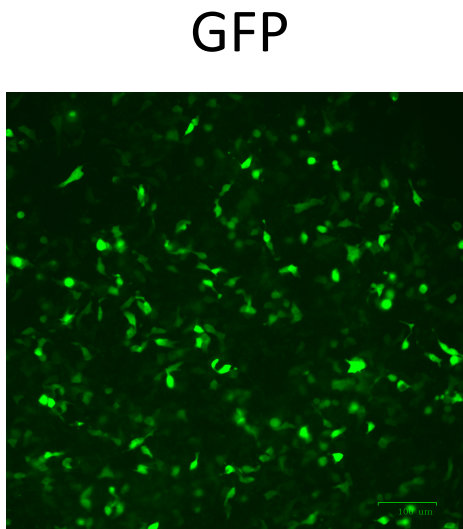

RFP

Merge

$\mathrm{B}$
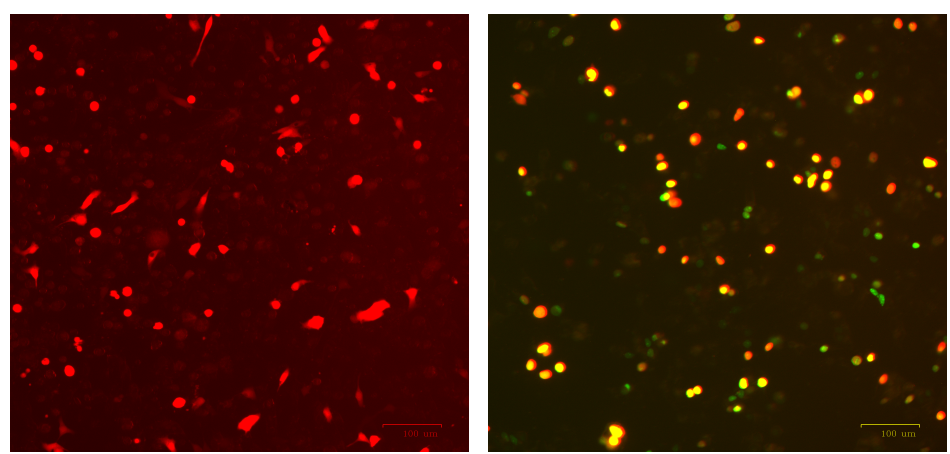

C

D
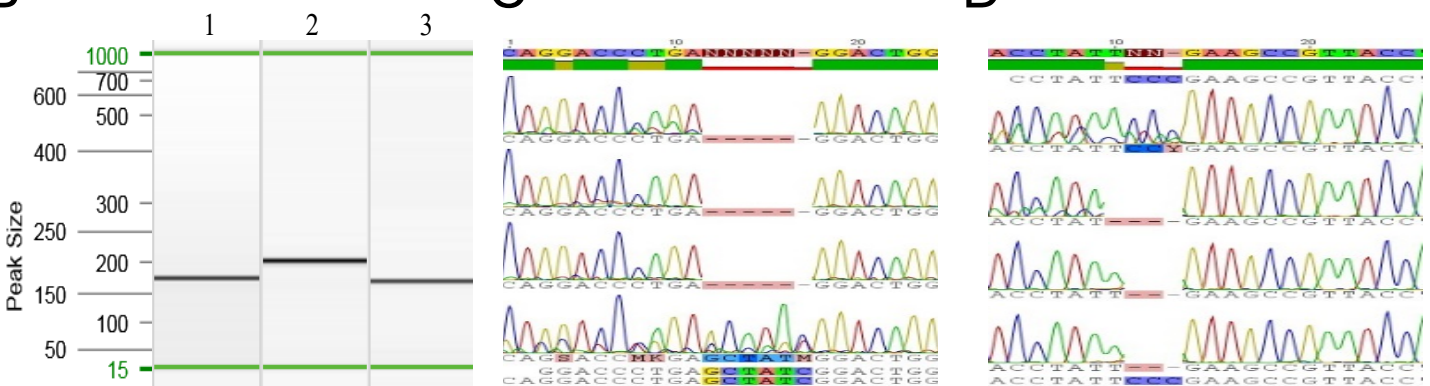

E

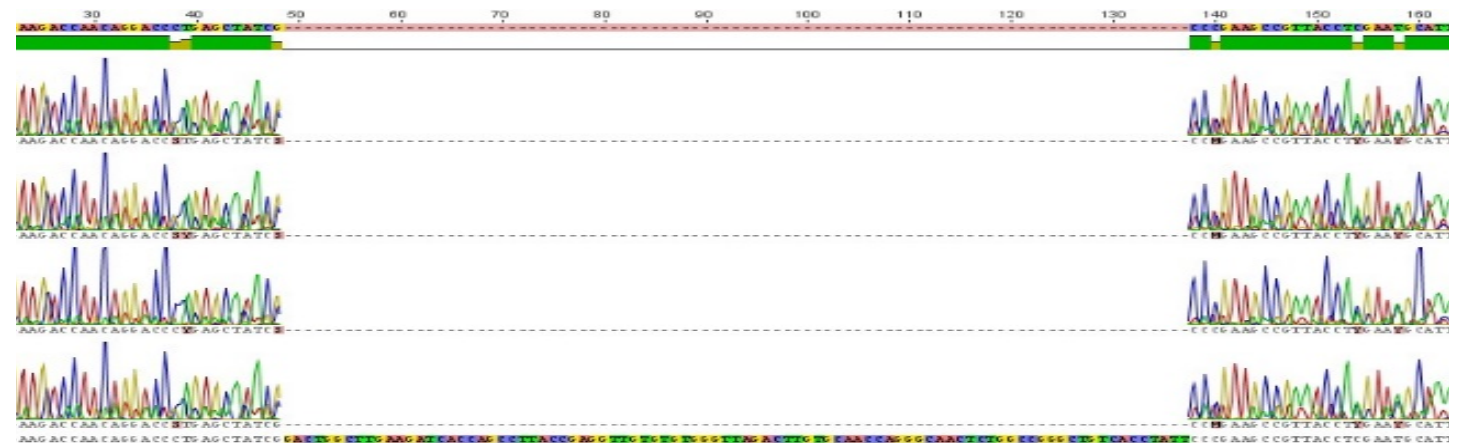

Figure 6: Molecular analysis of $\boldsymbol{u} \boldsymbol{P} \boldsymbol{A \boldsymbol { R } ^ { - / }}$ clones. A: GFP and RFP double positive cells were FACS sorted for single cell cultivation. B: gRNA target site specific PCR revealed a heterozygous deletion. C and D: Small mismatch repair errors in both gRNA target sites and E: a large deletion was observed by Sanger sequence analysis. 


\subsection{Phenotypic analysis of AsPC-1 $u P A R^{-/-}$cells shows decreased cell growth, reduced migration and increased mesenchymal to epithelial transition (MET)}

To characterize the phenotype of the $u P A R^{-/-}$clones we first investigated analysed cell proliferation and motility (Aguirre Ghiso et al. 1999; Aguirre-Ghiso et al. 2001; Nguyen et al. 1999; Smith et al. 2008). This revealed a reduced cellular growth for the $u P A R^{-1-}$ clones 12 and 14 in comparison to AsPC-1 WT (Fig. 7B). $u P A R^{-/-}$cells had also a severe reduction of their migratory ability as shown in Fig. 8A and B.

A

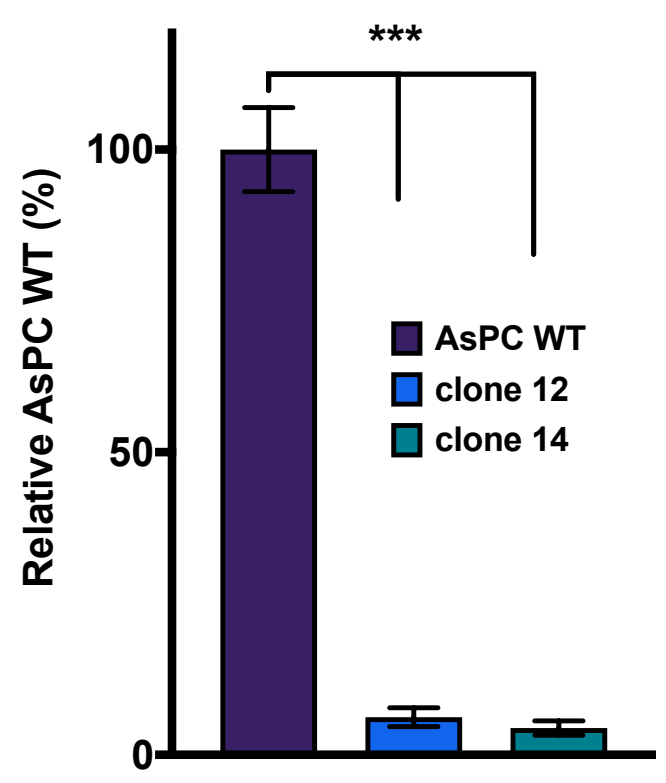

B

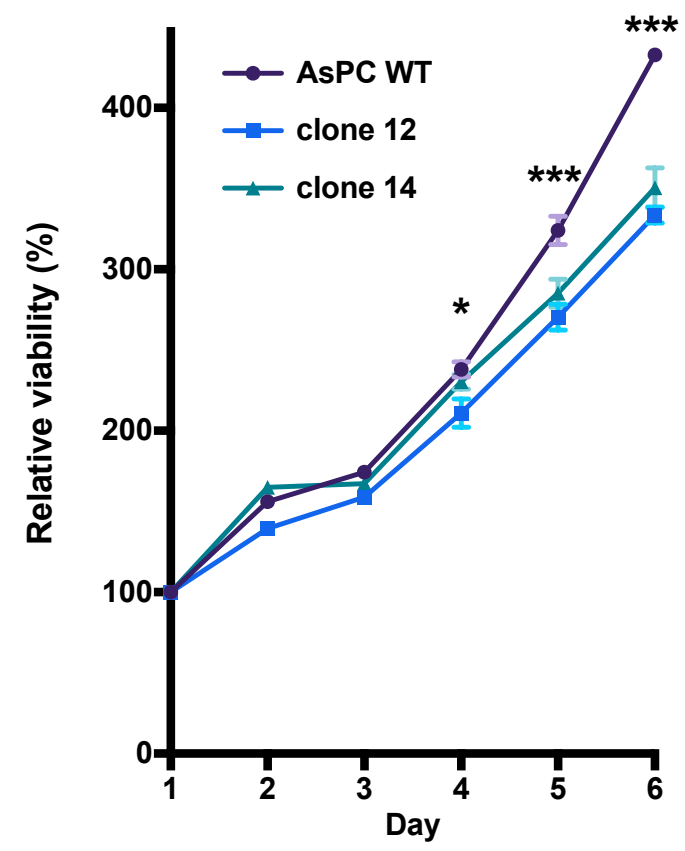

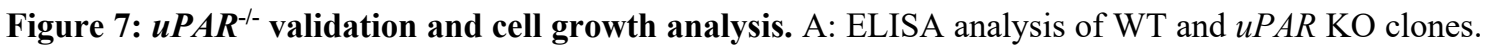
Percentages of WT and KO clone exhibiting a significant reduction of uPAR levels. B: Cells growth analysis over a 6-day period showed a significant slower growth for $u P A R \mathrm{KO}$ clones $(\mathrm{n}=6)$.

This observation suggested that UPAR was involved in cellular pasticity. Since it is also known that uPAR-initiated cell signaling induces EMT (Jo et al. 2009b; Lester et al. 2007) we investigated $u P A R^{-/}$AsPC-1 for the expression of eight specific EMT markers. This revealed a clear dominant expression of epithelial markers like E-cadherin, $\beta$-catenin, claudin-1, slug and $\mathrm{N}$-cadherin in the $u P A R^{-/}$clones whereas the stromal markers vimentin, ZEB1 and ZO-1 were suppressed compared to AsPC-1 WT cells (Fig. 8C). In 
addition confocal microscopy studies showed reduced actin filaments and more cell-cell junctions in $u P A R^{-/-}$cells (Fig. 9A). Taken together, the finding suggested that uPAR has a critical role in regulating the EMT/MET process. 
A

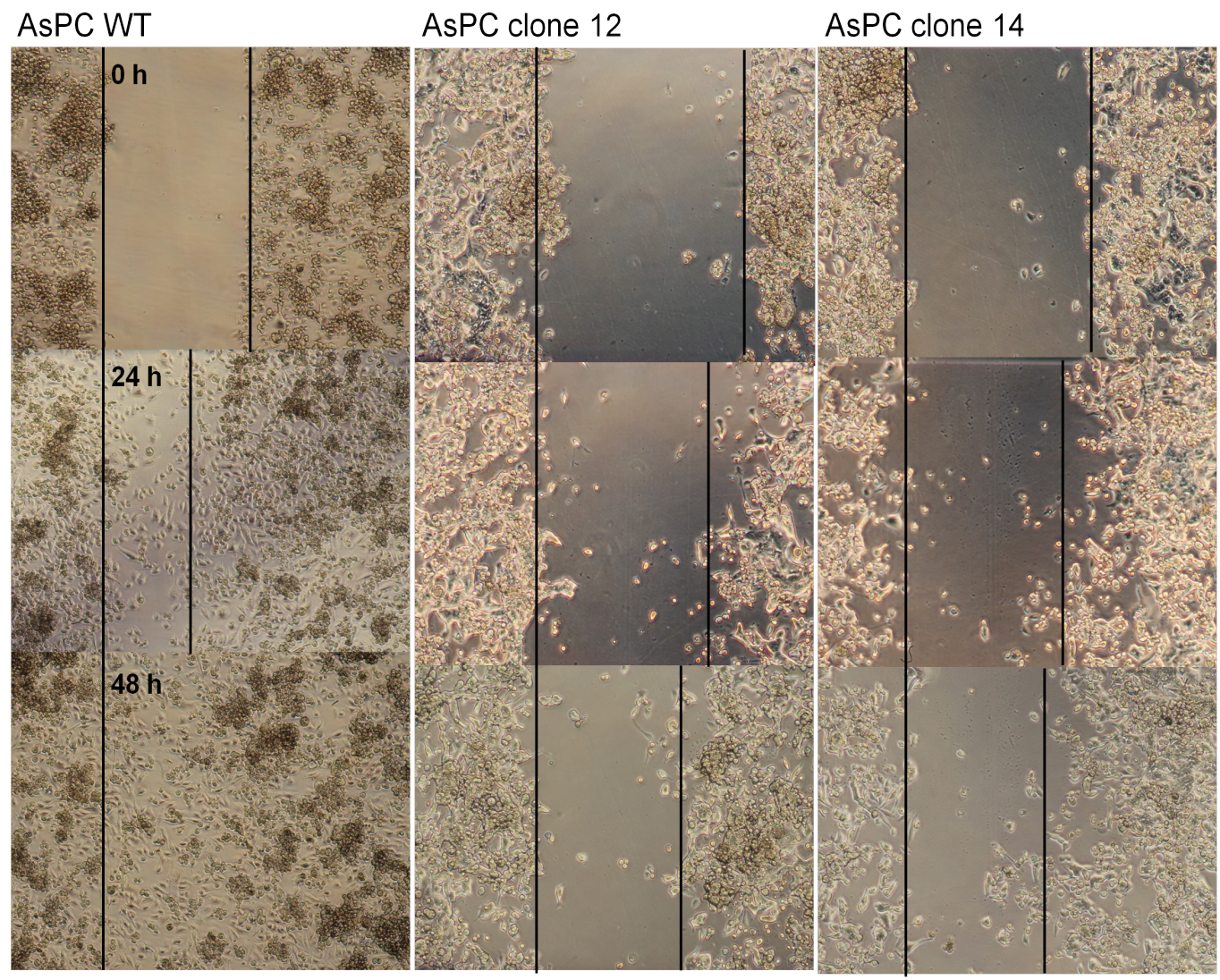

B

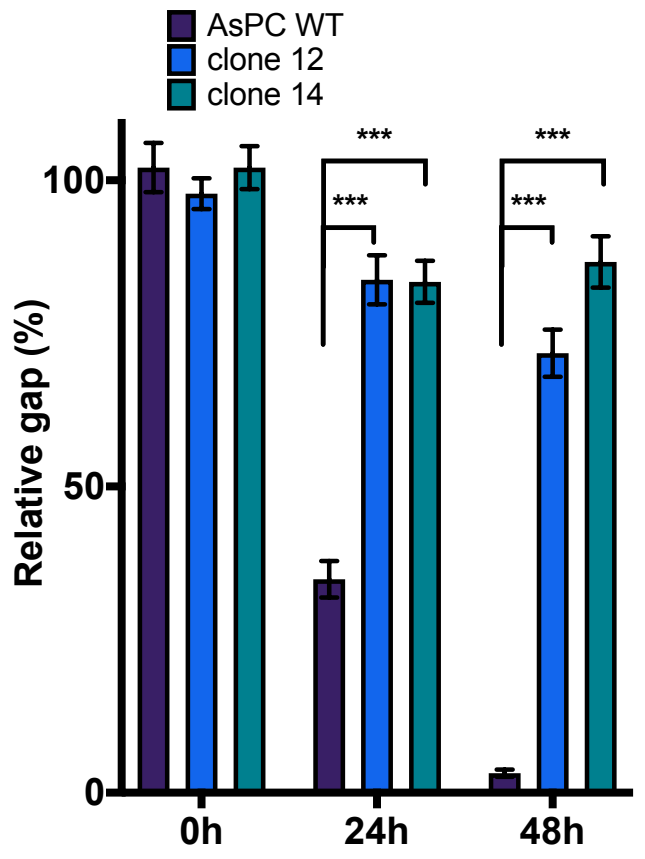

C

AsPC WT clone 12 clone 14

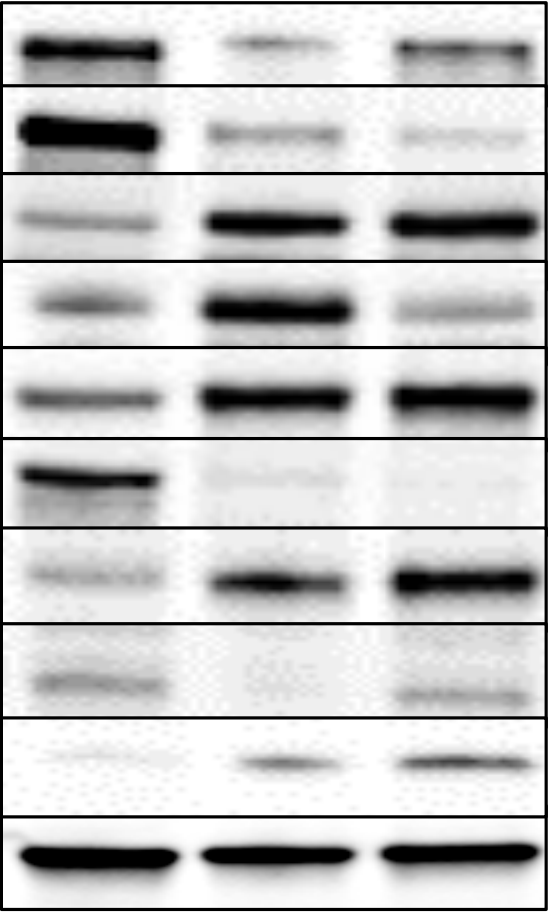




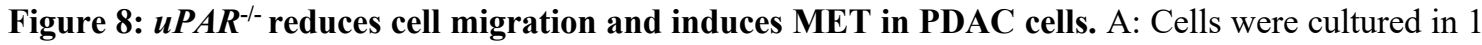
$\%$ FBS overnight before scratching with sterile $100 \mu$ tips. B: Statistical analysis of migration ability of uPAR $^{-/}$cells. C: EMT/MET markers were investigated by western blot. GAPDH was used as housekeeping gene.

\subsection{Effects of uPAR on cell survival and apoptosis}

To investigate whether uPAR modulates apoptosis (Wykosky et al. 2015), cells were treated with $1 \mu \mathrm{M}$ staurosporine for $24 \mathrm{~h}$. Western blot analysis of caspase- 3 and poly ADP ribose polymerase (PARP) showed no cleavage or activations of either treated $u P A R^{-/-}$or AsPC-1 WT cells (Fig. $9 \mathrm{~B}$ ).

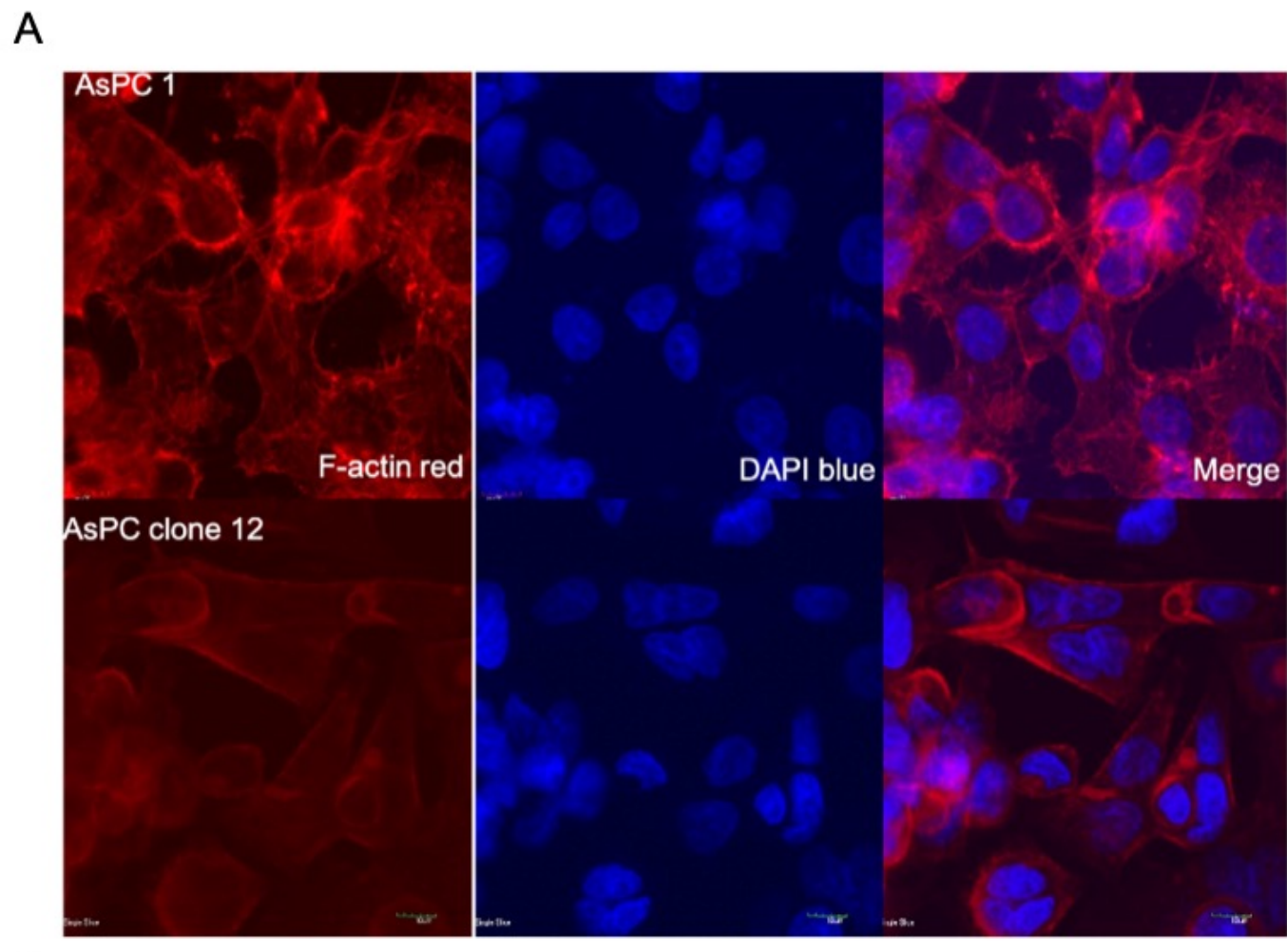

B

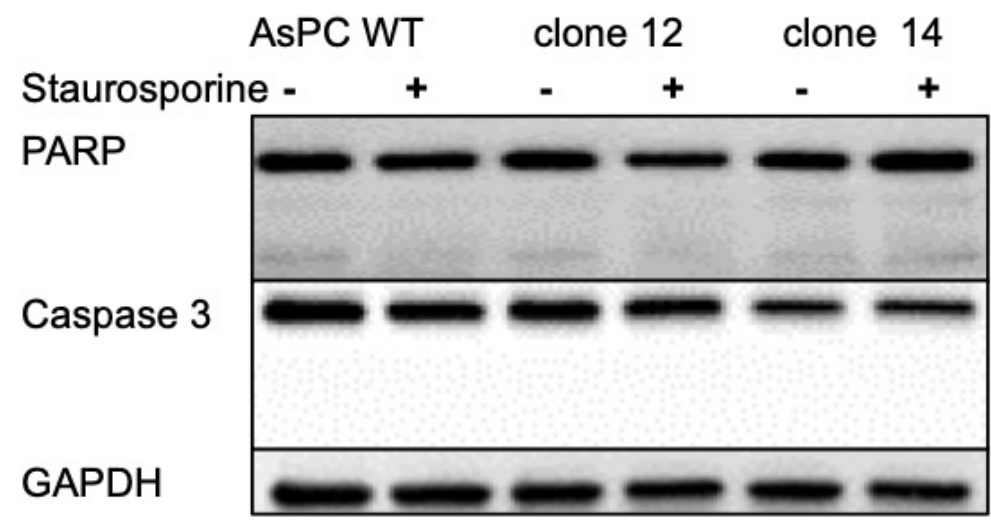


Figure 9: $\boldsymbol{u} \boldsymbol{P} A \boldsymbol{R}^{-/-}$influences cellular plasticity but not apoptosis. A: Phalloidin staining (red) of WT and clonal cells revealed less stress fibers in $u P A R^{-/}$cells. B: Induction of apoptosis with staurosporine $1 \mu \mathrm{M}$ or without for $24 \mathrm{~h}$. Detection of potential targeted proteins using antibodies against PARP and Caspase 3 by western blot. GAPDH was used as a housekeep gene.

Further, three-dimensional culturing assays were performed to detect the impact of uPAR on cell growth and tumorigenesis as described in section 2.2.17. $u P A R^{-/-}$cells were greatly inhibited in their colony-forming ability (Fig. 10A).

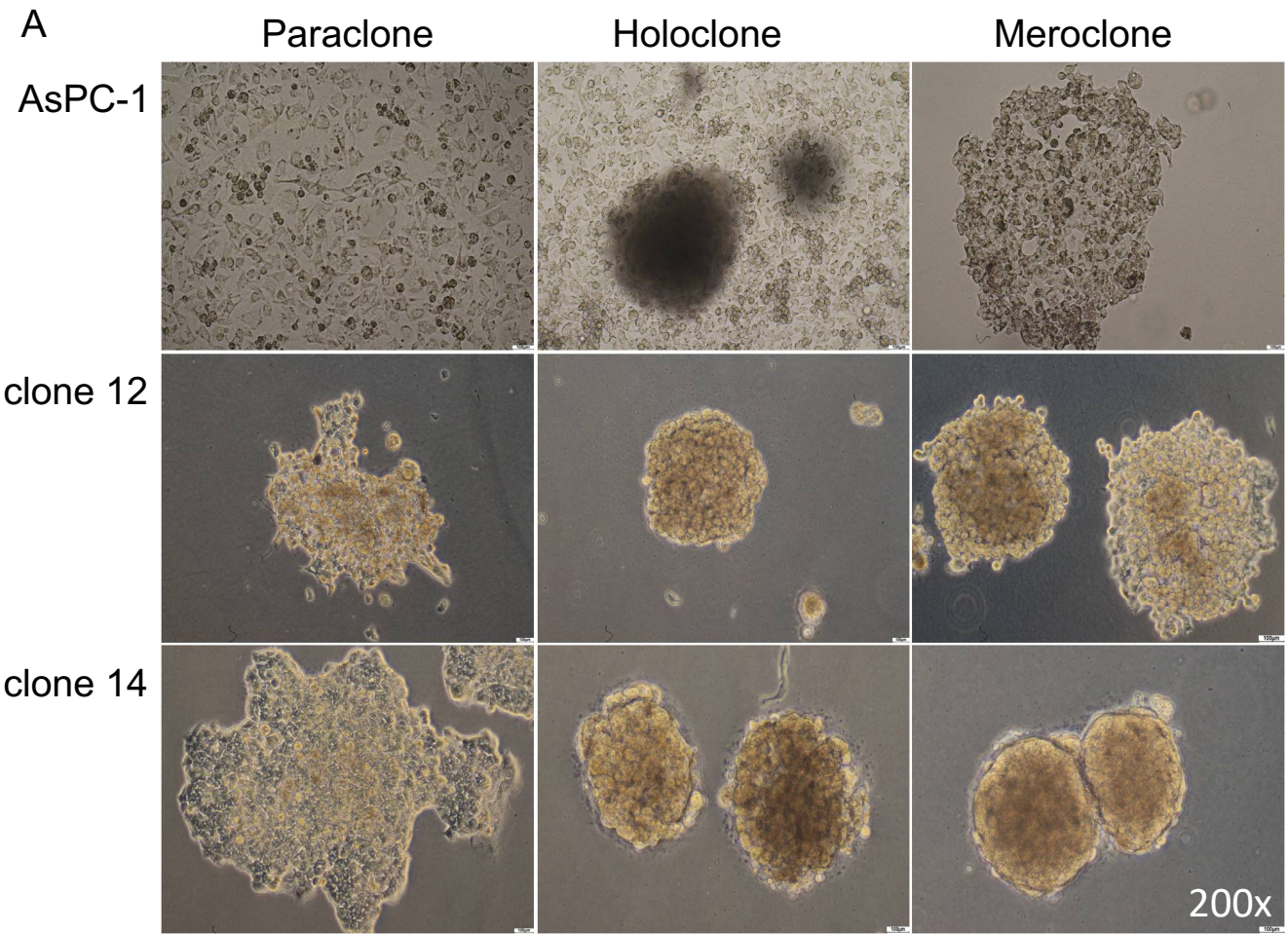

B

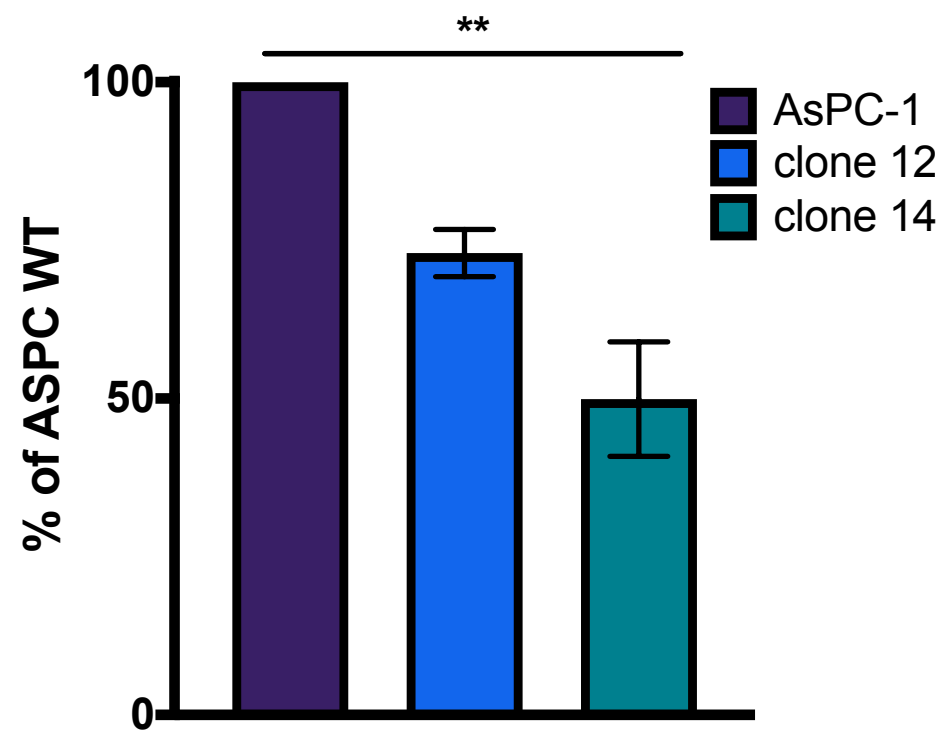


Figure 10: Knockout of $\boldsymbol{u P A R}$ influences tumorigenicity in AsPC-1 cells. A: Colony formation of AsPC1 cells in soft agar was measured during 14-day-incubation and counted as relative numbers of colonies (three types of holoclone, paraclone, and meroclone). B: Quantitative analysis of CFU in AsPC-1 and $\mathrm{uPAR}^{-/}$cells. Data presented as mean $\pm S E M$. Data represent three independent experiments.

Quantitative analysis showed that colony forming units (CFU) were significantly decreased $(p<0.05)$ in all KO clones in comparison to AsPC-1 WT cells (Fig. 10B). The so-called holoclones have the best reproductive capacity of the three types of clones (holoclones, paraclones and meroclones) (Fig. 10A). The holoclone ratio against paraclones and meroclones was greatly decreased in all $u P A R^{-/-}$clones compared to AsPC-1 WT. Together with the increased migratory ability these data suggest that uPAR is a regulator of tumor progression, which potentially could be a promising therapeutic target to suppress the metastatic capabilities of pancreatic cancers.

\section{6 uPAR ablation and FAK activation in AsPC-1 induces gemcitabine resistance independent of ERK}

$\mathrm{Wu}$ et al. reported that phosphorylated focal adhesion kinase (FAK) contributes to intrinsic chemoresistance against gemcitabine in pancreatic cancer cell lines (Huanwen et al. 2009). We therefore tested $u P A R^{-/-}$clones for their response towards gemcitabine. Cells were treated with three concentrations $(0.1,0.5$ and $1 \mu \mathrm{M})$ gemcitabine over $72 \mathrm{~h}$ and cell viability was tested as described in section 2.2.6. This revealed a strong resistance of $U P A R$ ablated cells over a wide range of increasing concentrations of gemcitabine compared to $u P A R$ WT cells (Fig. 11A). To investigate whether FAK activity is related to the gemcitabine resistance in $u P A R^{-/-}$AsPC-1 we knocked down FAK by specific siRNAs. Interestingly, this increased ERK activity in all cells and decreased CDC42 and p38MAPK activity only in $u P A R^{-/-}$cells (Fig. 11C). The FAK knock down also

significantly recovered the gemcitabine resistance in $u P A R^{-/-}$clones but not in AsPC-1 WT cells (Fig. 11D). 
A

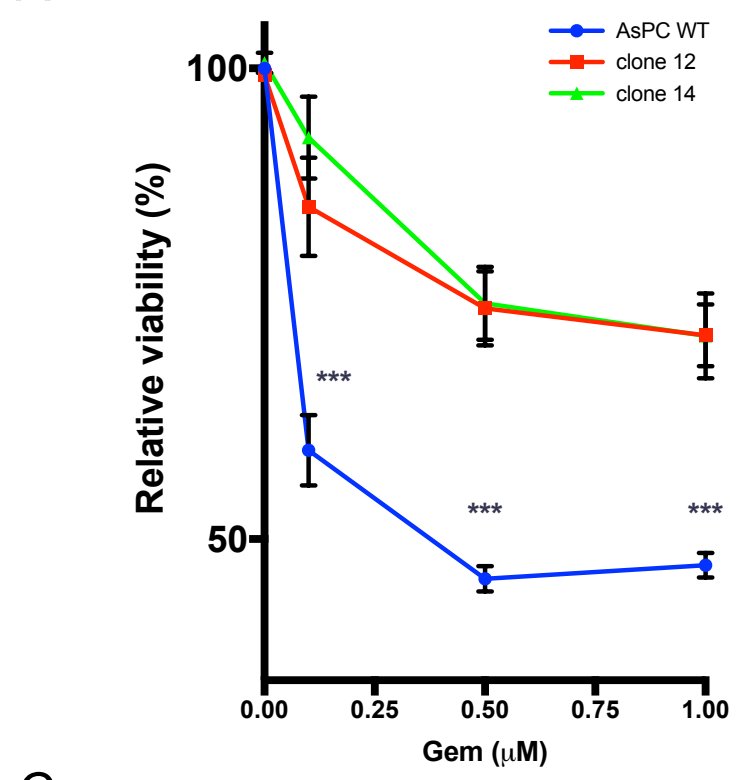

C

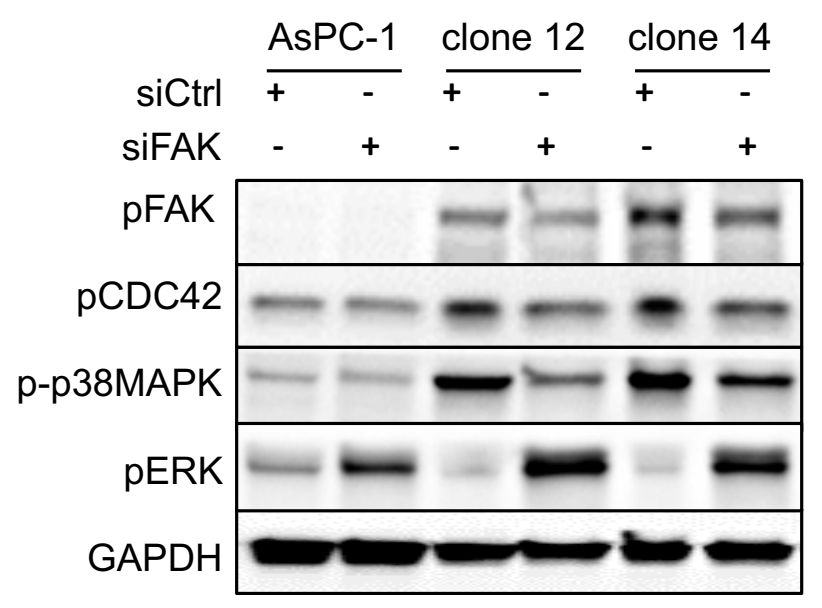

B
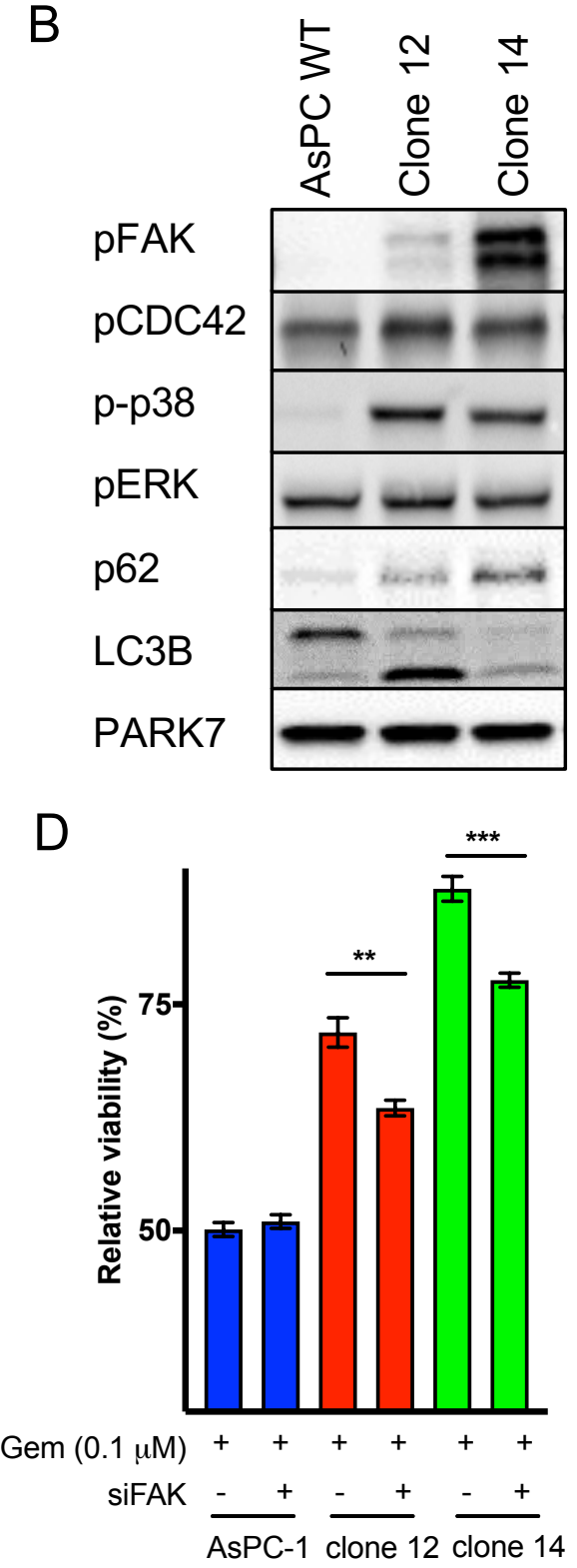

Figure 11: $u P A R^{-/}$clones activate FAK and MAPK signaling and induce resistance against gemcitabine. A: Cell viability measurement after gemcitabine treatment $(0.1,0.5$, and $1 \mu \mathrm{M})$ in AsPC-1 WT and $u P A R^{-/}$clones over $72 \mathrm{~h}$. B: FAK, CDC42, p38MAPK and autophagy activation in $u P A R^{-}$cells. C: Western blot analysis of pERK, p-p38MAPK, p62 and LC3B in AsPC-1 and $u P A R^{-/}$clones after siRNA knockdown of FAK. D: Cell viability after specific FAK knock down by siRNA and treatment with gemcitabine $(0.1 \mu \mathrm{M})$ over $72 \mathrm{~h}$. Data is shown as mean $\pm S E M$ of at least four independent replicates experiment.

\section{7 $u P A R^{-/-}$initiates pFAK and activates CDC42-p38MAPK mediated} autophagy and negatively regulates ERK 
It has been described that chemoresistance of tumor cells confers p38MAPK induced autophagy (Paillas et al. 2012). uPAR ablation resulted in constitutive activation of CDC42, p38MAPK and enhanced protein levels of the autophagy markers LC3B and p62 (Klionsky et al. 2016). This indicates that UPAR induces autophagy via p38MAPK (Fig. 11B) (Zhou et al. 2017). For the functional validation of the p38MAPK signaling we knocked down $C D C 42$ and $p 38 M A P K$ by siRNAs. Knock down of FAK by siRNA decreased CDC42 and p-p38MAPK levels in $u P A R$ ablated cells (Fig. 11C). Knocking down $C D C 42$ decreased p38MAPK activity but also strongly activated ERK in all cell types (Fig. 12A). In addition, siRNAs against $C D C 42$ also reversed the resistance against gemcitabine in $u P A R^{-/-}$as seen in FAK knock down cells (Fig. 12B). In $u P A R^{-/-}$clones knockdown of p38MAPK and CDC42 strongly decreased p62 and LC3B proteins (Fig. 12C). Also, the down regulation of $p 38 M A P K$ significantly increased the susceptibility towards gemcitabine (Fig. 12D). The pharmacologic inhibition of ERK increased p38MAPK and autophagy whereas the inhibition of p38MAPK reduced autophagy markers and significantly reduced the resistance against gemcitabine in $u P A R^{-/-}$cells (Fig. $12 \mathrm{E}$ and $\mathrm{F}$ ). These results further confirmed the link to autophagy through LC3B activation. 
A

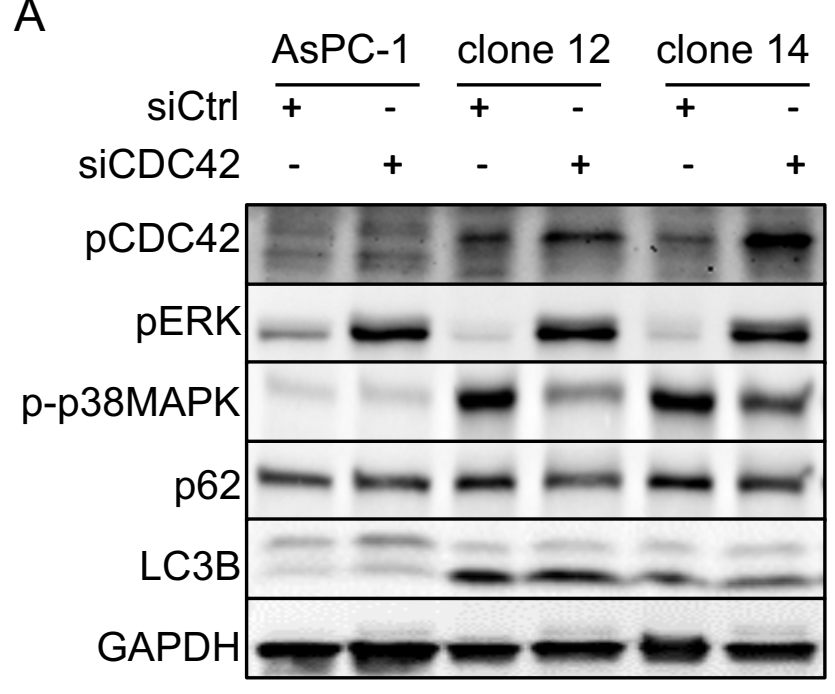

C

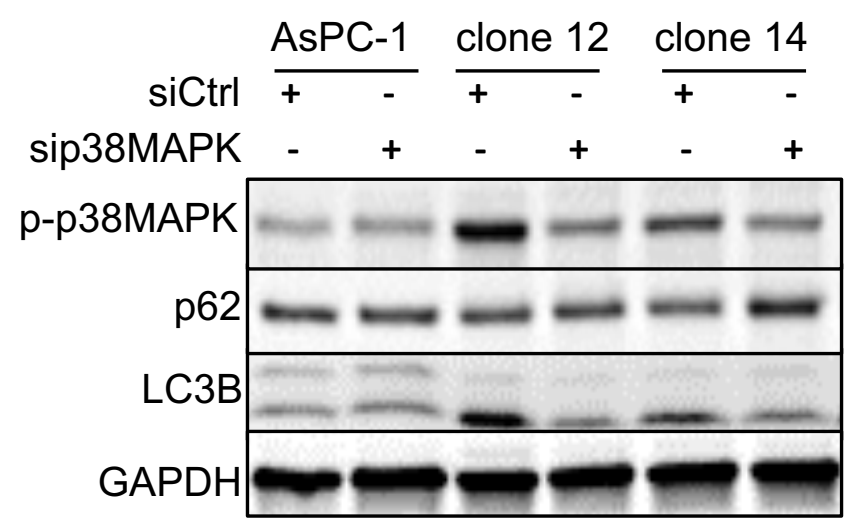

E

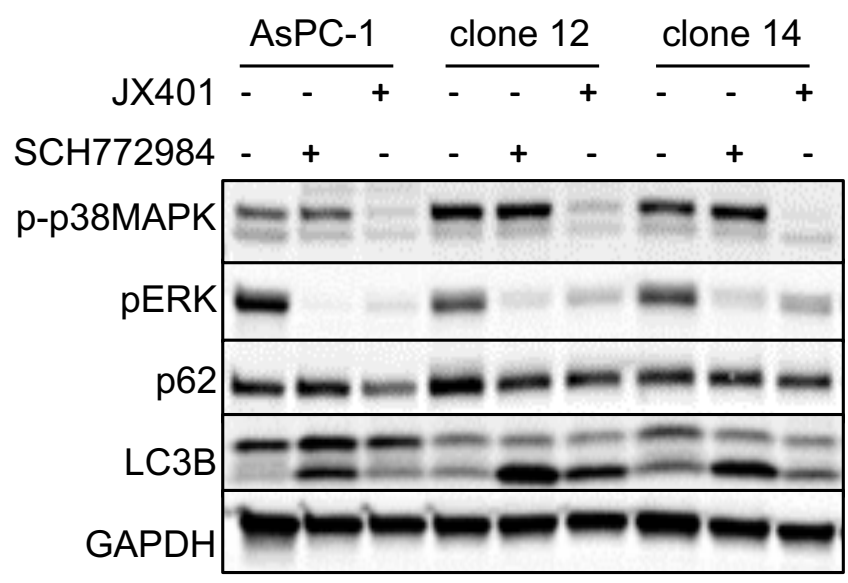

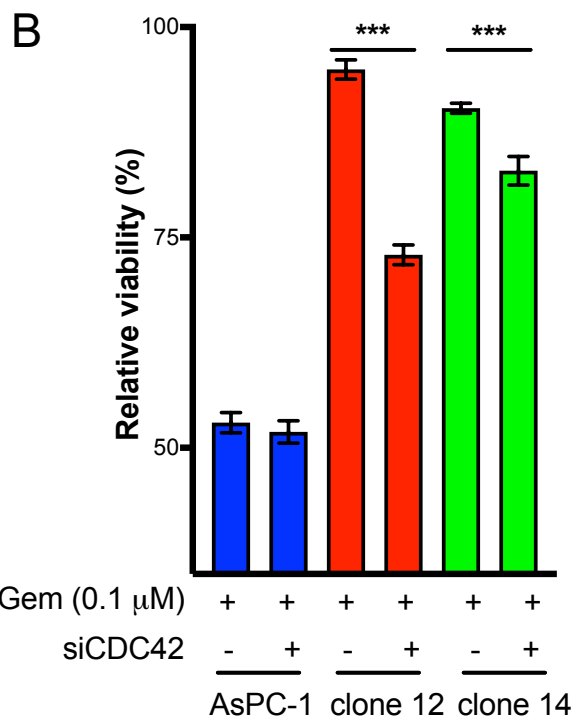

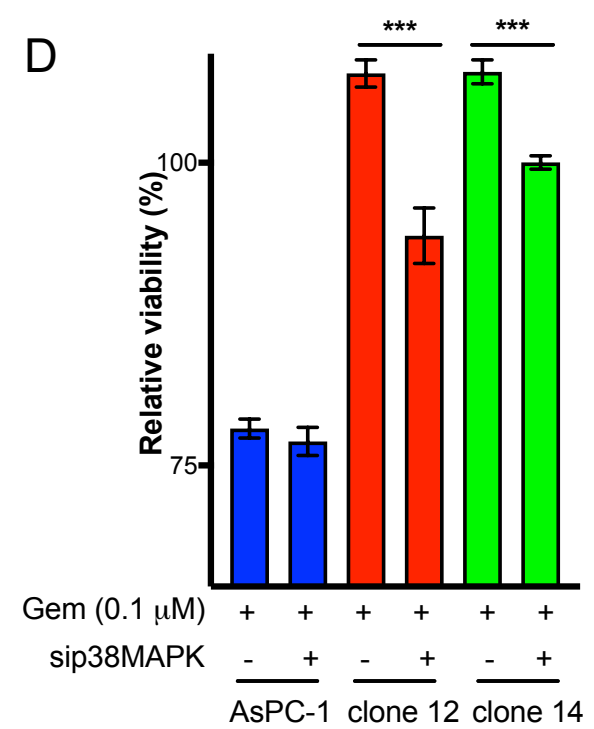

F

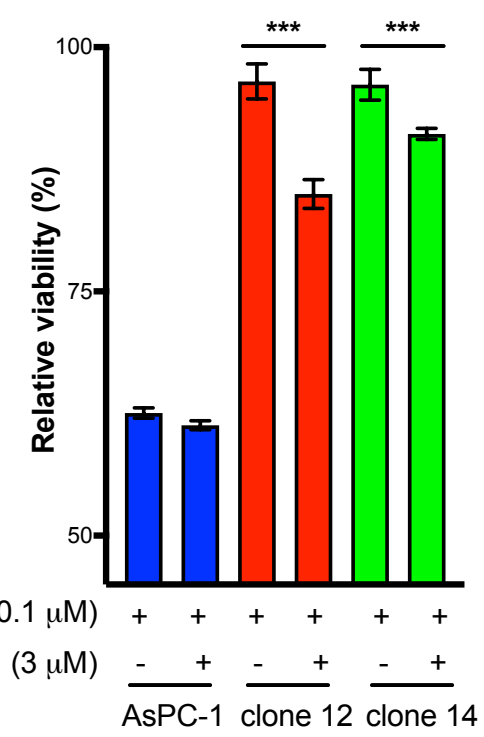


Figure 12: $u P A R^{-/}$clones activate FAK and SRC signaling and induce autophagy dependent resistance against gemcitabine. A: Western blot analysis of pERK, p-p38MAPK, p62 and LC3B in AsPC1 and $u P A R^{-/-}$clones after siRNA knockdown of CDC42 and (B) gemcitabine response $(0.1 \mu \mathrm{M})$. C: Western blot analysis of p62 and LC3B in AsPC-1 and $u P A R^{-/}$clones after siRNA knockdown of p38MAPK and (D) gemcitabine response $(0.1 \mu \mathrm{M})$. E and F: Western blot of pERK, p-p38MAPK, p62 and LC3B and cell viability after inhibition of p38MAPK with JX401 $(3 \mu \mathrm{M})$ in AsPC-1 and $u P A R^{-/}$clones treated with gemcitabine $(0.1 \mu \mathrm{M})$.

\section{8 $u P A R$ induces a functional switch from FAK/p38MAPK to ERK signaling}

It was previously shown in other cancers that uPAR can switch p38MAPK to Ras-ERK signaling (Aguirre-Ghiso et al. 2001; Gandhari et al. 2006; Laurenzana et al. 2017). Knock down of $F A K$ by siRNA resulted in strong activation of pERK in especially in AsPC-1 $u P A R^{-/}$cells (Fig. 11C). To test whether ERK influenced gemcitabine resistance in $u P A R^{-\digamma}$ cells, we used the specific ERK inhibitor SCH772984. SCH772984 treatment increased autophagy in AsPC-1 WT as well as in $u P A R^{-/}$cells (Fig. 13A). However, ERK inhibition massively increased the resistance against gemcitabine in WT, but did not have any effect in $u P A R^{-/}$cells (Fig. 13B).

A

B
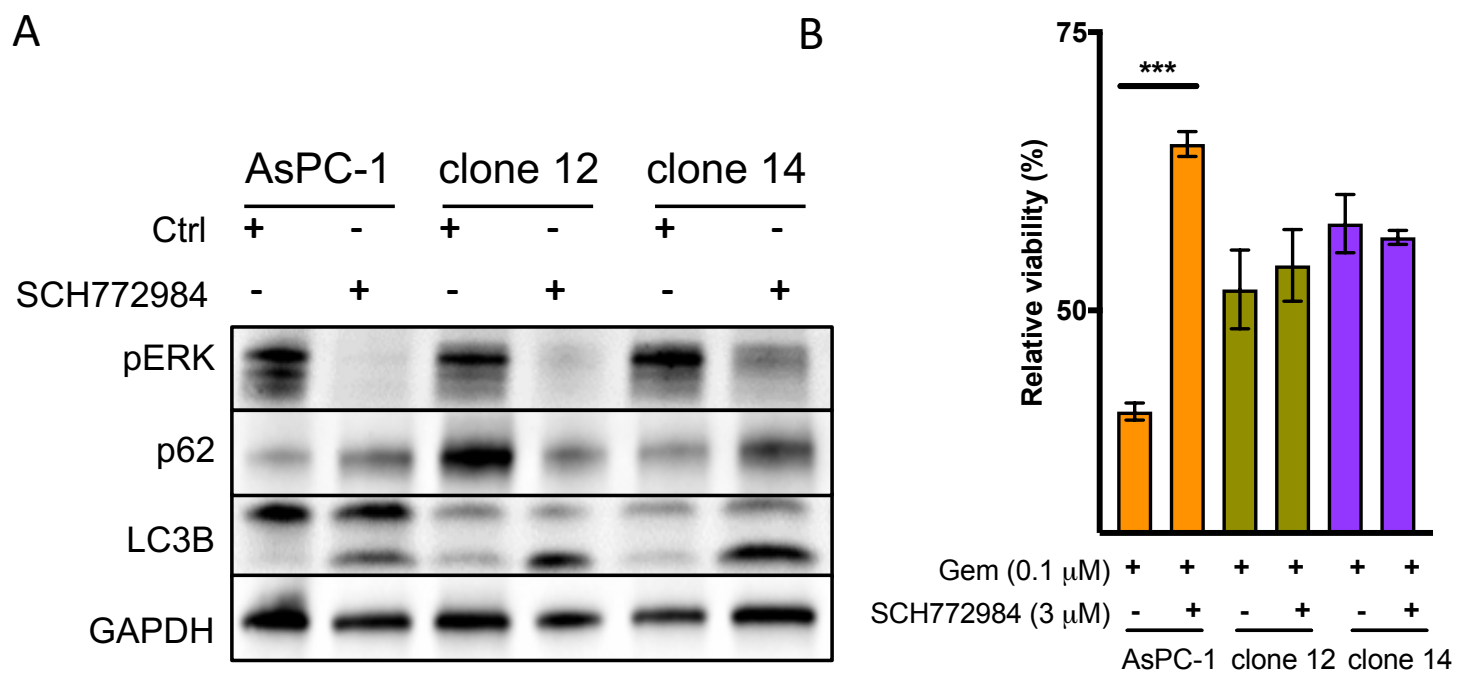

Figure 13: Pharmacologic inhibition of ERK show different effects in AsPC-1 than in $u P A R^{-/-}$clones. A: Western blot analysis and (B) cell viability after gemcitabine treatment $(0.1 \mu \mathrm{M})$ of ERK inhibited AsPC-1 and $u P A R^{-/-}$clones with SCH772984 (3 $\left.\mu \mathrm{M}\right)$. 


\subsection{KR $A S$ regulates UPAR expression and gemcitabine responsibility}

In a next step, we tried to evaluate how much of the effects described above depend on KRAS signaling. AsPC-1 cells harbor an KRAS activating p.G12D mutation. KRAS activity was not different in AsPC-1 $u P A R^{-/}$compared to AsPC-1 WT (Fig. 14A). Knockdown of $K R A S$ by siRNA in $u P A R^{-/}$cells showed a significantly decrease in UPAR levels (Fig 14C) and showed only a minor increase of pFAK, p-p38MAPK and autophagy (Fig. 14B). At the same time KRAS knockdown rendered the cells more chemoresistant, whereas WT cells became more susceptible towards gemcitabine (Fig. 14A).

A

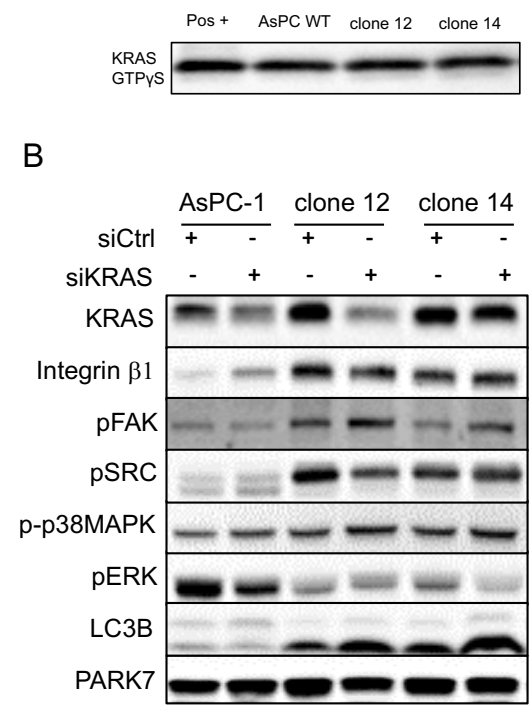

C

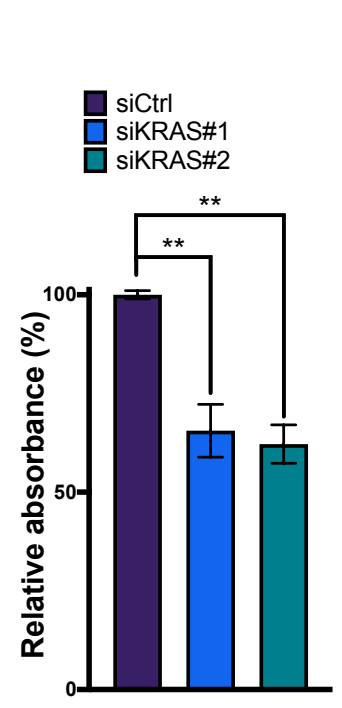

D

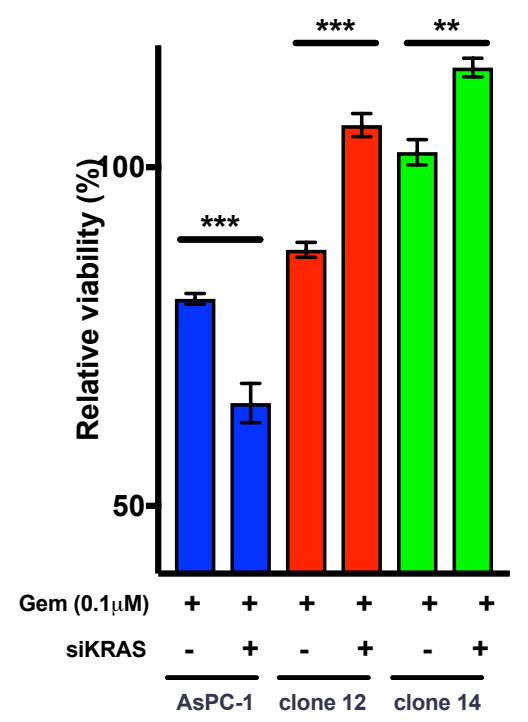

Figure 14: KRAS shows different effects in AsPC-1 than in $u P A R^{-/-}$clones. (A) KRAS measurement shows a constitutive high activity in WT and KO AsPC-1 cells. (B) Western blot of KRAS siRNA knock down cells. (C) ELISA measurement of uPAR expression after $48 \mathrm{~h} K R A S$ siRNA knock down in AsPC-1 WT and $u P A R^{-/}$clones. (D) Cell viability measurement after gemcitabine treatment $(0.1 \mu \mathrm{M})$ in AsPC-1 WT and $u P A R^{-/}$clones with $K R A S$ knock down.

\subsection{Gemcitabine resistance can be reverted by inhibiting autophagy in $u P A R^{-/-}$cells}

It has been shown that autophagy promotes tumor cell survival and contributes to therapy resistance (Amaravadi et al. 2011; Kondo et al. 2005; Levy et al. 2017). In addition, it has been suggested that increased autophagy in PDAC is responsible for gemcitabine 
resistance and that autophagy inhibitors could improve drug response (Bryant et al. 2019). To investigate whether increased autophagy in $u P A R^{-/}$clones is responsible for gemcitabine resistance, we inhibited autophagy with 3-methyladenine (3-MA) or chloroquine (CQ). Even though protein levels of p62 and LC3B were largely unaltered upon treatment with $5 \mu \mathrm{M}$ of either inhibitor, p38MAPK was inactivated and gemcitabine resistance was reduced in AsPC-1 $u P A R^{-/}$but not in WT cells (Fig. 15A and B). Nevertheless, immunofluorescence analysis of LC3B and of p62 in AsPC-1 $u P A R^{-/}$and WT cells clearly revealed that autophagy inhibition with 3-MA for $24 \mathrm{~h}$ increased autophagosome formation in $u P A R^{-/}$compared to WT cells (Fig. 15C). 
A

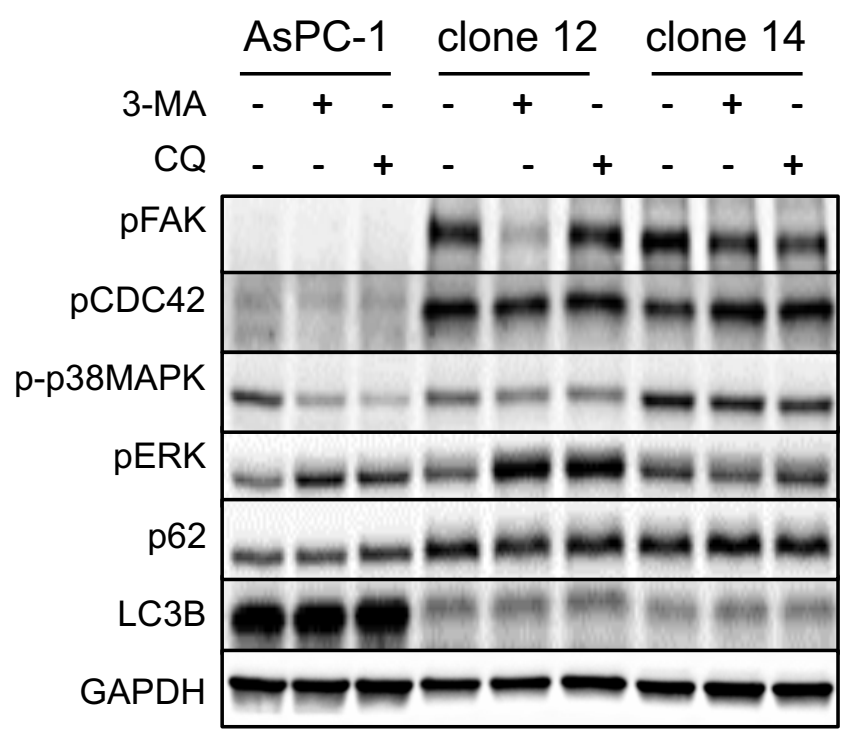

C

AsPC-1
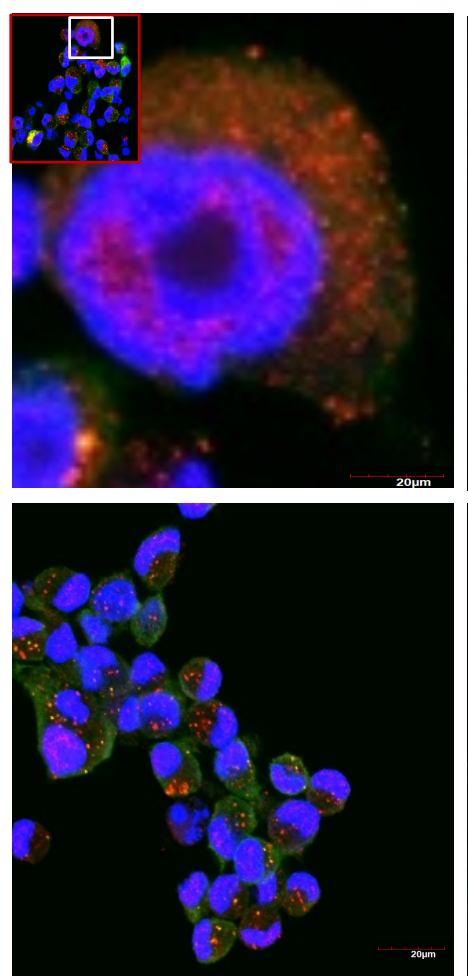

B

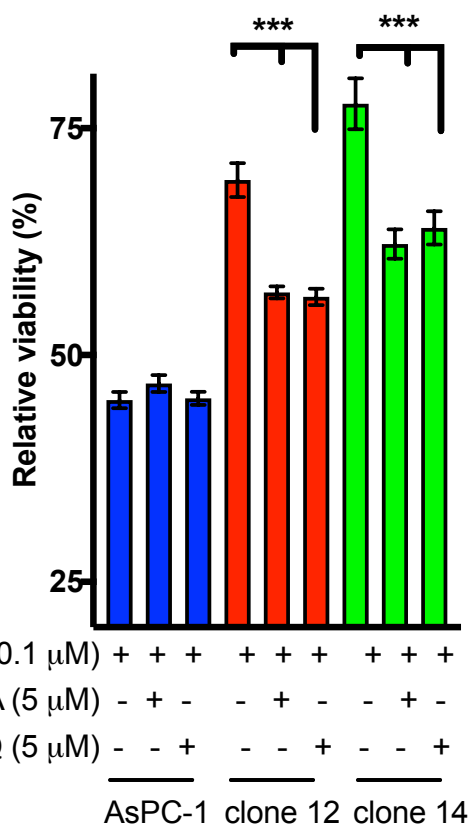

clone 12
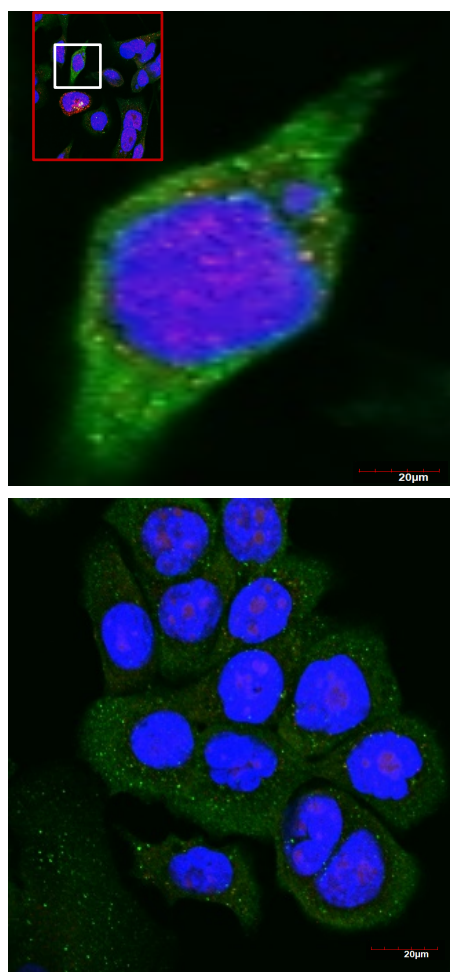

clone 14
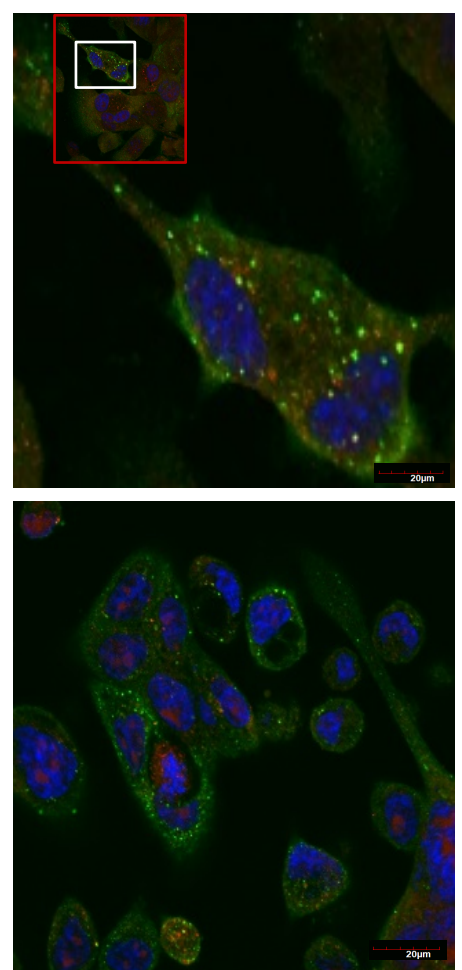

Figure 15: Autophagy inhibition recovers the susceptibility to gemcitabine. A: Autophagy inhibition by 3-MA or CQ reduces p-p38MAPK signaling in WT and $u P A R^{-/}$clones. B: The inhibition of autophagy by 3-MA or CQ recovered the susceptibility of $u P A R^{-/-}$clones to gemcitabine. C: Immunofluorescence staining of LC3B (red) and p62 (green) after 24 h 3-MA treatment. Nuclear staining with 4',6-Diamidino2-phenylindole dihydrochloride (DAPI, blue). 


\subsection{1 p38MAPK signaling and autophagy induce cellular dormancy}

Autophagy has been described to promote survival of dormant tumor cells (Lu et al. 2008; Sosa et al. 2014). uPAR, p38MAPK and autophagy have also been connected to glycolysis, quiescence and survival of dormant cancer cells. We therefore tested glutamate-ammonia ligase (GLUL), methenyltetrahydrofolate cyclohydrolase 2 (MTHFD2) as representatives of glycolysis (Laurenzana et al. 2017) and cyclin B1 (CNNB1) and forkhead box protein M1 (FOXM1) as markers of p38MAPK induced dormancy and quiescence (Gillespie et al. 2015; Huang et al. 2014; Vera-Ramirez et al. 2018). Western blot analyses revealed no change of GLUL in $u P A R^{-/}$clones compared to WT. However, MTHFD2, FOXM1 and CNNB1 were less abundant in $u P A R^{-/-}$than in WT (Fig. 16), indicating that uPAR prevents cellular dormancy in pancreatic cancer cells.

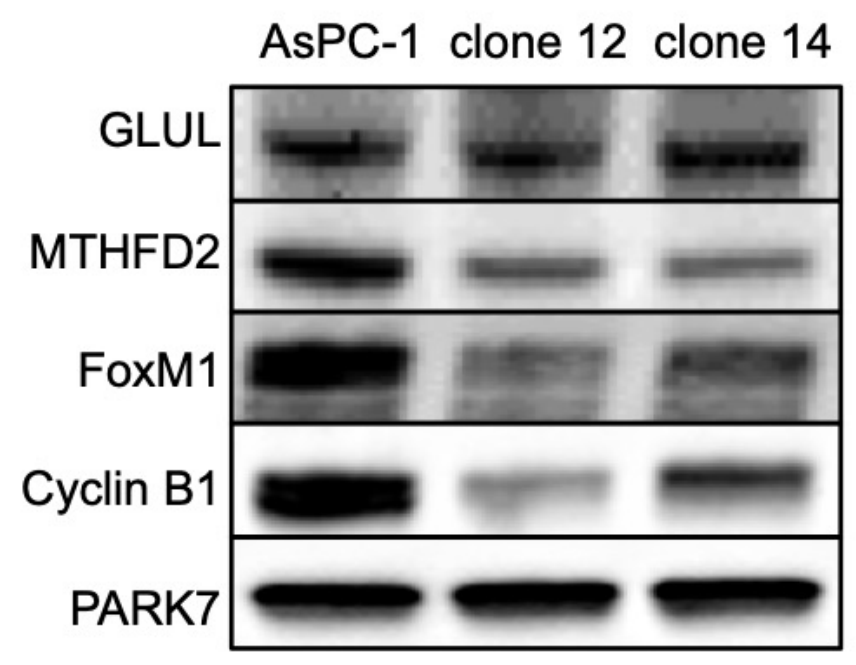

Figure 16: uPAR regulated dormancy markers. Western blot analysis of cellular dormancy related factors in AsPC-1 and $u P A R^{-\digamma}$ clones.

\subsection{Re-expression of uPAR partially restores gemcitabine sensitivity}

To evaluate whether uPAR restores the phenotype of AsPC-1 $u P A R^{-/}$cells, we stably transfected cells with a human $u P A R$ gene expression vector and UPAR protein levels were assessed by ELISA (Fig. 17A). We found that restored uPAR strongly inhibited p38MAPK activation while it had no impact on pERK compared to the parental cell clone 14 (Fig. 17B). uPAR rescue markedly restored the sensitivity to gemcitabine compared 
to parental cells and the inhibition of p38MAPK had no effect on the cytotoxicity (Fig. 17C). Furthermore, we found that rescued uPAR could in part restore the migratory capacity of the cells (Fig. 17D).

A

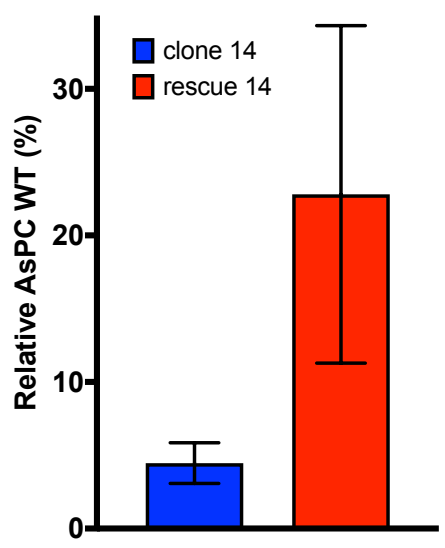

C

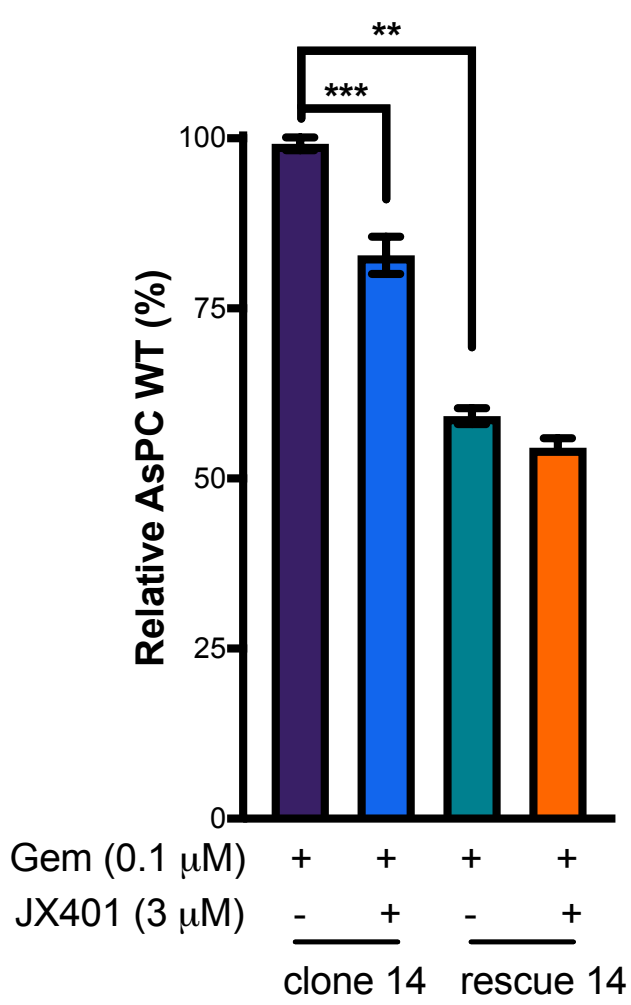

B
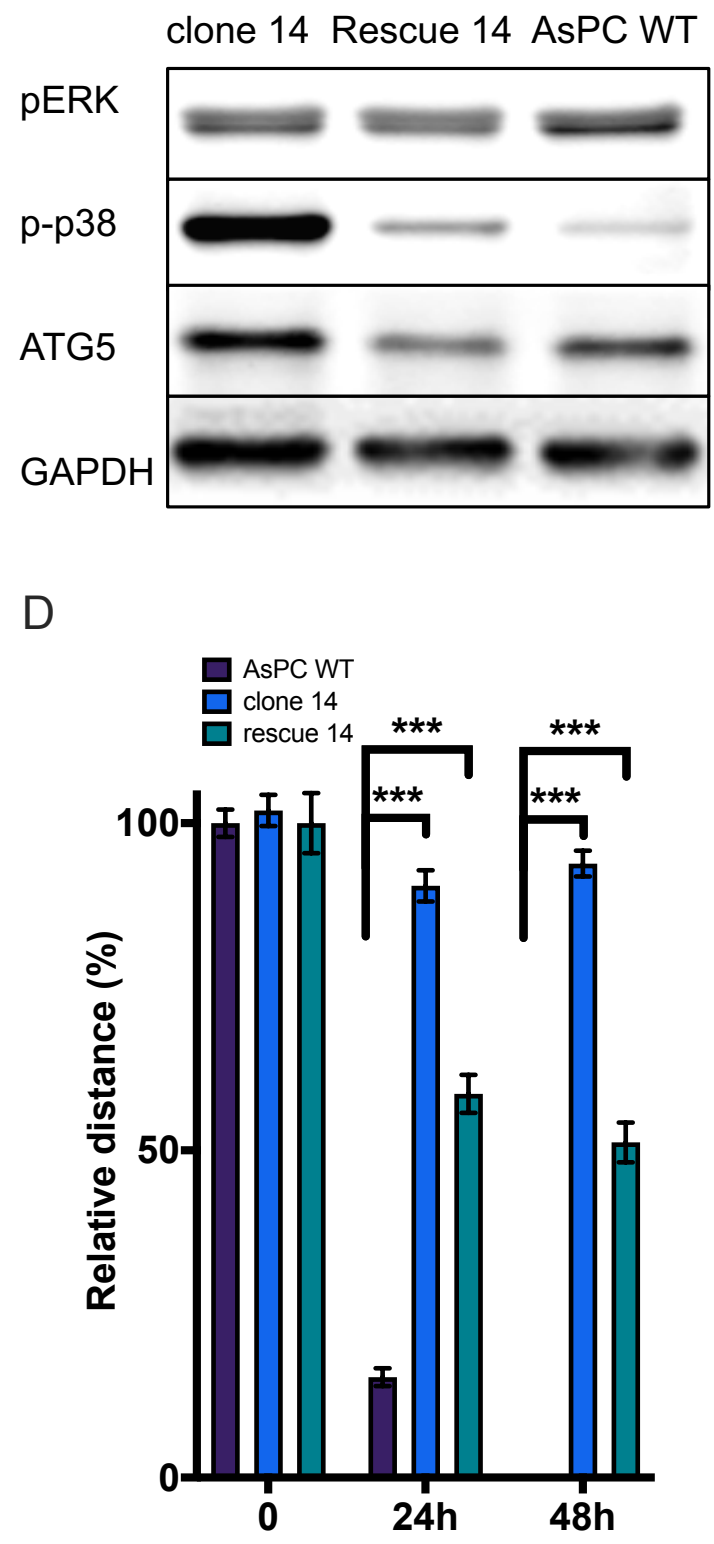

Figure 17: UPAR rescue reduces p38MAPK and recovers the migratory ability. A: Verification of rescue uPAR expression by ELISA. B: pERK, p-p38MAPK and ATG5 expression in uPAR rescue clone 14 in comparison to WT. C: Cell viability of uPAR rescue clone 14 in comparison to clone 14 after gemcitabine $(0.1 \mu \mathrm{M})$ and JX401 $(3 \mu \mathrm{M})$ treatment. (D) Migration analysis of uPAR rescue clone 14. 


\subsection{3 $\mathrm{uPAR}^{\text {low }} / \mathrm{p38MAPK}^{\text {high }}$ status in PDAC is associated with a better prognosis}

To evaluate the clinical relevance of our in vitro findings, we examined the UPAR expression and p38MAPK activation in 59 patients with PDAC (Table 1 and Fig. 18A). The overall survival of patients with $\mathrm{uPAR}^{\mathrm{low}} / \mathrm{p} 38 \mathrm{MAPK}^{\text {high }}$ tumors was significantly longer than those with $\mathrm{UPAR}^{\text {low }} / \mathrm{p} 38 \mathrm{MAPK}^{\text {low }}$ tumors (median survival 868 days vs. 417 days, $p=0.027$ ) (Fig. 18B). No significant difference was observed comparing p38MAPK ${ }^{\text {high }}$ and $\mathrm{p} 38 \mathrm{MAPK}^{\text {low }}$ cases independently of uPAR or in $\mathrm{uPAR}^{\text {high }}$ samples (Fig. 18C and D).

A

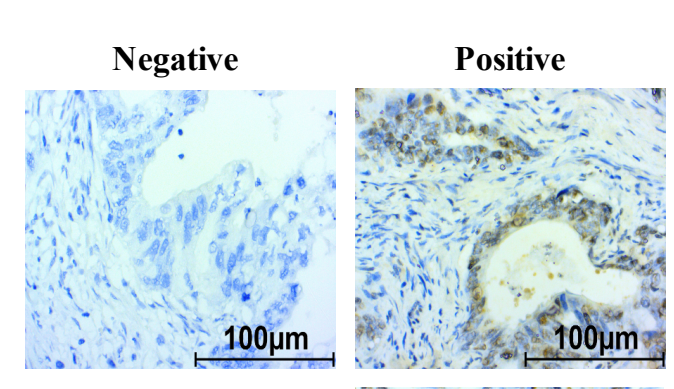

C

uPAR independent

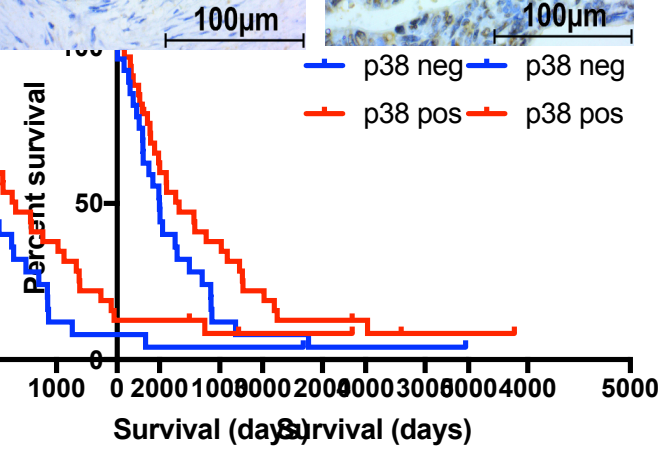

B

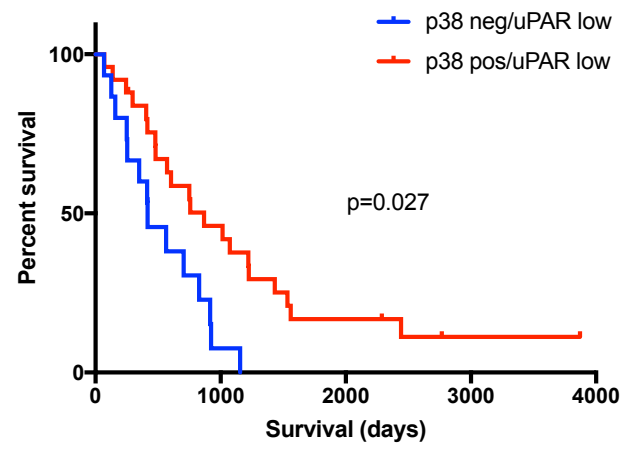

D

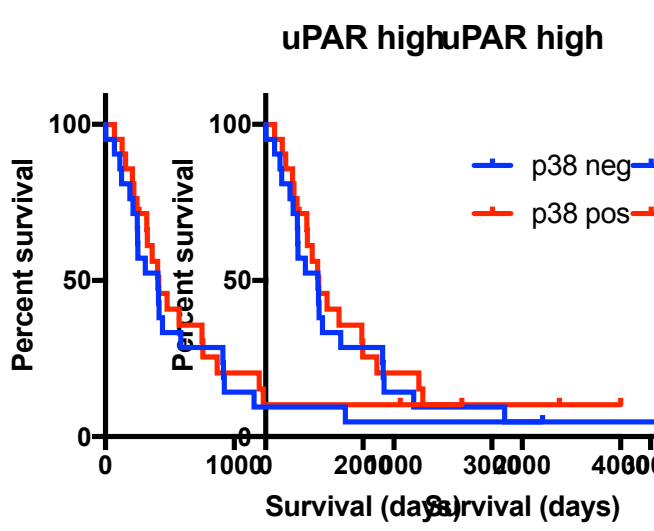

Figure 18: Statistical correlation between uPAR levels, p38MAPK activation and OS in PDAC patients. A: Immunohistochemical stainings of p-p38MAPK in PDAC patients samples show a distinct positive and negative pattern. B: Patients with low uPAR levels and activated p38MAPK showed a significant better OS in a Kaplan-Meier-analysis (Cox- Mantel-test) than patients with high uPAR levels or inactive p38MAPK. C: No significant difference in OS when comparing p38MAPK high vs. low tumors 
without considering uPAR and (D) no statistical difference when comparing p38MAPK high vs. low in uPAR high tumors. 


\section{Discussion}

Genomic $u P A R$ amplification and increased UPAR protein levels have been implicated in PDAC (Hildenbrand et al. 2009), NSCLC and CRC tumors (Almasi et al. 2011; Lomholt et al. 2010) and are characterized by a poor prognosis however, the specific function of UPAR in the disease progression of PDAC has not been fully elucidated. Elevated uPAR signaling has been associated with growth factor activation and increased proliferation and cellular migration through the regulation of varies pathways including Ras-ERK signaling (Aguirre Ghiso 2002; Jo et al. 2009a). In addition it has been known that uPAR and fibronectin are responsible to switch from proliferative Ras-ERK pathway to the alternative p38MAPK pathway leading to cellular dormancy (Aguirre-Ghiso et al. 2001; Gandhari et al. 2006). In this study, we connect for the first time uPAR signaling with p38MAPK induced resistance against gemcitabine by activating autophagy and propose a combined treatment with autophagy inhibitors to overcome gemcitabine resistance in patients with low uPAR levels and activated p38MAPK.

Several studies have shown the Ras-ERK pathway is often activated in tumors by aberrant upstream signaling (Aguirre Ghiso et al. 1999; Bamford et al. 2004; Kabeya et al. 2000). Next to EGFR, uPAR can by interacting with $\alpha_{5} \beta_{1}$ integrin, to induce Ras/ERK activation (Zannetti et al. 2000). This also leads to the activation of Src and FAK that are critical mediators of cell migration (Smith and Marshall 2010). Activation of FAK has recently been described to induce resistance against gemcitabine in PDAC (Huanwen et al. 2009). We show that a uPAR knockout in the pancreatic cell line AsPC-1 leads not only to cellular dormancy, but also increases the resistance against gemcitabine. Our results demonstrate that ablated uPAR lead to an activation of FAK, CDC42 and p38MAPK that induces a strong resistant against gemcitabine in $K R A S$ mutated AsPC-1.

Independent of patient treatment we were able show that an increased uPAR expression goes along with a poorer OS of PDAC. Paradoxically we were able to demonstrate that uPAR knock out cells go thru a MET like process that is phenotypically associated with a decreased proliferation and migration, an increased expression of the epithelial markers E-cadherin, N-cadherin, $\beta$-catenin and Slug and the down-regulation of the endothelial markers ZO1, Snai1, vimentin and ZEB1 and an increased resistance against gemcitabine treatment.

By inhibiting the deregulated factors after the UPAR depletion we could proof the activation and connection of FAK, CDC42, p38MAPK and autophagy whereas, the Ras- 
ERK signaling is turned off. The specific knock down of FAK, CDC42, p38MAPK and the pharmacologic inhibition of p38MAPK by JX401 partially rescued the gemcitabine resistance in uPAR knock out clones. We observed by knockdown experiments that this only functionally active in a $K R A S$-mutant situation whereas siRNA-mediated $K R A S$ suppression increased the activating pERK and suppressed p62 and LC3B protein levels (Guo et al. 2011; Yang et al. 2014).

Previous studies have also shown that the p38MAPK activation is critical for the response to platinum-based compounds in TP53 mutant tumors (Cannell et al. 2015; Morandell et al. 2013; Paillas et al. 2012), and that ablating or inhibiting autophagy attenuated pancreatic tumor growth and progression in a genetically engineered TP53 mutant xenograft model (Yang and Kimmelman 2014). p38MAPK was shown to cause cell cycle arrest via the activation of TP53 which responsible for G2/M checkpoint arrest (Gurgis et al. 2014), finally leading to cell growth inhibition. This is in good agreement with the TP53 mutant cell line AsPC-1 where the activation p38MAPK reduced cell growth.

It has been shown in other cancers that UPAR and fibronectin are responsible for switching from p38MAPK to Ras-ERK signaling pathways (Aguirre-Ghiso et al. 2001; Gandhari et al. 2006; Laurenzana et al. 2017), thus switching from a status of relative cellular dormancy (Gonias and $\mathrm{Hu} 2015$ ) to proliferation. The situation in PDAC is special, since $90-95 \%$ of cases show KRAS gain of function mutations (Yang et al. 2018), which occur early in the pathogenesis of the disease and are probably the most essential oncogenic drivers of PDAC. Wang et al. (1999) described that KRAS regulates UPAR expression. By siRNA knock down of KRAS in AsPC-1 we could validate that constitutive KRAS activation is decisively involved in the high uPAR expression in PDAC.

Most surprising was the observation that ERK played an extensive role in the gemcitabine susceptibility in AsPC-1 WT cells, whereas in $u P A R^{-/}$clones ERK inhibition did not show a difference in the response towards gemcitabine. However, the inhibition of KRAS had an inversed effect. While it decreased the resistance in AsPC-1 WT, KRAS knock down in $u P A R^{-/}$resulted in more resistance against gemcitabine (Fig. 4). This has importance in the choice of specific treatment strategies. Bryant et al. (2019) proposed that a combined ERK and autophagy inhibition is a treatment option in PDAC. Our observations indicate that autophagy inhibition is UPAR dependent and that an additional 
ERK inhibition is only effective in uPAR low cases. This observation should be taken into account when considering combined therapies of PDAC.

The fact that not all KRAS mutated cases go along with high uPAR expression is not new and has been shown before (Mauro et al. 2017). However, it indicates that UPAR expression is partially KRAS dependent and that KRAS function is enhanced by uPAR.

Previous studies have also shown that the p38MAPK activation is critical for the response to platinum-based compounds in TP53 mutant tumors (Cannell et al. 2015; Morandell et al. 2013; Paillas et al. 2012), and that ablating or inhibiting autophagy attenuated pancreatic tumor growth and progression in a genetically engineered TP53 mutant xenograft model (Yang A and Kimmelman 2014). In addition, Ossowski and colleagues (2015) have shown that uPAR regulates dormancy in cancer cells. Our results not only underline this concept but also connect UPAR signaling with p38MAPK induction of autophagy. Others have shown that in particular constitutively activated autophagy is important for PDAC growth and development (New et al. 2017). We show here that autophagy is an important factor in the resistance against gemcitabine in cells with low uPAR expression that can be targeted by clinically approved inhibitors.

Furthermore, we were able show that an increased uPAR expression goes along with poor OS in PDAC patients. Immunohistochemistry staining of p-p38MAPK revealed that $41 \%$ of PDACs were positive but we did not find a correlation to UPAR levels or significant difference in OS. However, when analyzing the OS of p38MAPK positive and negative samples in uPAR low tumors, patients with high p38MAPK had a significantly better prognosis (Fig. 18B).

We propose that $\mathrm{UPAR}$ is an important factor in the process of changing cells from a more proliferative mesenchymal to a more dormant epithelial type. UPAR expression is regulated by the constitutively activated mutated $K R A S$ as shown before. However, uPAR is not only regulated by KRAS and the frequent UPAR amplification is only one of the factors that influences UPAR levels. We show here that UPAR levels influence cellular plasticity by degrading integrins in the ECM and by modulating EMT. Next to the mesenchymal-epithelial 


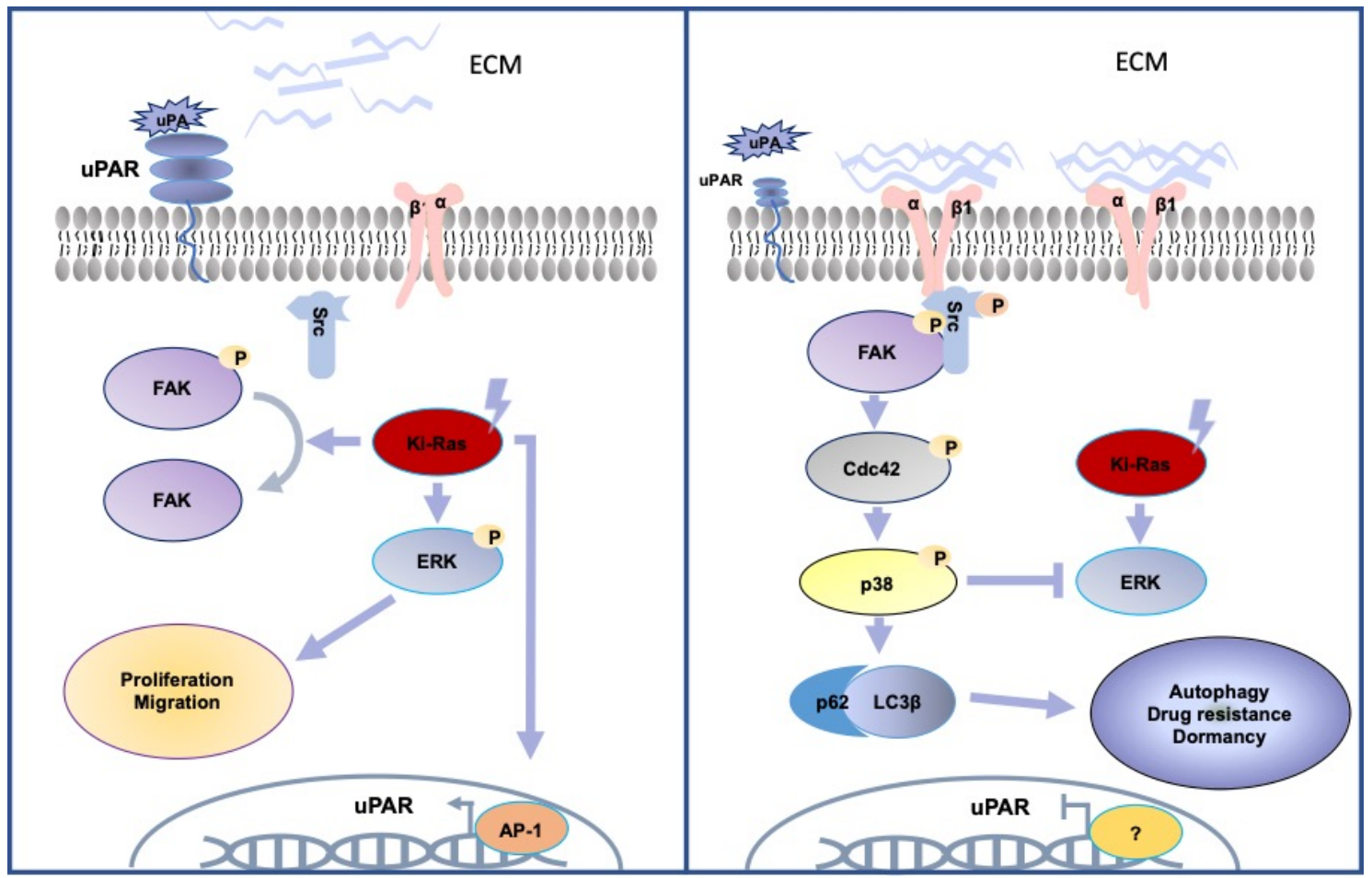

Figure 19: Signaling diagram displaying the interaction nodes used in this study. uPAR regulates FAK, CDC42 and p38MAPK signaling initiating gemcitabine resistance and cellular dormancy. Even though the crosstalk of uPAR signaling and the Ras-RAF signaling needs further investigation, we propose that uPAR expression is partially independent of KRAS and that low UPAR levels activate p38MAPK signaling and inhibit the Ras-RAF pathway. 


\section{Summary}

In summary, we show that UPAR enhances Ras-ERK signaling and contributes to the aggressiveness of the cell as an explanation for the poor OS of PDAC patients with high uPAR levels. We find that attenuation of uPAR signaling leads to pFAK, pCDC42 and p-p38MAPK mediated cellular dormancy and autophagy that confer resistance against gemcitabine. Therefore, we propose a combined treatment of gemcitabine and autophagy inhibitors such as 3-MA to overcome gemcitabine resistance and to improve OS especially in a subgroup of patients with low uPAR levels and activated p38MAPK in their tumors. 


\section{References}

Aguirre Ghiso JA (2002): Inhibition of FAK signaling activated by urokinase receptor induces dormancy in human carcinoma cells in vivo. Oncogene 21, 2513-2524

Aguirre Ghiso JA, Kovalski K, Ossowski L (1999): Tumor dormancy induced by downregulation of urokinase receptor in human carcinoma involves integrin and MAPK signaling. J Cell Biol 147, 89-104

Aguirre-Ghiso JA, Liu D, Mignatti A, Kovalski K, Ossowski L (2001): Urokinase receptor and fibronectin regulate the ERK(MAPK) to p38(MAPK) activity ratios that determine carcinoma cell proliferation or dormancy in vivo. Mol Biol Cell 12, 863-879

Allgayer H, Wang H, Shirasawa S, Sasazuki T, Boyd D (1999): Targeted disruption of the K-ras oncogene in an invasive colon cancer cell line down-regulates urokinase receptor expression and plasminogen-dependent proteolysis. Br J Cancer 무, 1884-1891

Almasi CE, Christensen IJ, Hoyer-Hansen G, Dano K, Pappot H, Dienemann H, Muley $\mathrm{T}$ (2011): Urokinase receptor forms in serum from non-small cell lung cancer patients: relation to prognosis. Lung Cancer $\underline{74}, 510-515$

Amaravadi RK, Lippincott-Schwartz J, Yin XM, Weiss WA, Takebe N, Timmer W, DiPaola RS, Lotze MT, White E (2011): Principles and current strategies for targeting autophagy for cancer treatment. Clin Cancer Res 17, 654-666

Apel A, Herr I, Schwarz H, Rodemann HP, Mayer A (2008): Blocked autophagy sensitizes resistant carcinoma cells to radiation therapy. Cancer Res $\underline{68}, 1485-1494$

Apte MV, Pirola RC, Wilson JS (2012): Pancreatic stellate cells: a starring role in normal and diseased pancreas. Front Physiol $\underline{3}, 344$

Apte MV, Wilson JS, Lugea A, Pandol SJ (2013): A starring role for stellate cells in the pancreatic cancer microenvironment. Gastroenterology 144, 1210-1219

Arumugam T, Ramachandran V, Fournier KF, Wang H, Marquis L, Abbruzzese JL, Gallick GE, Logsdon CD, McConkey DJ, Choi W (2009): Epithelial to mesenchymal transition contributes to drug resistance in pancreatic cancer. Cancer Res $\underline{69}, 5820-5828$

Attisano L, Labbe E (2004): TGFbeta and Wnt pathway cross-talk. Cancer Metastasis $\operatorname{Rev} \underline{23}, 53-61$

Bagrodia S, Derijard B, Davis RJ, Cerione RA (1995): Cdc42 and PAK-mediated signaling leads to Jun kinase and p38 mitogen-activated protein kinase activation. J Biol Chem 270, 27995-27998

Bailey P, Chang DK, Nones K, Johns AL, Patch AM, Gingras MC, Miller DK, Christ AN, Bruxner TJ, Quinn MC, et al. (2016): Genomic analyses identify molecular subtypes of pancreatic cancer. Nature 531, 47-52 
Bamford S, Dawson E, Forbes S, Clements J, Pettett R, Dogan A, Flanagan A, Teague J, Futreal PA, Stratton MR, et al. (2004): The COSMIC database and website. Br J Cancer $\underline{91}, 355-358$

Behrendt N, Jensen ON, Engelholm LH, Mortz E, Mann M, Dano K (2000): A urokinase receptor-associated protein with specific collagen binding properties. J Biol Chem 275, 1993-2002

Bene MC, Castoldi G, Knapp W, Rigolin GM, Escribano L, Lemez P, Ludwig WD, Matutes E, Orfao A, Lanza F, et al. (2004): CD87 function and pathology in hematological disorders: a review. Leukemia 18, 394-400

Beschorner R, Schluesener HJ, Nguyen TD, Magdolen V, Luther T, Pedal I, Mattern R, Meyermann R, Schwab JM (2000): Lesion-associated accumulation of uPAR/CD87expressing infiltrating granulocytes, activated microglial cells/macrophages and upregulation by endothelial cells following TBI and FCI in humans. Neuropathol Appl Neurobiol 26, 522-527

Biankin AV, Waddell N, Kassahn KS, Gingras MC, Muthuswamy LB, Johns AL, Miller DK, Wilson PJ, Patch AM, Wu J, et al. (2012): Pancreatic cancer genomes reveal aberrations in axon guidance pathway genes. Nature $\underline{491}, 399-405$

Biondani G, Zeeberg K, Greco MR, Cannone S, Dando I, Dalla Pozza E, Mastrodonato M, Forciniti S, Casavola V, Palmieri M, et al. (2018): Extracellular matrix composition modulates PDAC parenchymal and stem cell plasticity and behavior through the secretome. Febs 285, 2104-2124

Bray F, Ferlay J, Soerjomataram I, Siegel RL, Torre LA, Jemal A (2018): GLOBOCAN estimates of incidence and mortality worldwide for 36 cancers in 185 countries. CA Cancer J Clin $\underline{68}, 394-424$

Brown D, Waneck GL (1992): Glycosyl-phosphatidylinositol-anchored membrane proteins. J Am Soc Nephrol $\underline{3}$, 895-906

Bryant KL, Stalnecker CA, Zeitouni D, Klomp JE, Peng S, Tikunov AP, Gunda V, Pierobon M, Waters AM, George SD, et al. (2019): Combination of ERK and autophagy inhibition as a treatment approach for pancreatic cancer. Nat Med 25, 628-640

Candeias MM, Malbert-Colas L, Powell DJ, Daskalogianni C, Maslon MM, Naski N, Bourougaa K, Calvo F, Fahraeus R (2008): P53 mRNA controls p53 activity by managing Mdm2 functions. Nat Cell Biol 10, 1098-1105

Cannell IG, Merrick KA, Morandell S, Zhu CQ, Braun CJ, Grant RA, Cameron ER, Tsao MS, Hemann MT, Yaffe MB (2015): A Pleiotropic RNA-Binding Protein Controls Distinct Cell Cycle Checkpoints to Drive Resistance of p53-Defective Tumors to Chemotherapy. Cancer Cell 28, 831

Chiariello M, Vaque JP, Crespo P, Gutkind JS (2010): Activation of Ras and Rho GTPases and MAP Kinases by G-protein-coupled receptors. Methods Mol Biol $\underline{661}$, $137-150$ 
Comes F, Matrone A, Lastella P, Nico B, Susca FC, Bagnulo R, Ingravallo G, Modica S, Lo Sasso G, Moschetta A, et al. (2007): A novel cell type-specific role of p38alpha in the control of autophagy and cell death in colorectal cancer cells. Cell Death Differ 14 , 693-702

Commisso C, Davidson SM, Soydaner-Azeloglu RG, Parker SJ, Kamphorst JJ, Hackett S, Grabocka E, Nofal M, Drebin JA, Thompson CB, et al. (2013): Macropinocytosis of protein is an amino acid supply route in Ras-transformed cells. Nature $\underline{497}, 633-637$

Conese M, Nykjaer A, Petersen CM, Cremona O, Pardi R, Andreasen PA, Gliemann J, Christensen EI, Blasi F (1995): alpha-2 Macroglobulin receptor/Ldl receptor-related protein(Lrp)-dependent internalization of the urokinase receptor. J Cell Biol 131, 16091622

Cuenda A, Goedert M, Craxton M, Jakes R, Cohen P (1997): Activation of the novel MAP kinase homologue SAPK4 by cytokines and cellular stresses is mediated by SKK3 (MKK6). Biochem Soc Trans 25, 569

Cufi S, Vazquez-Martin A, Oliveras-Ferraros C, Martin-Castillo B, Vellon L, Menendez JA (2011): Autophagy positively regulates the CD44(+) CD24(-/low) breast cancer stem-like phenotype. Cell Cycle $\underline{10}, 3871-3885$

Cunningham O, Andolfo A, Santovito ML, Iuzzolino L, Blasi F, Sidenius N (2003): Dimerization controls the lipid raft partitioning of uPAR/CD87 and regulates its biological functions. Embo j 22, 5994-6003

Czekay RP, Kuemmel TA, Orlando RA, Farquhar MG (2001): Direct binding of occupied urokinase receptor (UPAR) to LDL receptor-related protein is required for endocytosis of uPAR and regulation of cell surface urokinase activity. Mol Biol Cell 12 , $1467-1479$

Dietlein F, Kalb B, Jokic M, Noll EM, Strong A, Tharun L, Ozretic L, Kunstlinger H, Kambartel K, Randerath WJ, et al. (2015): A Synergistic Interaction between Chk1- and MK2 Inhibitors in KRAS-Mutant Cancer. Cell 162, 146-159

Ellinger-Ziegelbauer H, Kelly K, Siebenlist U (1999): Cell cycle arrest and reversion of Ras-induced transformation by a conditionally activated form of mitogen-activated protein kinase kinase kinase 3. Mol Cell Biol 19, 3857-3868

Feig C, Gopinathan A, Neesse A, Chan DS, Cook N, Tuveson DA (2012): The pancreas cancer microenvironment. Clin Cancer Res $\underline{18}$, 4266-4276

Floridon C, Nielsen O, Holund B, Sunde L, Westergaard JG, Thomsen SG, Teisner B (1999): Localization and significance of urokinase plasminogen activator and its receptor in placental tissue from intrauterine, ectopic and molar pregnancies. Placenta $\underline{20}, 711-721$

Freed-Pastor WA, Prives C (2012): Mutant p53: one name, many proteins. Genes Dev $\underline{26}, 1268-1286$ 
Gandhari M, Arens N, Majety M, Dorn-Beineke A, Hildenbrand R (2006): Urokinasetype plasminogen activator induces proliferation in breast cancer cells. Int J Oncol $2 \underline{8}$, 1463-1470

Gardsvoll H, Ploug M (2007): Mapping of the vitronectin-binding site on the urokinase receptor: involvement of a coherent receptor interface consisting of residues from both domain I and the flanking interdomain linker region. J Biol Chem 282, 13561-13572

Ghosh S, Johnson JJ, Sen R, Mukhopadhyay S, Liu Y, Zhang F, Wei Y, Chapman HA, Stack MS (2006): Functional relevance of urinary-type plasminogen activator receptoralpha3beta1 integrin association in proteinase regulatory pathways. J Biol Chem $\underline{281}$, 13021-13029

Giannopoulou I, Mylona E, Kapranou A, Mavrommatis J, Markaki S, Zoumbouli C, Keramopoulos A, Nakopoulou L (2007): The prognostic value of the topographic distribution of uPAR expression in invasive breast carcinomas. Cancer Lett 246, 262267

Gillespie ZE, MacKay K, Sander M, Trost B, Dawicki W, Wickramarathna A, Gordon J, Eramian M, Kill IR, Bridger JM, et al. (2015): Rapamycin reduces fibroblast proliferation without causing quiescence and induces STAT5A/B-mediated cytokine production. Nucleus $\underline{6}, 490-506$

Gonias SL, Hu J (2015): Urokinase receptor and resistance to targeted anticancer agents. Front Pharmacol $\underline{6}, 154$

Gore AJ, Deitz SL, Palam LR, Craven KE, Korc M (2014): Pancreatic cancer-associated retinoblastoma 1 dysfunction enables TGF-beta to promote proliferation. J Clin Invest $\underline{124}, 338-352$

Guay J, Lambert H, Gingras-Breton G, Lavoie JN, Huot J, Landry J (1997): Regulation of actin filament dynamics by 38 map kinase-mediated phosphorylation of heat shock protein 27. J Cell Sci $\underline{110}, 357-368$

Guo JY, Chen HY, Mathew R, Fan J, Strohecker AM, Karsli-Uzunbas G, Kamphorst JJ, Chen G, Lemons JM, Karantza V, et al. (2011): Activated Ras requires autophagy to maintain oxidative metabolism and tumorigenesis. Genes Dev $\underline{25}, 460-470$

Gurgis FM, Ziaziaris W, Munoz L (2014): Mitogen-activated protein kinase-activated protein kinase 2 in neuroinflammation, heat shock protein 27 phosphorylation, and cell cycle: role and targeting. Mol Pharmacol $\underline{85}$, 345-356

Hamada S, Satoh K, Masamune A, Shimosegawa T (2012): Regulators of epithelial mesenchymal transition in pancreatic cancer. Front Physiol $\underline{3}, 254$

Hamurcu Z, Delibasi N, Gecene S, Sener EF, Donmez-Altuntas H, Ozkul Y, Canatan H, Ozpolat B (2018): Targeting LC3 and Beclin-1 autophagy genes suppresses proliferation, survival, migration and invasion by inhibition of Cyclin-D1 and uPAR/Integrin beta1/Src signaling in triple negative breast cancer cells. J Cancer Res Clin Oncol 144, 415-430 
He AR, Lindenberg AP, Marshall JL (2008): Biologic therapies for advanced pancreatic cancer. Expert Rev Anticancer Ther $\underline{8}, 1331-1338$

Helfand BT, Chang L, Goldman RD (2004): Intermediate filaments are dynamic and motile elements of cellular architecture. J Cell Sci 117, 133-141

Hernandez S, Chavez Munguia B, Gonzalez-Mariscal L (2007): ZO-2 silencing in epithelial cells perturbs the gate and fence function of tight junctions and leads to an atypical monolayer architecture. Exp Cell Res $\underline{313}$, 1533-1547

Hezel AF, Kimmelman AC, Stanger BZ, Bardeesy N, Depinho RA (2006): Genetics and biology of pancreatic ductal adenocarcinoma. Genes Dev 20, 1218-1249

Hildenbrand R, Niedergethmann M, Marx A, Belharazem D, Allgayer H, Schleger C, Strobel P (2009): Amplification of the urokinase-type plasminogen activator receptor (uPAR) gene in ductal pancreatic carcinomas identifies a clinically high-risk group. Am J Pathol 174, 2246-2253

Huai Q, Zhou A, Lin L, Mazar AP, Parry GC, Callahan J, Shaw DE, Furie B, Furie BC, Huang M (2008): Crystal structures of two human vitronectin, urokinase and urokinase receptor complexes. Nat Struct Mol Biol 15, 422-423

Huang C, Xie D, Cui J, Li Q, Gao Y, Xie K (2014): FOXM1c promotes pancreatic cancer epithelial-to-mesenchymal transition and metastasis via upregulation of expression of the urokinase plasminogen activator system. Clin Cancer Res $\underline{20}, 1477-$ 1488

Huanwen W, Zhiyong L, Xiaohua S, Xinyu R, Kai W, Tonghua L (2009): Intrinsic chemoresistance to gemcitabine is associated with constitutive and laminin-induced phosphorylation of FAK in pancreatic cancer cell lines. Mol Cancer $\underline{8}, 125$

Jacobs D, Glossip D, Xing H, Muslin AJ, Kornfeld K (1999): Multiple docking sites on substrate proteins form a modular system that mediates recognition by ERK MAP kinase. Genes Dev 13, 163-175

Jo M, Takimoto S, Montel V, Gonias SL (2009a): The urokinase receptor promotes cancer metastasis independently of urokinase-type plasminogen activator in mice. Am J Pathol 175, 190-200

Jo M, Lester RD, Montel V, Eastman B, Takimoto S, Gonias SL (2009b): Reversibility of epithelial-mesenchymal transition (EMT) induced in breast cancer cells by activation of urokinase receptor-dependent cell signaling. J Biol Chem 284, 22825-22833

Kabeya Y, Mizushima N, Ueno T, Yamamoto A, Kirisako T, Noda T, Kominami E, Ohsumi Y, Yoshimori T (2000): LC3, a mammalian homologue of yeast Apg8p, is localized in autophagosome membranes after processing. EMBO J $\underline{19}, 5720-5728$

Kamphorst JJ, Nofal M, Commisso C, Hackett SR, Lu W, Grabocka E, Vander Heiden MG, Miller G, Drebin JA, Bar-Sagi D, et al. (2015): Human pancreatic cancer tumors are nutrient poor and tumor cells actively scavenge extracellular protein. Cancer Res $\underline{75}$, 544-553 
Katsogiannou M, Andrieu C, Rocchi P (2014): Heat shock protein 27 phosphorylation state is associated with cancer progression. Front Genet $\underline{5}, 346$

Kenific CM, Stehbens SJ, Goldsmith J, Leidal AM, Faure N, Ye J, Wittmann T, Debnath J (2016): NBR1 enables autophagy-dependent focal adhesion turnover. J Cell Biol 212, $577-590$

Kjaergaard M, Hansen LV, Jacobsen B, Gardsvoll H, Ploug M (2008): Structure and ligand interactions of the urokinase receptor (uPAR). Front Biosci 13, 5441-5461

Kjoller L, Hall A (2001): Rac mediates cytoskeletal rearrangements and increased cell motility induced by urokinase-type plasminogen activator receptor binding to vitronectin. J Cell Biol 152, 1145-1157

Klionsky DJ, Abdelmohsen K, Abe A, Abedin MJ, Abeliovich H, Acevedo Arozena A, Adachi H, Adams CM, Adams PD, Adeli K, et al. (2016): Guidelines for the use and interpretation of assays for monitoring autophagy (3rd edition). Autophagy 12, 1-222

Kondo Y, Kanzawa T, Sawaya R, Kondo S (2005): The role of autophagy in cancer development and response to therapy. Nat Rev Cancer $\underline{5}$, 726-734

Kong HK, Park JH (2012): Characterization and function of human Ly-6/uPAR molecules. BMB Rep $\underline{45}$, 595-603

Kopper F, Binkowski AM, Bierwirth C, Dobbelstein M (2014): The MAPK-activated protein kinase 2 mediates gemcitabine sensitivity in pancreatic cancer cells. Cell Cycle $\underline{13}, 884-889$

Laurenzana A, Chilla A, Luciani C, Peppicelli S, Biagioni A, Bianchini F, Tenedini E, Torre E, Mocali A, Calorini L, et al. (2017): uPA/uPAR system activation drives a glycolytic phenotype in melanoma cells. Int J Cancer 141, 1190-1200

Lee JJ, Perera RM, Wang H, Wu DC, Liu XS, Han S, Fitamant J, Jones PD, Ghanta KS, Kawano S, et al. (2014): Stromal response to Hedgehog signaling restrains pancreatic cancer progression. Proc Natl Acad Sci U S A 111, 3091-3100

Lester RD, Jo M, Montel V, Takimoto S, Gonias SL (2007): uPAR induces epithelialmesenchymal transition in hypoxic breast cancer cells. J Cell Biol 178, 425-436

Levy JMM, Towers CG, Thorburn A (2017): Targeting autophagy in cancer. Nat Rev Cancer 17, 528-542

Liu D, Aguirre Ghiso J, Estrada Y, Ossowski L (2002): EGFR is a transducer of the urokinase receptor initiated signal that is required for in vivo growth of a human carcinoma. Cancer Cell 1, 445-457

Lock R, Kenific CM, Leidal AM, Salas E, Debnath J (2014): Autophagy-dependent production of secreted factors facilitates oncogenic RAS-driven invasion. Cancer Discov $\underline{4}, 466-479$ 
Lomholt AF, Christensen IJ, Hoyer-Hansen G, Nielsen HJ (2010): Prognostic value of intact and cleaved forms of the urokinase plasminogen activator receptor in a retrospective study of 518 colorectal cancer patients. Acta Oncol $\underline{49}, 805-811$

Lu Z, Luo RZ, Lu Y, Zhang X, Yu Q, Khare S, Kondo S, Kondo Y, Yu Y, Mills GB, et al. (2008): The tumor suppressor gene ARHI regulates autophagy and tumor dormancy in human ovarian cancer cells. J Clin Invest 118, 3917-3929

Ma Z, Thomas KS, Webb DJ, Moravec R, Salicioni AM, Mars WM, Gonias SL (2002): Regulation of Rac1 activation by the low density lipoprotein receptor-related protein. $\mathrm{J}$ Cell Biol 159, 1061-1070

Madsen CD, Ferraris GM, Andolfo A, Cunningham O, Sidenius N (2007): uPARinduced cell adhesion and migration: vitronectin provides the key. J Cell Biol 177, 927939

Mahmood N, Mihalcioiu C, Rabbani SA (2018): Multifaceted Role of the UrokinaseType Plasminogen Activator (uPA) and Its Receptor (uPAR): Diagnostic, Prognostic, and Therapeutic Applications. Front Oncol $\underline{8}, 24$

Matsushita A, Gotze T, Korc M (2007): Hepatocyte growth factor-mediated cell invasion in pancreatic cancer cells is dependent on neuropilin-1. Cancer Res 67, 1030910316

Matter K, Balda MS (2007): Epithelial tight junctions, gene expression and nucleojunctional interplay. J Cell Sci $\underline{120}, 1505-1511$

Mauro CD, Pesapane A, Formisano L, Rosa R, D'Amato V, Ciciola P, Servetto A, Marciano R, Orsini RC, Monteleone F, et al. (2017): Urokinase-type plasminogen activator receptor (UPAR) expression enhances invasion and metastasis in RAS mutated tumors. Sci Rep 7, 9388

Monaghan-Benson E, McKeown-Longo PJ (2006): Urokinase-type plasminogen activator receptor regulates a novel pathway of fibronectin matrix assembly requiring Src-dependent transactivation of epidermal growth factor receptor. J Biol Chem $\underline{281}$, 9450-9459

Morandell S, Reinhardt HC, Cannell IG, Kim JS, Ruf DM, Mitra T, Couvillon AD, Jacks T, Yaffe MB (2013): A reversible gene-targeting strategy identifies synthetic lethal interactions between MK2 and p53 in the DNA damage response in vivo. Cell Rep $\underline{5}$, 868-877

Mowers EE, Sharifi MN, Macleod KF (2017): Autophagy in cancer metastasis. Oncogene $\underline{36}, 1619-1630$

Muzumdar MD, Chen PY, Dorans KJ, Chung KM, Bhutkar A, Hong E, Noll EM, Sprick MR, Trumpp A, Jacks T (2017): Survival of pancreatic cancer cells lacking KRAS function. Nat Commun $\underline{8}, 1090$ 
Neoptolemos JP, Stocken DD, Friess H, Bassi C, Dunn JA, Hickey H, Beger H, Fernandez-Cruz L, Dervenis C, Lacaine F, et al. (2004): A randomized trial of chemoradiotherapy and chemotherapy after resection of pancreatic cancer. $\mathrm{N}$ Engl $\mathrm{J}$ Med $\underline{350}, 1200-1210$

Neoptolemos JP, Palmer DH, Ghaneh P, Psarelli EE, Valle JW, Halloran CM, Faluyi O, O'Reilly DA, Cunningham D, Wadsley J, et al. (2017): Comparison of adjuvant gemcitabine and capecitabine with gemcitabine monotherapy in patients with resected pancreatic cancer (ESPAC-4): a multicentre, open-label, randomised, phase 3 trial. Lancet 389, 1011-1024

New M, Van Acker T, Long JS, Sakamaki JI, Ryan KM, Tooze SA (2017): Molecular Pathways Controlling Autophagy in Pancreatic Cancer. Front Oncol 7, 28

Nguyen DH, Catling AD, Webb DJ, Sankovic M, Walker LA, Somlyo AV, Weber MJ, Gonias SL (1999): Myosin light chain kinase functions downstream of Ras/ERK to promote migration of urokinase-type plasminogen activator-stimulated cells in an integrin-selective manner. J Cell Biol 146, 149-164

Nistico P, Bissell MJ, Radisky DC (2012): Epithelial-mesenchymal transition: general principles and pathological relevance with special emphasis on the role of matrix metalloproteinases. Cold Spring Harb Perspect Biol 4, 011908

Ogura T, Yamao K, Hara K, Mizuno N, Hijioka S, Imaoka H, Sawaki A, Niwa Y, Tajika M, Kondo S, et al. (2013): Prognostic value of K-ras mutation status and subtypes in endoscopic ultrasound-guided fine-needle aspiration specimens from patients with unresectable pancreatic cancer. J Gastroenterol $\underline{48}$, 640-646

Okuno M, Adachi S, Kozawa O, Shimizu M, Yasuda I (2016): The Clinical Significance of Phosphorylated Heat Shock Protein 27 (HSPB1) in Pancreatic Cancer. Int J Mol Sci $\underline{17}, 137$

Ozdemir BC, Pentcheva-Hoang T, Carstens JL, Zheng X, Wu CC, Simpson TR, Laklai H, Sugimoto H, Kahlert C, Novitskiy SV, et al. (2014): Depletion of carcinomaassociated fibroblasts and fibrosis induces immunosuppression and accelerates pancreas cancer with reduced survival. Cancer Cell 25, 719-734

Paillas S, Causse A, Marzi L, de Medina P, Poirot M, Denis V, Vezzio-Vie N, Espert L, Arzouk H, Coquelle A, et al. (2012): MAPK14/p38alpha confers irinotecan resistance to TP53-defective cells by inducing survival autophagy. Autophagy $\underline{8}, 1098-1112$

Peinado H, Olmeda D, Cano A (2007): Snail, Zeb and bHLH factors in tumour progression: an alliance against the epithelial phenotype? Nat Rev Cancer $\underline{7}, 415-428$

Peng YF, Shi YH, Ding ZB, Ke AW, Gu CY, Hui B, Zhou J, Qiu SJ, Dai Z, Fan J (2013): Autophagy inhibition suppresses pulmonary metastasis of HCC in mice via impairing anoikis resistance and colonization of HCC cells. Autophagy $\underline{9}, 2056-2068$

Pereira L, Igea A, Canovas B, Dolado I, Nebreda AR (2013): Inhibition of p38 MAPK sensitizes tumour cells to cisplatin-induced apoptosis mediated by reactive oxygen species and JNK. EMBO Mol Med s, 1759-1774 
Plesner T, Ralfkiaer E, Wittrup M, Johnsen H, Pyke C, Pedersen TL, Hansen NE, Dano $\mathrm{K}$ (1994): Expression of the receptor for urokinase-type plasminogen activator in normal and neoplastic blood cells and hematopoietic tissue. Am J Clin Pathol 102, 835841

Ploug M, Ellis V (1994): Structure-function relationships in the receptor for urokinasetype plasminogen activator. Comparison to other members of the Ly-6 family and snake venom alpha-neurotoxins. FEBS Lett $\underline{349}$, 163-168

Puleo F, Nicolle R, Blum Y, Cros J, Marisa L, Demetter P, Quertinmont E, Svrcek M, Elarouci N, Iovanna J, et al. (2018): Stratification of Pancreatic Ductal Adenocarcinomas Based on Tumor and Microenvironment Features. Gastroenterology $\underline{155}, 1999-2013$

Qiang L, Zhao B, Ming M, Wang N, He TC, Hwang S, Thorburn A, He YY (2014): Regulation of cell proliferation and migration by p62 through stabilization of Twist1. Proc Natl Acad Sci U S A 111, 9241-9246

Quint K, Tonigold M, Di Fazio P, Montalbano R, Lingelbach S, Ruckert F, Alinger B, Ocker M, Neureiter D (2012): Pancreatic cancer cells surviving gemcitabine treatment express markers of stem cell differentiation and epithelial-mesenchymal transition. Int $\mathrm{J}$ Oncol 41, 2093-2102

Rasch MG, Lund IK, Almasi CE, Hoyer-Hansen G (2008): Intact and cleaved uPAR forms: diagnostic and prognostic value in cancer. Front Biosci 13, 6752-6762

Reichert M, Muller T, Hunziker W (2000): The PDZ domains of zonula occludens-1 induce an epithelial to mesenchymal transition of Madin-Darby canine kidney I cells. Evidence for a role of beta-catenin/Tcf/Lef signaling. J Biol Chem 275, 9492-9500

Reinhardt HC, Yaffe MB (2013): Phospho-Ser/Thr-binding domains: navigating the cell cycle and DNA damage response. Nat Rev Mol Cell Biol 14, 563-580

Remenyi A, Good MC, Bhattacharyya RP, Lim WA (2005): The role of docking interactions in mediating signaling input, output, and discrimination in the yeast MAPK network. Mol Cell 20, 951-962

Romer J, Lund LR, Eriksen J, Pyke C, Kristensen P, Dano K (1994): The receptor for urokinase-type plasminogen activator is expressed by keratinocytes at the leading edge during re-epithelialization of mouse skin wounds. J Invest Dermatol 102, 519-522

Ryan DP, Hong TS, Bardeesy N (2014): Pancreatic adenocarcinoma. N Engl J Med $\underline{371}$, 1039-1049

Seymour AB, Hruban RH, Redston M, Caldas C, Powell SM, Kinzler KW, Yeo CJ, Kern SE (1994): Allelotype of pancreatic adenocarcinoma. Cancer Res 54, 2761-2764

Sharifi MN, Mowers EE, Drake LE, Collier C, Chen H, Zamora M, Mui S, Macleod KF (2016): Autophagy Promotes Focal Adhesion Disassembly and Cell Motility of Metastatic Tumor Cells through the Direct Interaction of Paxillin with LC3. Cell Rep $\underline{15}, 1660-1672$ 
Shen Y, Li N, Wu S, Zhou Y, Shan Y, Zhang Q, Ding C, Yuan Q, Zhao F, Zeng R, et al. (2008): Nudel binds Cdc42GAP to modulate Cdc42 activity at the leading edge of migrating cells. Dev Cell 14, 342-353

Shin K, Fogg VC, Margolis B (2006): Tight junctions and cell polarity. Annu Rev Cell Dev Biol 22, 207-235

Sidenius N, Andolfo A, Fesce R, Blasi F (2002): Urokinase regulates vitronectin binding by controlling urokinase receptor oligomerization. J Biol Chem 277, 2798227990

Siegel RL, Miller KD, Jemal A (2018): Cancer statistics, 2018. CA Cancer J Clin $\underline{68}$, 730

Singh A, Greninger P, Rhodes D, Koopman L, Violette S, Bardeesy N, Settleman J (2009): A gene expression signature associated with "K-Ras addiction" reveals regulators of EMT and tumor cell survival. Cancer Cell 15, 489-500

Smith HW, Marshall CJ (2010): Regulation of cell signalling by uPAR. Nat Rev Mol Cell Biol 11, 23-36

Smith HW, Marra P, Marshall CJ (2008): uPAR promotes formation of the p130Cas-Crk complex to activate Rac through DOCK180. J Cell Biol 182, 777-790

Solberg H, Ploug M, Hoyer-Hansen G, Nielsen BS, Lund LR (2001): The murine receptor for urokinase-type plasminogen activator is primarily expressed in tissues actively undergoing remodeling. J Histochem Cytochem $\underline{49}$, 237-246

Sosa MS, Bragado P, Aguirre-Ghiso JA (2014): Mechanisms of disseminated cancer cell dormancy: an awakening field. Nat Rev Cancer 14, 611-622

Sturge J, Wienke D, East L, Jones GE, Isacke CM (2003): GPI-anchored uPAR requires Endo180 for rapid directional sensing during chemotaxis. J Cell Biol 162, 789-794

Tang CH, Hill ML, Brumwell AN, Chapman HA, Wei Y (2008): Signaling through urokinase and urokinase receptor in lung cancer cells requires interactions with beta1 integrins. J Cell Sci 121, 3747-3756

Thiery JP, Acloque H, Huang RY, Nieto MA (2009): Epithelial-mesenchymal transitions in development and disease. Cell 139, 871-890

Tjwa M, Sidenius N, Moura R, Jansen S, Theunissen K, Andolfo A, De Mol M, Dewerchin M, Moons L, Blasi F, et al. (2009): Membrane-anchored uPAR regulates the proliferation, marrow pool size, engraftment, and mobilization of mouse hematopoietic stem/progenitor cells. J Clin Invest 119, 1008-1018

Turner FE, Broad S, Khanim FL, Jeanes A, Talma S, Hughes S, Tselepis C, Hotchin NA (2006): Slug regulates integrin expression and cell proliferation in human epidermal keratinocytes. J Biol Chem 281, 21321-21331 
Umeda K, Ikenouchi J, Katahira-Tayama S, Furuse K, Sasaki H, Nakayama M, Matsui T, Tsukita S, Furuse M, Tsukita S (2006): ZO-1 and ZO-2 independently determine where claudins are polymerized in tight-junction strand formation. Cell $\underline{126}, 741-754$

Uszynski M, Perlik M, Uszynski W, Zekanowska E (2004): Urokinase plasminogen activator (uPA) and its receptor (uPAR) in gestational tissues; Measurements and clinical implications. Eur J Obstet Gynecol Reprod Biol 114, 54-58

Vera-Ramirez L, Vodnala SK, Nini R, Hunter KW, Green JE (2018): Autophagy promotes the survival of dormant breast cancer cells and metastatic tumour recurrence. Nat Commun $\underline{9}, 1944$

Vial E, Marshall CJ (2003): Elevated ERK-MAP kinase activity protects the FOS family member FRA-1 against proteasomal degradation in colon carcinoma cells. J Cell Sci $\underline{116}, 4957-4963$

Vincent A, Herman J, Schulick R, Hruban RH, Goggins M (2011): Pancreatic cancer. Lancet $\underline{378}, 607-620$

Vogelstein B, Lane D, Levine AJ (2000): Surfing the p53 network. Nature 408, 307-310

von Wichert G, Seufferlein T, Adler G (2008): Palliative treatment of pancreatic cancer. J Dig Dis $\underline{9}, 1-7$

Vousden KH, Lane DP (2007): p53 in health and disease. Nat Rev Mol Cell Biol $\underline{8}$, 275283

Waddell N, Pajic M, Patch AM, Chang DK, Kassahn KS, Bailey P, Johns AL, Miller D, Nones K, Quek K, et al. (2015): Whole genomes redefine the mutational landscape of pancreatic cancer. Nature $\underline{518}, 495-501$

Wang X, Zheng M, Liu G, Xia W, McKeown-Longo PJ, Hung MC, Zhao J (2007): Kruppel-like factor 8 induces epithelial to mesenchymal transition and epithelial cell invasion. Cancer Res 67, 7184-7193

Wang XS, Diener K, Jannuzzi D, Trollinger D, Tan TH, Lichenstein H, Zukowski M, Yao Z (1996): Molecular cloning and characterization of a novel protein kinase with a catalytic domain homologous to mitogen-activated protein kinase kinase kinase. J Biol Chem 271, 31607-31611

Wang Y (2001): The role and regulation of urokinase-type plasminogen activator receptor gene expression in cancer invasion and metastasis. Med Res Rev 21, 146-170

Webb DJ, Nguyen DH, Gonias SL (2000): Extracellular signal-regulated kinase functions in the urokinase receptor-dependent pathway by which neutralization of low density lipoprotein receptor-related protein promotes fibrosarcoma cell migration and matrigel invasion. J Cell Sci 113, 123-134

Wei C, Moller CC, Altintas MM, Li J, Schwarz K, Zacchigna S, Xie L, Henger A, Schmid H, Rastaldi MP, et al. (2008): Modification of kidney barrier function by the urokinase receptor. Nat Med 14, 55-63 
Wei Y, Waltz DA, Rao N, Drummond RJ, Rosenberg S, Chapman HA (1994): Identification of the urokinase receptor as an adhesion receptor for vitronectin. J Biol Chem 269, 32380-32388

Wei Y, Tang CH, Kim Y, Robillard L, Zhang F, Kugler MC, Chapman HA (2007): Urokinase receptors are required for alpha 5 beta 1 integrin-mediated signaling in tumor cells. J Biol Chem 282, 3929-3939

Whibley C, Pharoah PD, Hollstein M (2009): p53 polymorphisms: cancer implications. Nat Rev Cancer $\underline{9}, 95-107$

Wolf J, Dewi DL, Fredebohm J, Muller-Decker K, Flechtenmacher C, Hoheisel JD, Boettcher M (2013): A mammosphere formation RNAi screen reveals that ATG4A promotes a breast cancer stem-like phenotype. Breast Cancer Res $\underline{15}, 109$

Wykosky J, Hu J, Gomez GG, Taylor T, Villa GR, Pizzo D, VandenBerg SR, Thorne AH, Chen CC, Mischel PS, et al. (2015): A urokinase receptor-Bim signaling axis emerges during EGFR inhibitor resistance in mutant EGFR glioblastoma. Cancer Res $\underline{75}, 394-404$

Xu Z, Vonlaufen A, Phillips PA, Fiala-Beer E, Zhang X, Yang L, Biankin AV, Goldstein D, Pirola RC, Wilson JS, et al. (2010): Role of pancreatic stellate cells in pancreatic cancer metastasis. Am J Pathol 177, 2585-2596

Yang A, Kimmelman AC (2014): Inhibition of autophagy attenuates pancreatic cancer growth independent of TP53/TRP53 status. Autophagy 10, 1683-1684

Yang A, Rajeshkumar NV, Wang X, Yabuuchi S, Alexander BM, Chu GC, Von Hoff DD, Maitra A, Kimmelman AC (2014): Autophagy is critical for pancreatic tumor growth and progression in tumors with p53 alterations. Cancer Discov $\underline{4}, 905-913$

Yang K, Li Y, Lian G, Lin H, Shang C, Zeng L, Chen S, Li J, Huang C, Huang K, et al. (2018): KRAS promotes tumor metastasis and chemoresistance by repressing RKIP via the MAPK-ERK pathway in pancreatic cancer. Int J Cancer 142, 2323-2334

Yin T, Wei H, Gou S, Shi P, Yang Z, Zhao G, Wang C (2011): Cancer stem-like cells enriched in Panc-1 spheres possess increased migration ability and resistance to gemcitabine. Int J Mol Sci 12, 1595-1604

Ying H, Kimmelman AC, Lyssiotis CA, Hua S, Chu GC, Fletcher-Sananikone E, Locasale JW, Son J, Zhang H, Coloff JL, et al. (2012): Oncogenic Kras maintains pancreatic tumors through regulation of anabolic glucose metabolism. Cell 149, 656670

Zannetti A, Del Vecchio S, Carriero MV, Fonti R, Franco P, Botti G, D'Aiuto G, Stoppelli MP, Salvatore M (2000): Coordinate up-regulation of Sp1 DNA-binding activity and urokinase receptor expression in breast carcinoma. Cancer Res $\underline{60}, 1546-$ 1551 
Zeitouni D, Pylayeva-Gupta Y, Der CJ, Bryant KL (2016): KRAS Mutant Pancreatic Cancer: No Lone Path to an Effective Treatment. Cancers $\underline{8}, 45$

Zhang S, Han J, Sells MA, Chernoff J, Knaus UG, Ulevitch RJ, Bokoch GM (1995): Rho family GTPases regulate p38 mitogen-activated protein kinase through the downstream mediator Pak1. J Biol Chem 270, 23934-23936

Zheng Y, Xia Y, Hawke D, Halle M, Tremblay ML, Gao X, Zhou XZ, Aldape K, Cobb $\mathrm{MH}$, Xie K, et al. (2009): FAK phosphorylation by ERK primes ras-induced tyrosine dephosphorylation of FAK mediated by PIN1 and PTP-PEST. Mol Cell 35, 11-25

Zhou C, Ma K, Gao R, Mu C, Chen L, Liu Q, Luo Q, Feng D, Zhu Y, Chen Q (2017): Regulation of mATG9 trafficking by Src- and ULK1-mediated phosphorylation in basal and starvation-induced autophagy. Cell Res 27, 184-201 


\section{Acknowledgments}

I would like to express my special thanks of gratitude to my supervisor Prof. Dr. med. Philipp Ströbel as well as my principal who gave me the golden opportunity to do the wonderful project on the topic "uPAR a role in PDAC", for immense knowledge and the professional working environment created throughout the research process; for the continuous support of my project and research,

Secondly my very great appreciation to Dr. sc. hum. Küffer Stefan for his valuable and constructive, insightful expertise during the work in the lab. His willingness to give his time so generously has been very much appreciated,

I am profoundly grateful to Prof. Dr. med. Philipp Ströbel, Dr. sc. hum. Küffer Stefan,

Prof. Dr. med. Volker Ellenrieder, for stimulating discussions and brilliant comments regarding an earlier version of the manuscript within the limited time frame,

Dr. med. Hanibal Bohnenberger for my training and student's registration,

Dr. med. Vivek Venkataramani for fruitful discussions and Monique Küffer, Stefanie Schwager, for technical assistance,

I am really thankful to them

THANK YOU! 
